25 innovative and inspiring solutions to combat

\title{
PLASTIC MARINE LITTER in the Mediterranean Region
}

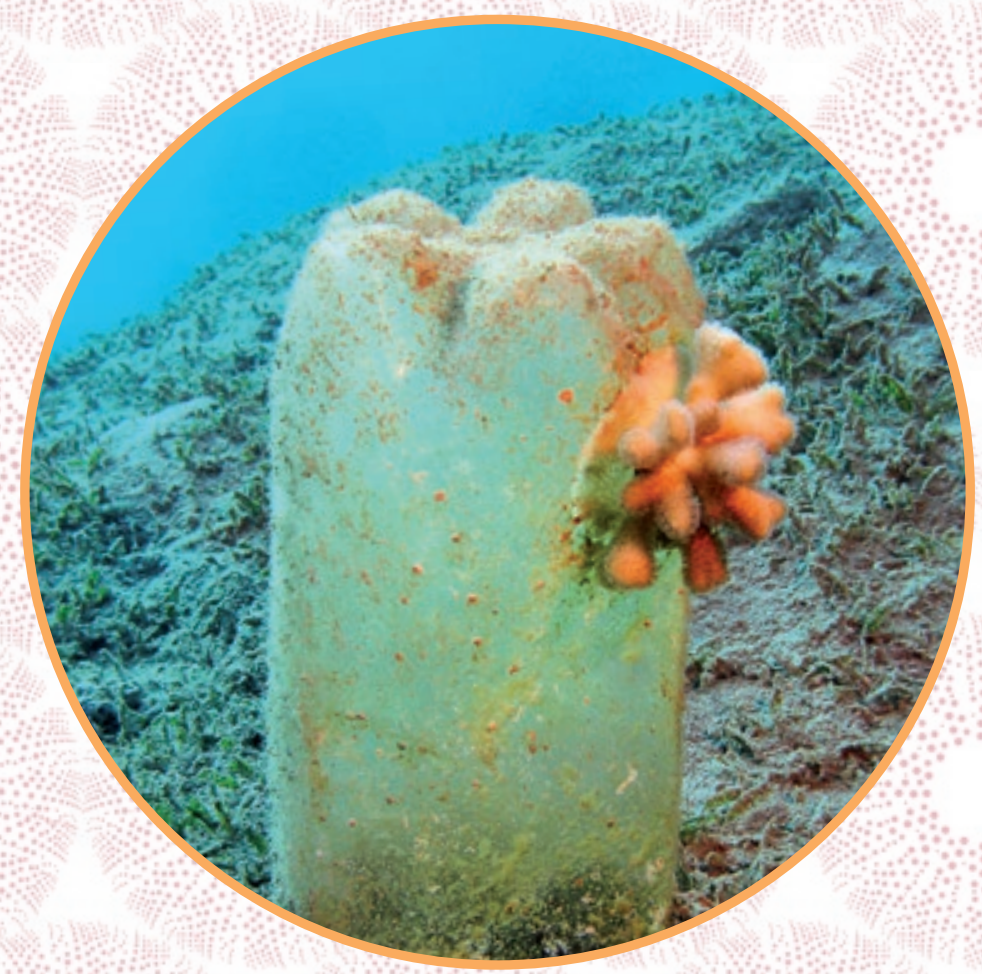

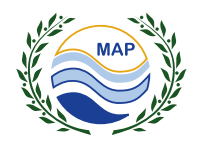

Mediterranean Action Plan Barcelona Convention 
This publication was developed by the Regional Activity Centre for Sustainable Consumption and Production (SCP/RAC) as part of the EU-funded SwitchMed Programme. SwitchMed benefits from collaborative coordination between the European Union, the United Nations Industrial Development Organization (UNIDO), the UN Environment and Action Plan for the Mediterranean and its Regional Activity Centre for Sustainable Consumption and Production (SCP/RAC) and the UN Environment Division.

Supervision and coordination:

Magali Outters, Regional Activity Centre for Sustainable Consumption and Production (SCP/RAC)

Technical support: Pedro Fernández (SCP/RAC), Carolina Pérez and Maria Ferreira (Coastal \& Marine Union - EUCC), and Frederic Gallo (Waste Agency of Catalonia)

Production: Lucille Guiheneuf (SCP/RAC)

For bibliographic purposes this volume may be cited as: 25 innovative and inspiring solutions to combat plastic marine litter in the Mediterranean Region. Regional Activity Centre for Sustainable Consumption and Production (SCP/RAC). Barcelona, 2017.

Design, formatting, graphics and illustrations:

Dalia Sciama

Cover photo: @ Ziggy Livnat/Marine Photobank

Printing: GAM Digital, Barcelona, printed on recycled Cocoon Offset paper

Copyright:

This publication may be reproduced, in full or in part, for educational or non-profit purposes without special permission from the Regional Activity Centre for Sustainable Consumption and Production (SCP/RAC) provided that the source is acknowledged. SCP/RAC would like to receive a copy of any publication using this publication as a source. This publication may not be resold or used for any other commercial purpose without the written permission of SCP/RAC.

Disclaimer:

This publication was produced with the assistance of the European Union.

The contents of this publication are the sole responsibility of the Regional Activity Centre for Sustainable Consumption and Production (SCP/RAC) and do not reflect the views of the European Union.

Acknowledgements:

The authors express their gratitude to the people behind the initiatives presented in this publication, who facilitated valuable information and checked it.

For further information, please contact:

www.switchmed.eu

moutters@scprac.org

English version 2017, also available in French

Legal deposit: B 23755-2017 
25 innovative and inspiring solutions to combat

\section{PLASTIC MARINE LITTER in the Mediterranean Region}




\section{CONTENTS}

INTRODUCTION

The issue of marine litter in the Mediterranean sea

Tackling marine litter a contribution from Switchmed 8

How to use this publication 9

\section{SOLUTIONS: OVERVIEW}

The process of selecting solutions. Context and limitations

SPOTLIGHT ON 25 MARINE LITTER SOLUTIONS

Design and production

Full Cycle Bioplastics 18

EcoOcean $^{\mathrm{TM}}$, a marine-biodegradable material 20

Circular Plastics Incubator: BeStart, cleantech start-ups 22

Ocean Plastic Bottle: A new responsible container 24

Clickeat: An alternative to single-use plastic cutlery 26

Operation Clean Sweep ${ }^{\circledR}$ : Engaging industry to prevent plastic leaks 28

DEC, designing with cardboard 30

Plan A by Marks \& Spencer: Food packaging component 32

Karta-Pack ${ }^{\mathrm{TM}}$, moulding a better world 34

Paper-stem cotton buds 36

Cora Ball: A consumer solution to microfibre pollution 38

Festival Republic: Greening mass events 40

Return to offender campaign 42

Courtauld Commitment 3: Resource efficiency in the grocery sector 44 
Use and Consumption

Goccia Verde: Sale in bulk to avoid single-use plastic containers

Plastic bag charge in supermarkets

Bye Bye Plastic Bags, the power of youth

Breaking the world record with the longest plastic-bag chain

Bag it and Bin it - Don't Flush it

\section{Collection and waste transfer}

Antivolabossa, a device preventing bin sacks from blowing away 56

Waste management on AIDA cruises and Deerberg Converter ${ }^{\circledR}$ technology 58

“ Recycling we all win”: Reverse vending machine franchise 60

Fishing-line recycling bins 62

Recycling

Thread: Responsible fabric from Ground to Good ${ }^{\mathrm{m}}$ 64

Plastimobile, reduction through plastic recycling and prevention of littering 66 

he Mediterranean region has long been recognized for its natural and cultural heritage. Representing less than $1 \%$ of the area of the world's oceans, the Mediterranean Sea accounts for over $10 \%$ of all known species, including many endemic species. It hosts a remarkable diversity of life and is a vital breeding area for key pelagic species, some of which are endangered.

At the same time, the Mediterranean Sea has been described as one of the areas most affected by marine litter in the world. The problem is exacerbated by the basin's limited exchanges with other oceans and its densely populated coasts and highly developed tourism; $30 \%$ of the world's maritime traffic passes through it and various additional inputs of litter reach it from rivers and very urbanized areas.

Plastic, which is the main litter component, has now become ubiquitous in the region and may comprise up to $95 \%$ of the waste accumulated on shorelines, the ocean surface, or the sea floor. Of particular concern is the presence of microplastics, which have been found in quantities very comparable to those encountered in the oceanic gyres, also known as "plastic soups".

Marine litter can have severe consequences for the Mediterranean's biological resources and the human communities that depend on them, from a health, environmental and economic perspective. Increasingly, studies are showing that marine litter directly affects living organisms, especially through entanglement with macro-plastics and the ingestion of micro-plastics. There is also growing evidence that plastic particles may carry and transfer toxic substances (in particular, persistent organic pollutants and endocrine disruptors) 
to marine organisms, mainly when ingested, and, currently, scientists are focusing on the risk of possibly hazardous plastic particles being transferred via food chains.

The most recent assessment report on marine litter in the Mediterranean undertaken by UNEP/MAP (2015) indicates that most marine litter originates from land-based rather than sea-based sources. The report concludes that despite the uncertainties and knowledge gaps, existing evidence is more than sufficient to justify immediate action toward preventing and reducing marine litter and its impact on the marine and coastal environment.

Within the UNEP/MAP Barcelona Convention, marine litter is addressed specifically through the Regional Plan on Marine Litter Management in the Mediterranean. Moreover, current production and consumption patterns are at the very heart of this problem, an issue which is being tackled by another instrument fostering circular economy in the region: the Sustainable Consumption and Production (SCP) Action Plan for the Mediterranean.

With a view to responding to this emerging and problematic issue, SCP/RAC (Regional Activity Centre for Sustainable Consumption and Production), with the support of the SwitchMed Programme (www.switchmed.eu), has identified the 25 best existing ecoinnovative solutions to prevent or minimize the use of persistent plastics liable to end up as marine litter in the Mediterranean.

Innovative solutions capable of generating revenues from all parts of the globe have been prioritized through a multi-criteria analysis of their effectiveness and replicability in the MENA region. They are showcased here as a way of inspiring businesses, entrepreneurs and civil society organizations in the Mediterranean region to take action against marine litter. Through this publication, SCP/RAC calls on green entrepreneurs, committed CSOs, innovators and change-makers in the Mediterranean to develop and scale the most adaptable solutions with the support of the SwitchMed Programme. In order to promote action, the programme will enable the pilot actions inspired by these initiatives to be implemented in the region.
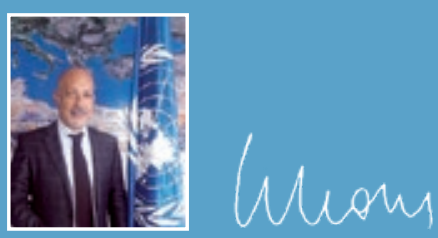

Gaetano Leone

Coordinator

UN Environment/Mediterranean Action Plan Coordinating Unit Barcelona Convention Secretariat
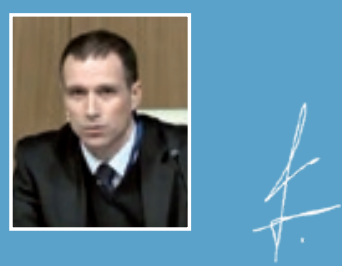

Enrique de Villamore Martín

Director

Regional Activity Centre for Sustainable

Consumption and Production (SCP/RAC)

UN Environment/Mediterranean Action Plan 
INTRODUCTION

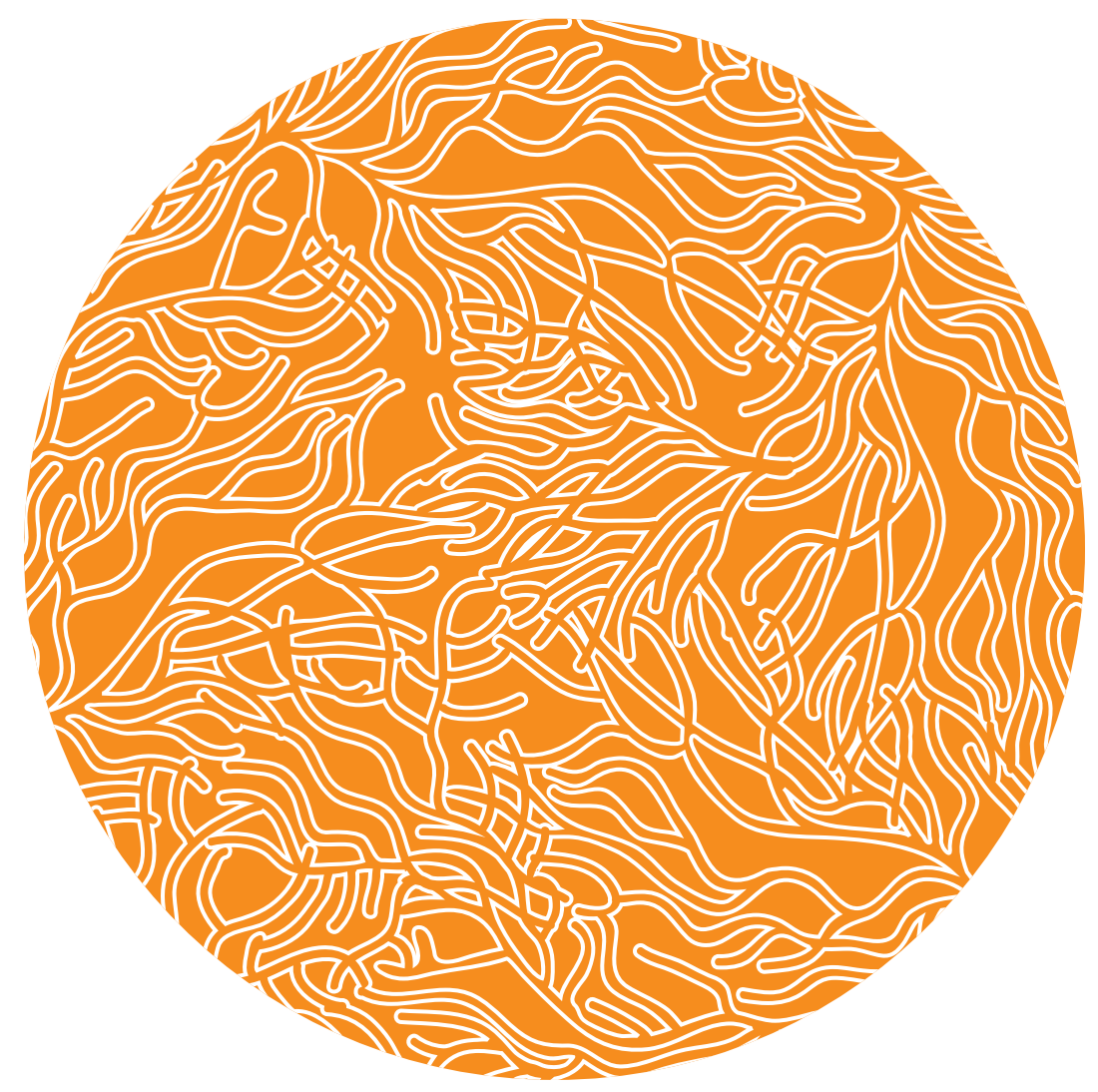




\section{The issue of marine litter in the Mediterranean sea}

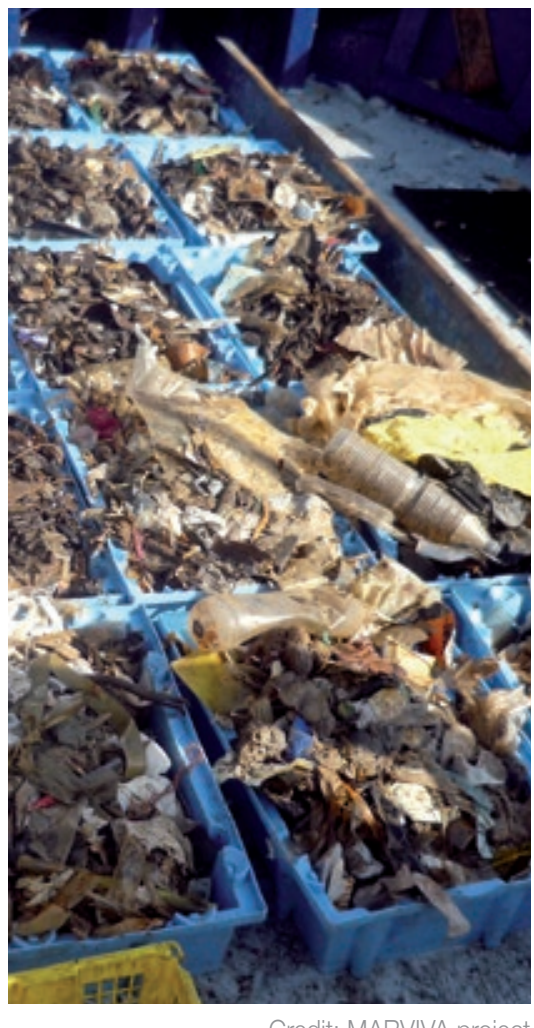

Credit: MARVIVA project arine litter is a consequence of our current paradigm of linear use of resources and our inability to fully deal with the volume of waste this produces. It presents a challenge to society and to our economic and political systems to mitigate much more effectively and without delay marine litter's damage in our oceans and to our welfare.

Omnipresent in our daily lives, plastic items are likewise consistently the dominant fraction of marine litter. According to the most recent assessment report on marine litter in the Mediterranean undertaken by UNEP/MAP (2015), plastics constitute the largest fraction of beach litter, more than $85 \%$ of floating litter and $45 \%$ to $95 \%$ of the litter present on the seafloor compartment. The most prevalent litter categories include packaging (plastic bags; food and drink containers) and single-use, disposable items (e.g. straws, bottles, cotton bud sticks). Marine litter brings not only environmental impacts but also enormous social and economic costs, e.g. litter clean-ups.

In order to respond to this emerging and problematic issue, the UNEP/MAP Barcelona Convention has adopted (2013) the first ever legally binding Regional Plan on Marine Litter Management in the Mediterranean. Last February 2016 (COP19), the Contracting Parties to the Barcelona Convention adopted a Sustainable Consumption and Production (SCP) Action Plan for the Mediterranean, which constitutes a forward-looking framework to move towards a circular economy in the region.

\section{Tackling marine litter, a contribution from SwitchMed}

$\mathrm{n}$ addition to this regional context, the SwitchMed Programme (www.switchmed.eu) is a multidimensional regional initiative funded by the European Union and implemented thanks to collaboration between the EU, UNIDO, UNEP/MAP, SCP/RAC and UNEP DTIE. The global aim of the SwitchMed initiative is to facilitate the transition towards sustainable consumption and production (SCP) in the southern Mediterranean region, namely Morocco, Algeria, Tunisia, Egypt, Israel, Palestine, Jordan and Lebanon.
SCP/RAC stands for the Regional Activity Centre for Sustainable Consumption and Production. It was established by the Barcelona Convention with the specific mandate of providing support to the Contracting Parties in the promotion of SCP and sound chemical management

Accordingly, SCP/RAC has developed a programme providing training, coaching and advisory services, including the design of a specific and innovative training package. Almost 
1,700 green entrepreneurs and SMEs plus 120 grassroots initiatives have benefitted from the programme. To date, these efforts have contributed to the creation of 150 new green businesses, 25 of which are currently being incubated through one-on-one mentorship.

Within this context, SCP/RAC has conducted a screening of the best eco-innovative solutions in existence for the prevention or minimization of the use of persistent plastics liable to end up as marine litter that could also be replicated and promoted in the Middle EastNorth Africa (MENA) region by companies and civil society organizations. This publication is the final output and unveils these solutions, aimed at inspiring and aiding entrepreneurs and organizations in taking action against marine litter as well as supporting socioeconomic development in the region. In a later stage, in order to trigger concrete action, the SwitchMed Programme will make available funds so some of these initiatives are replicated and adapted in selected countries of the MENA region.

Notwithstanding, this publication has been conceived as a useful and practical tool for entrepreneurs and organizations worldwide who are willing to contribute to combating marine litter. Last but not least, it acknowledges the effort, courage and creativity of people, businesses and associations from all over the world in combating marine litter.

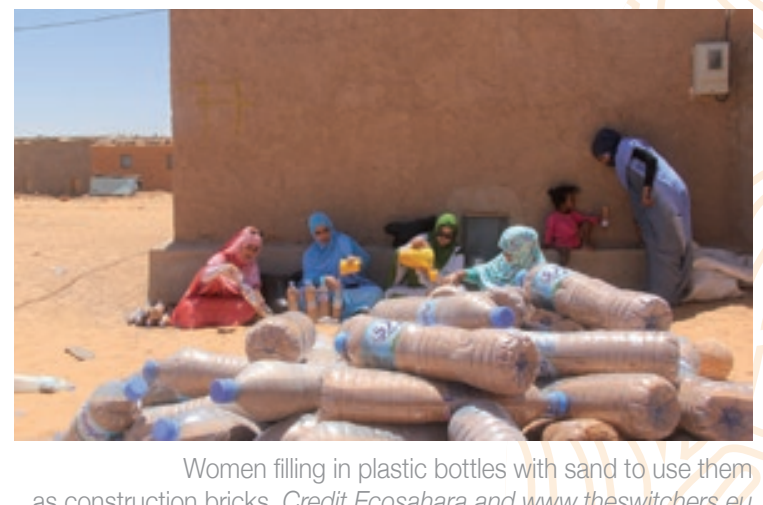

\section{How to use this publication}

The aim of the present publication is to be a practical tool for entrepreneurs, businesses and civil society organizations. In order to make it as operational as possible, the summary table on the next page shows a summary of the initiatives and key information to guide the reader. This will allow you to find the information that most interests you according to several criteria:

INITIATOR. Whether you are an entrepreneur, private business or a CSO, you will find easily the options that fit your profile.

MARINE LITTER SOURCE. There might be a particular source of marine litter you wish to address, probably depending on your local conditions. You will find easily those sources and the related actions you may wish to take.

MARINE LITTER ITEM. Likewise, you may be interested in addressing a particular type of marine litter, e.g. cotton buds, plastic bottles, etc.

PRODUCT-TO-WASTE STAGE. You can address specific marine litter sources and items at different stages of the product-towaste chain. You might find that the action is more effective if you focus more on the initial stages, namely the design and production stage, but you may simultaneously address different stages to have a greater impact.

After the summary tables you will find an in-depth description of each initiative, following the same structure. You may be particularly interested in reading the opportunities to promote further, replicate and adapt the initiative in the MENA region, as this gives an indication of the approach and steps you could take. Finally, contact information is included so you can get in touch with the original initiators. 

SOLUTIONS:

OVERVIEW

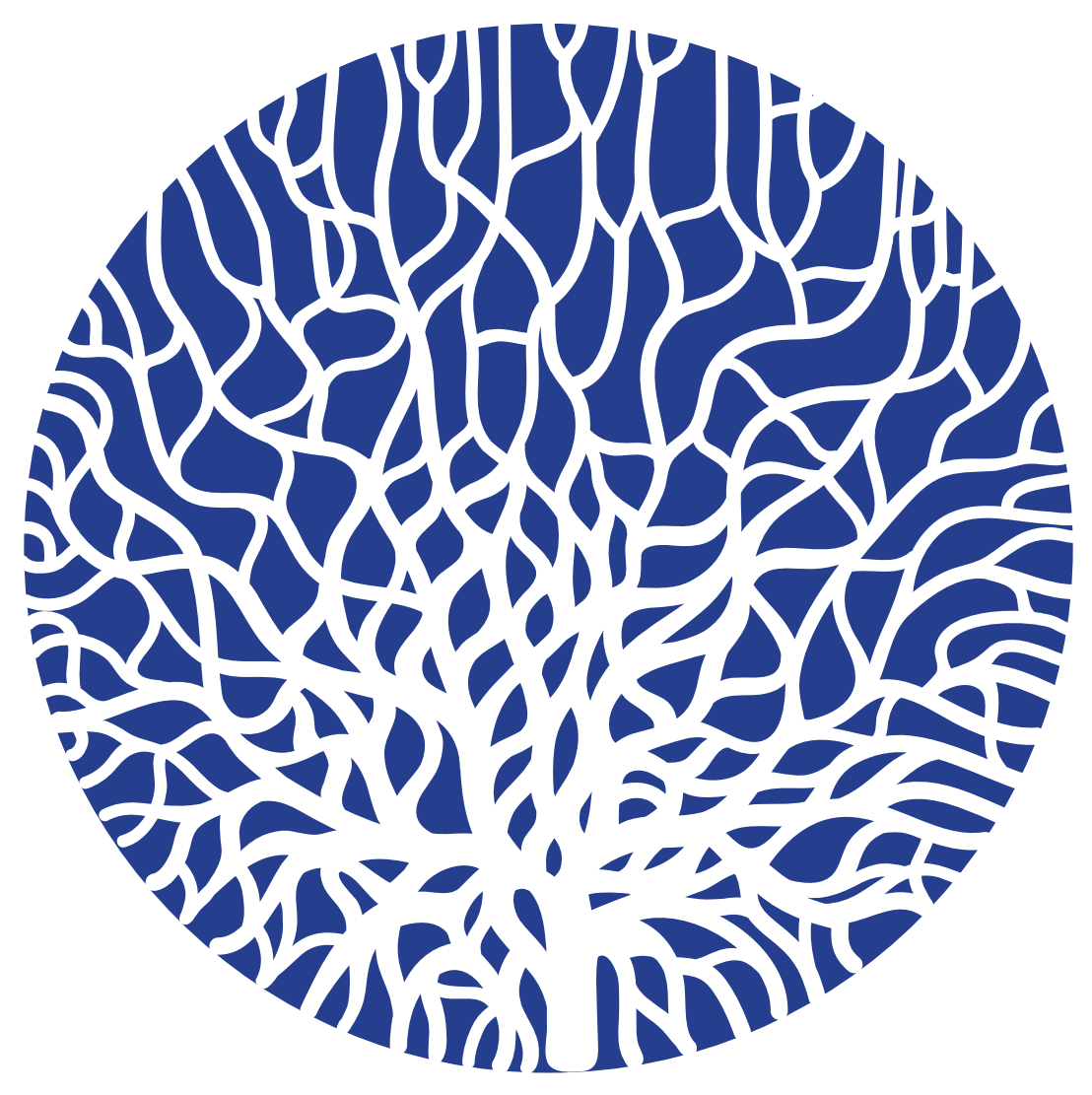


Page Initiative name

18

Full Cycle Bioplastics

nitiator

Private sector

ML source

ML item

\section{$20 \quad$ EcoOcean}

Private sector

Agricultur

Plastic producers

Plastic products

Pastic bags ilms

Circular Plastics Incubator

Entrepreneurs

Plastic producers

and manufacturer

Diverse

24

Ocean Plastic Bottle

Private sector

Plastic manufacturers

Plastic

beverage bottles

CLICKEAT $^{\circledR}$

Entrepreneurs

Snacks \& restaurants

Plastic cutlery

Resin pellets,

flakes and powder

Private sector

DEC, designing

with cardboard

Plan A, Marks \& Spencer

Private sector

Private sector

Mix

Paper-stem cotton buds

Private sector

Cora Ball

Festival Republic

Private sector

Recreation

Food \& beverage

industry

Retail sector Food \& beverage industry

plastic bottles, wrappers)

Food packaging
In a nutshell

Full Cycle Bioplastics (FCB) has developed a proprietary technology that converts organic waste, such as inedible food waste, agricultural by-products and dirty paper/cardboard, into a compostable bioplastic called polyhydroxyalkanoate (PHA) that degrades harmlessly in the soil and the ocean.

Designed with the environment in mind, EcoOcean's content is $77 \%$ biobased and is fully marine biodegradable and can replace conventional plastic bags and films.

Entrepreneurs, creative students and innovators in the field of circular plastic have come to Friesland, the Netherlands, establishing a community of creative talent to launch start-ups and to design new high-quality products.

Ecover has designed a plastic bottle made from bioplastics, recycled plastics and plastics fished from the oceans. The innovative bottle is $10 \%$ plastic that has been recovered from or was destined for the sea and the rest comes from other recycled sources.

SIMPLO takes on the challenge of rethinking disposables by designing new products and solutions that improve the experience of use and performance and which, once disposed of, are harmless to the environment and, moreover, cost effective.

The campaign's goal is to help manufacturers and operators to implement good practices to work towards achieving zero pellet, flake, and powder loss.

Cardboard is the raw material used by DEC to produce furniture and much more, with the ability to replace plastic in certain products.

In 2007, the global retailer M\&S launched Plan A, a corporate sustainability policy to reduce waste as a result of food packaging, among other things.

PulpWorks' flagship product is Karta-Pack ${ }^{\mathrm{TM}}$, an environmentally friendly alternative to the toxic, dangerous and ubiquitous plastic blister pack. The company offers compostable products, moulded from $100 \%$ post-consumer waste paper and agriculture.

Plastic cotton buds rank among the most predominant types of marine litter. The UK market has taken steps, boosted by civil society organizations, to offer alternatives to plastic, which is being replaced mainly by paper.

Rozalia Project has developed Cora Ball, a device to be used in the washing machine. It collects microfibres as well as hair and prevents them from flowing out with the drain water.

An increasing number of artists, companies, venues and festivals are joining initiatives to decrease their environmental impact, including plastic waste, and use these mass events to raise awarenes and stimulate changes in mindset.

This campaign sends marine litter items found on UK beaches back to the manufacturers and distributors to improve their commercial performance with the ultimate goal of preventing marine litter generation.
Working in partnership with grocery retailers, brands and suppliers as well as governments, WRAP developed and delivered a collaborative solution to reduce waste. 
USE AND CONSUMPTION

\section{Page Initiative name}

Initiator

$46 \quad$ Goccia Verde

Private secto

ML item

lastic

container

$48 \quad$ Plastic bag charge

Private sector

Retail sector

Retail sector

Recreation

Retail sector

Sewage-related debris

Mix

$54 \quad$ Bag it and Bin it -

Don't flush it

COLLECTION AND WASTE TRANSFER
Single-use plastic bags

Single-use plastic bags

\section{Single-use} plastic bags

Sanitary and cosmetic products

\section{In a nutshell}

Goccia Verde addresses the need to raise social awareness and bring about a transformation in current consumption patterns through the commercialization of detergents and soaps in bulk.

Numerous supermarkets in the world have introduced charges to the free distribution of the plastic bag, whether on a voluntary basis or driven by government action. This has brought about a drastic reduction in their use.

Youth power to drive change can convince an island like Bali to go plastic bag-free. It consists of a volunteer team of 25-30 students, both local and international, from schools all around Bali.

With a length of $9 \mathrm{~km}$, the longest plastic-bag chain in the world was made from 30,000 plastic bags in Berlin, 2014.

This awareness-raising campaign in the UK is aimed at reducing the incidence of sewage-related debris on beaches and riverbanks.

$\begin{array}{lllll}\text { Page } & \text { Initiative name } & \text { Initiator } & \text { ML source } & \text { ML item } \\ 56 & \text { Antivolabossa } & \text { Private sector } & \text { Diffuse } & \text { Diverse }\end{array}$

Waste management on AIDA cruises and Deerberg Converter ${ }^{\circledR}$ technology

$60 \quad$ Recycling we all win

Entrepreneurs

Pastic manufacturers

Plastic bottles

Aluminium cans

Private sector

ecreational fisheries

Fishing lines

\section{In a nutshel}

This small yet efficient device is designed to prevent the wind from blowing bin sacks away and spreading their content throughout the public space.

AIDA's cruises implemented an efficient waste management system, using the latest technology available, such as the Deerberg Converter ${ }^{\otimes}$, and prevention actions.

First green SME to commercialize reverse vending machines (RVMs) in Spain, giving incentives to reward the action of recycling.

This initiative not only raises awareness about marine debris but also provides containers along the South African coast to collect discarded fishing lines.
Page Initiative name

64 Thread: responsible fabric from Ground to Good $^{\text {T }}$

Private sector

ML source

ML item

Plastic bottles

Plastic manufacturers

Private sector
Diverse
Thread's mission is to alleviate poverty by creating dignified jobs and high-performance fabrics. Thread transforms plastic bottles from the streets and canals of Haiti and Hondura into responsible fabric.

This educational programme is aimed at teaching school children and the wider public about the environmental impact of plastics. The programme promotes plastic awareness, recycling and litter prevention. 


\section{The process \\ of selecting solutions. \\ Context and limitations}

T

he methodology to select the 25 innovative solutions involved different steps, which are listed below.

1. Desk study to identify programmes, initiatives and projects in Europe and worldwide addressing innovative solutions for plastic marine litter (and within that, plastic products), circular economy approaches to plastic, ecoinnovation and eco-design, among others, which could serve as a source of inspiration for the study. This included the inventory of basic data and contacts for those programmes, initiatives and projects. Sixty-seven initiatives were identified in this stage.

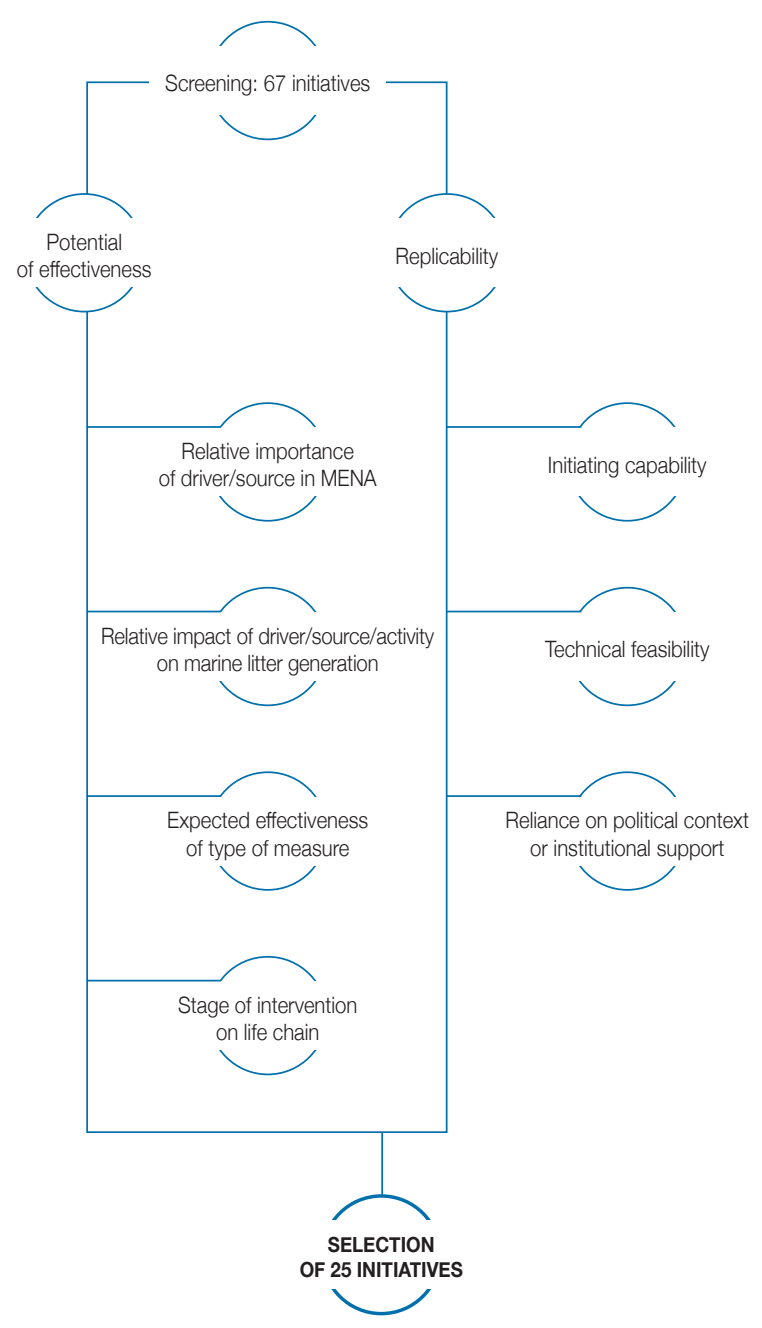

2. Once a long list of initiatives was identified, a multi-criterion analysis was run in order to prioritize them. Criteria were grouped in two main blocks, effectiveness and replicability. Thus, the result was a ranking indicating the initiatives that effectively address the problem of marine litter and at the same time can feasibly be replicated or further promoted in the MENA region.

3. The top 25 initiatives from this ranking were selected for further exploration. In this stage, public information was used and, when possible, interviews were held with the initiators in order to provide direct insight into the case studies. The final result was the description of these cases, presented in this publication. 


\section{Some important remarks regarding the scope, context and limitations of this study}

- Only SME- or NGO-initiated initiatives were included, not those linked to administration or policy measures.

- The initiatives cover multiple geographical areas and types and have an impact on different product life-cycle stages. The initiatives are representative but not a full inventory.

- Focus is on relatively small, replicable solutions. Larger changes remain desirable and even necessary within the current consumption and production system, but this goes beyond the target audience of this publication.

- In the field of the "new generation" of plastics, the focus has been on determining those whose behaviour could prove to be potentially harmful to the marine environment, as they are potential marine litter. This resulted in some initiatives that were valid inland in a fully controlled product-to-waste management process being discarded.
- There have been limitations to performing the study in terms of access to information, interest of companies in participating, reluctance to provide details (especially financial aspects) and discretion regarding the replicability of the initiative. This has been acknowledged by the research team, since companies and organizations may have market strategies that prevent them from releasing confidential data.

- The order of the initiatives presented in this publication does not reflect their importance. They have been grouped following the different stages of the product-to-waste chain, in order to give priority to actions addressing the design and production stage. However, action in all stages is still necessary and complementary. It is also important to note that some initiatives do not tackle a single stage but many of them simultaneously.

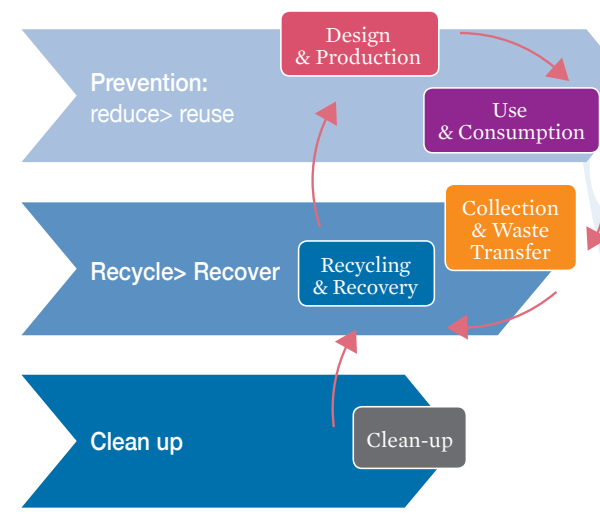

* Veiga J., Leslie H., Fernández P., Pérez C., Ferreira M. and Altvater S. (2015). Policy options for litter-free seas. Developed under the CleanSea project co-funded by the European Union Seventh Framework Programme under grant agreement no. 308370 . 


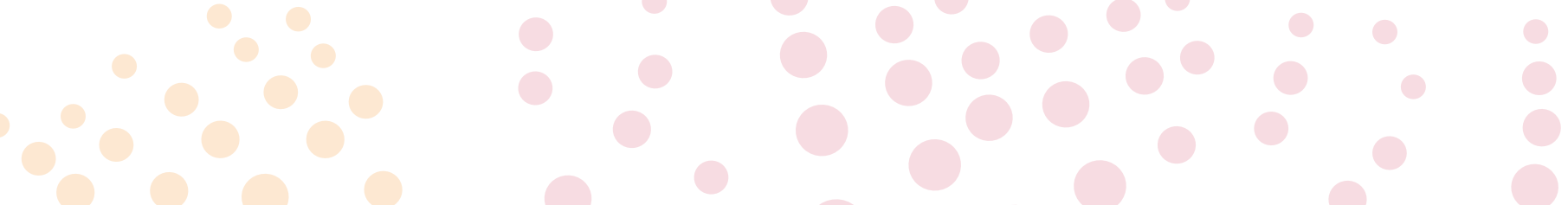

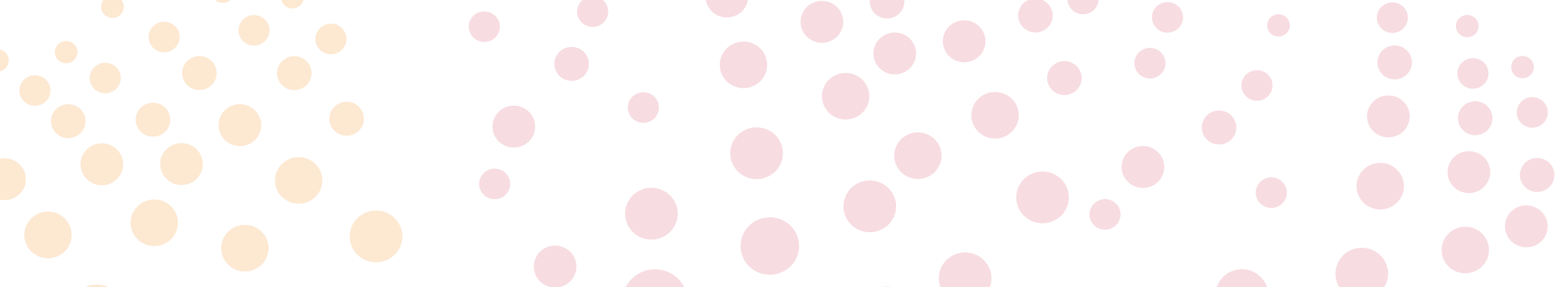

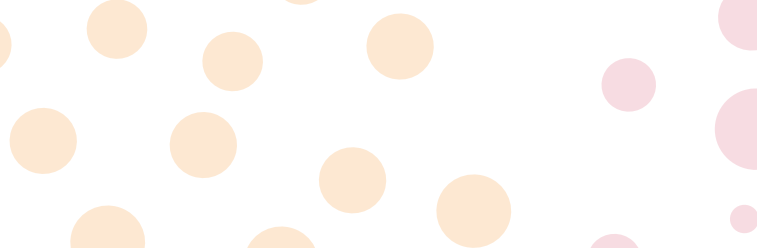

$\circ 0^{\circ} \circ$

व

○ 0

○

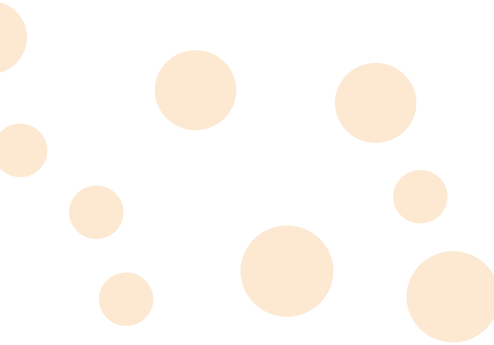

○

-

○。

- 0

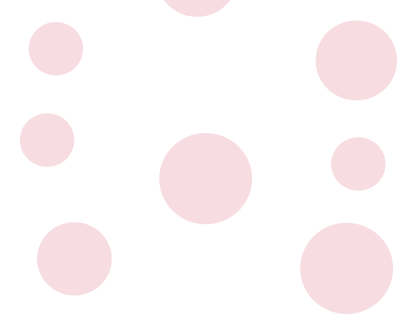

(3)

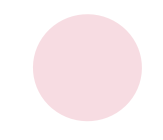

$(3$
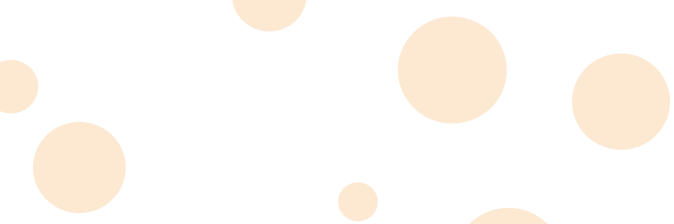

(

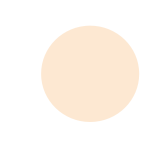

。

-
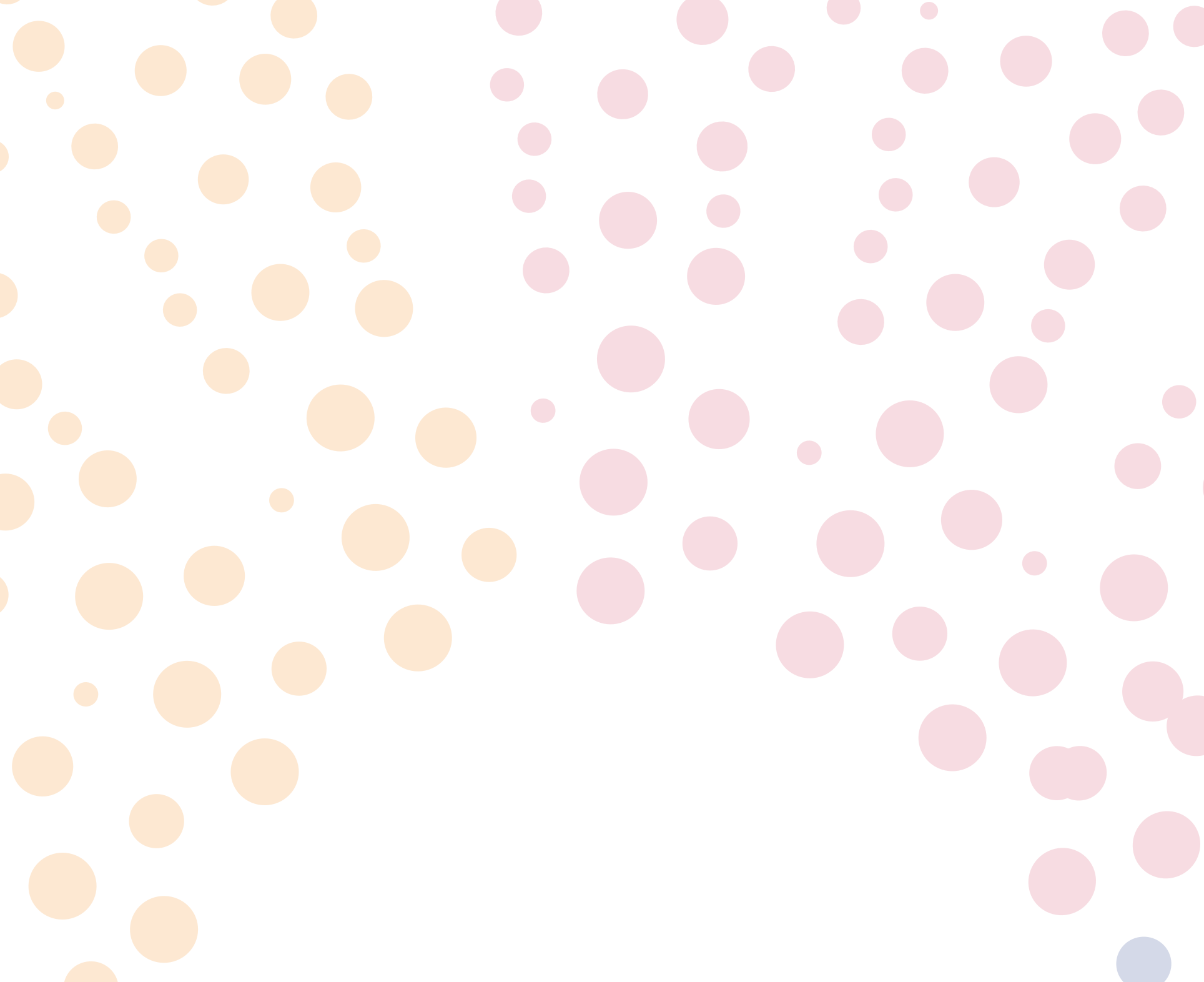

$(0$
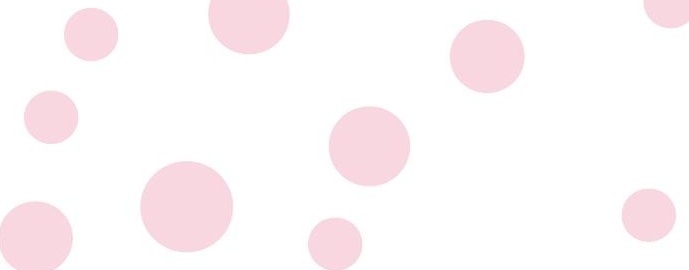


\section{SPOTLIGHT \\ ON 25 MARINE LITTER \\ SOLUTIONS}

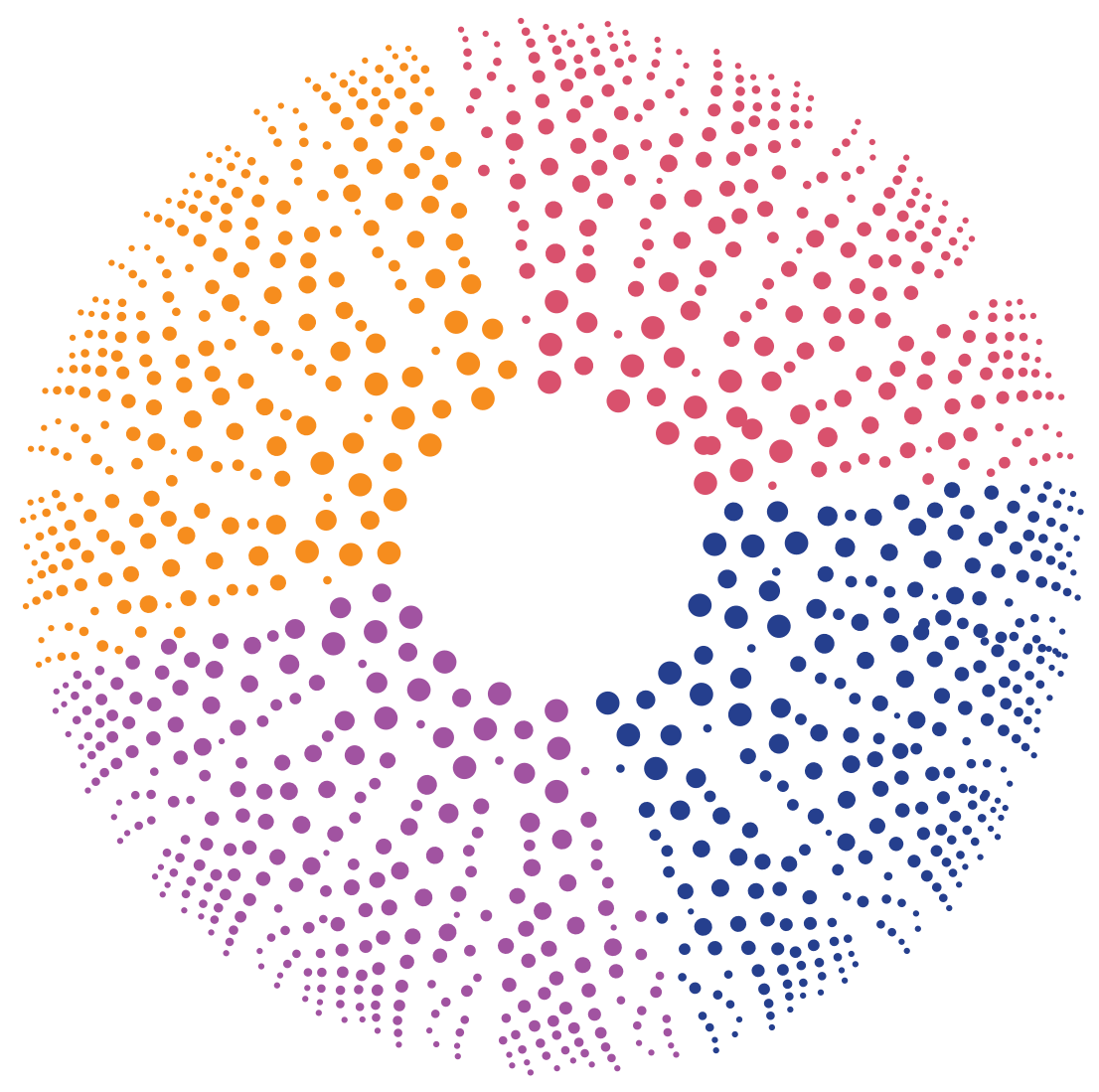




\section{Full Cycle Bioplastics}

Full Cycle Bioplastics (FCB) has developed a proprietary technology that converts organic waste, such as inedible food waste, agricultural by-products and dirty paper/cardboard, into a compostable bioplastic called polyhydroxyalkanoate (PHA) that degrades harmlessly in the soil and the ocean.

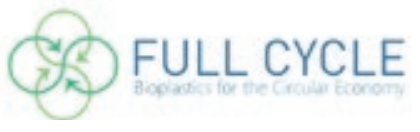

Success factors

- Full Cycle has entered a strategic partnership with a commercial partner to showcase its game-changing innovation via an on-site pilot project followed by a larger demonstration facility.

\section{- With great success} at the bench, in the lab, and at small pilot scale, Full Cycle has developed a wait list of leading brands and commercial partners eager for Full Cycle's growth and commercialization.

\section{- Full Cycle continues} to be invited to showcase its technology and thought leadership at global events and has been recognized with prestigious awards for its potential to drive system-level change across the plastics, packaging, and waste/renewables markets.

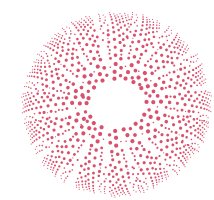

\section{What it's about}

Full Cycle provides a circular-economy solution for organic waste and plastic pollution by converting mixed organic waste into a compostable alternative for fossil fuelderived plastics. Full Cycle Bioplastics (Full Cycle) manufactures poly-

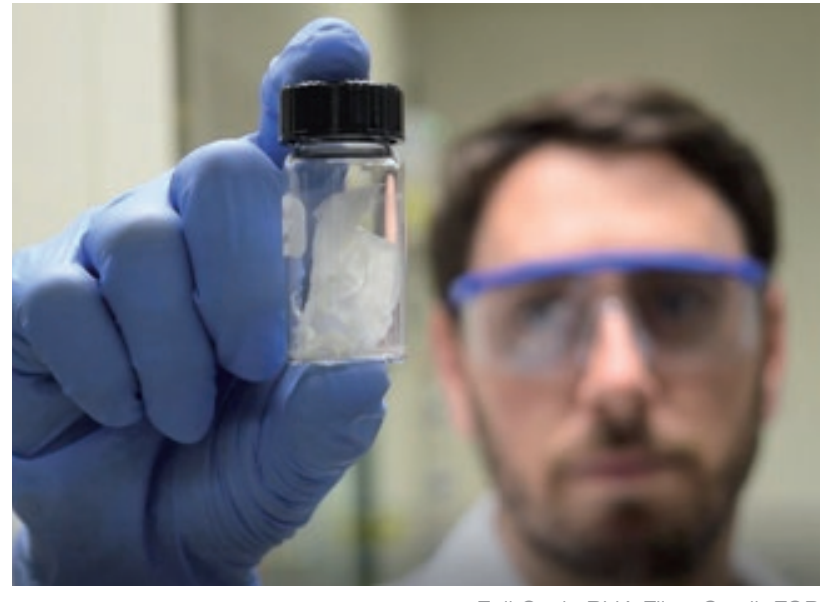

Full Cycle PHA Film. Credit FCB hydroxyalkanoate (PHA) bioplastic using a novel process that utilizes organic and cellulosic waste as the feedstock. It is well known that PHAs harmlessly and naturally degrade in marine and terrestrial ecosystems, but commercially available PHA is currently made from crop-based feedstock, such as food-grade sugar or seed oil. Full Cycle's non-GMO-based process is environmentally friendly from the start, using food waste, by-products, cardboard and waste paper as the raw materials. Full Cycle can even utilize PHA products, at the end of their life, as feedstock for the production of virgin PHA-a true closed-loop system.

Full Cycle licenses its technology to large waste producers and handlers, such as landfills, compost sites, MRFs, food or beverage processors, and paper mills. These licensees can convert discarded material and by-products into bioplastic resin. The output, PHA, is a naturally occurring polymer made by bacteria, yet it is an adaptable, high-performing replacement for fossil fuel-derived alternatives like polyethylene or polypropylene. At end-of-life, PHA products can re-enter the Full Cycle system as feedstock to be up-cycled again and again into virgin PHA-a repeatable, regenerative solution.

\section{Challenges addressed}

Demand for bioplastics is accelerating rapidly with forecasted growth of over $40 \%$ per year through 2025 . Full Cycle sees particularly strong demand from the food, food packaging, agricultural film, industrial coatings and beverage industries.

Supply of organic waste from which to produce PHA is large and growing; North America's municipal solid waste alone (not including agricultural or industrial waste) would support 250-400 potential Full Cycle installations. The Full Cycle technology addresses growing volumes of organic and 
plastic waste that clog landfills, contribute to greenhouse gas emissions, and create pollution threats to both terrestrial and marine environments. Full Cycle's PHA keeps organics out of the landfill and provides a bio-benign alternative to traditional plastic materials-mitigating climate change and stemming plastic pollution and toxicity.

\section{Initiator and collaborations}

Full Cycle was established in 2012 in the USA, and in 2014 it opened laboratory facilities as a research partner with the USDA Agricultural Research Service's Western Regional Research Center. Since then, Full Cycle has expanded its capacity to include a small pilot facility, and in 2017 it started the process of further expanding with a commercial partner to install an on-site pilot facility. Full Cycle will work with this commercial partner to also support a partnership with University of California, Davis, which has space and equipment available for a close to commercial scale demonstration project. Full Cycle has built a strong network of waste supply, material development, plastic converter and PHAdemand partners to support commercial growth and scale.

\section{Financial aspects}

Full Cycle received seed funding from investment firm Fifth Season Ventures in 2014. Full Cycle profits by licensing their intellectual property to a variety of host partners-agriculture producers, food/ beverage processors, compo sters and landfills, biorefineries, and even large campus environments. Full Cycle co-locates with large waste aggregators/

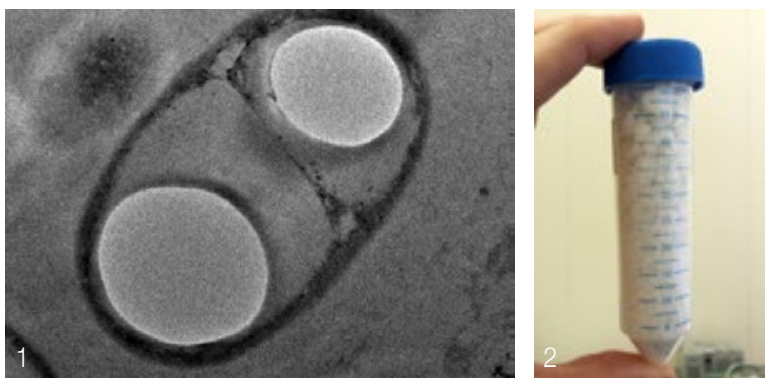

1. Full Cycle PHA Microbe; 2. Vial of PHA bioplastic. Credit FCB producers. These licensees own the facilities. Full Cycle receives an upfront license fee plus a recurring production volume-based fee. A third revenue stream may exist should the licensee choose an operation and maintenance contract. Full Cycle is responsible for the continuous optimization of the PHA production process and, where necessary, brokering the PHA into the market. The facility footprint is small ( $1 / 2$ to 3 acres) and generates incremental revenue of $\$ 75$ to $\$ 500$ per ton of waste processed (assuming a PHA price of $\$ 1.50 / \mathrm{lb}$.). Capital expenditure estimates are $\$ 15$ to $\$ 50$ million depending on scale, with a payback period of around 2 to 7 years*.

Further market opportunities and replicability aspects By licensing Full Cycle technology, companies with large waste streams, either as producers (i.e. food processing) or collectors (i.e. waste handling), can produce $\mathrm{PHA}$ to generate revenue and mitigate disposal costs, thus creating the highest and best value from waste.

This is particularly interesting in the MENA region, where there are important gaps in waste management systems. The adoption of this technology as a pilot experience in sectors such as agriculture and food processing, or on a municipal waste management scale, may open doors to improving waste management performance in the region. Full Cycle's solution is particularly wellsuited for implementation alongside other organic waste technologies in areas where organic waste content is a relatively high percentage of total waste, and where moisture content of organic waste is high.

\footnotetext{
* This information is representative. Each project must be evaluated specifically.
}

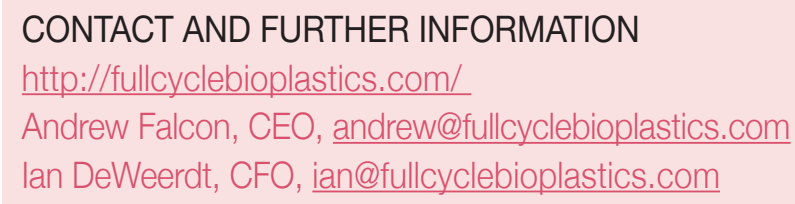

\section{SIMILAR INITIATIVES}

In Europe, the project BREAD4PLA is a LIFE demonstrative project which aims to demonstrate the feasibility of an innovative, user-friendly and sustainable environmental solution which promotes waste recovery in the specific agrofood sector of the bakery industry. The main objective is to demonstrate, in a pre-productive continuous pilot plant process, the viability of polylactic acid (PLA) synthesis from the bakery industry's waste products and its use in the fabrication of a 100\%-biodegradable film to be used in the packaging of bakery products, closing the life cycle. 


\title{
EcoOcean ${ }^{\mathrm{TM}}$, a marine-biodegradable material
}

\author{
Designed with the environment in mind, EcoOcean's content is $77 \%$ biobased \\ and is fully marine biodegradable and can replace conventional plastic bags and films.
}

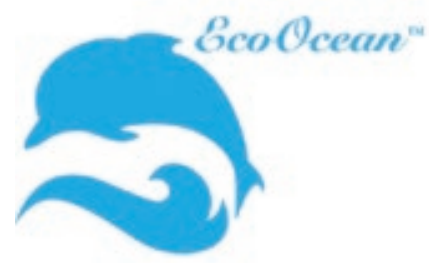

Success factors

- One of the first marine-biodegradable materials to be used as bags and films.

- The product's R\&D possibilities were made possible through an EU-funded project.

- Cooperation with other partners in lobbying.

\section{- Biodegradability} certificates.

\section{What it's about}

EcoCortec's speciality is the introduction of the EcoOcean ${ }^{\mathrm{TM}}$ material: film and bags constructed from the latest biobased polymer technology on the market, PHA. Designed with the environment in mind, EcoOcean contains $77 \%$ biobased resins (sugar cane origin) and is fully

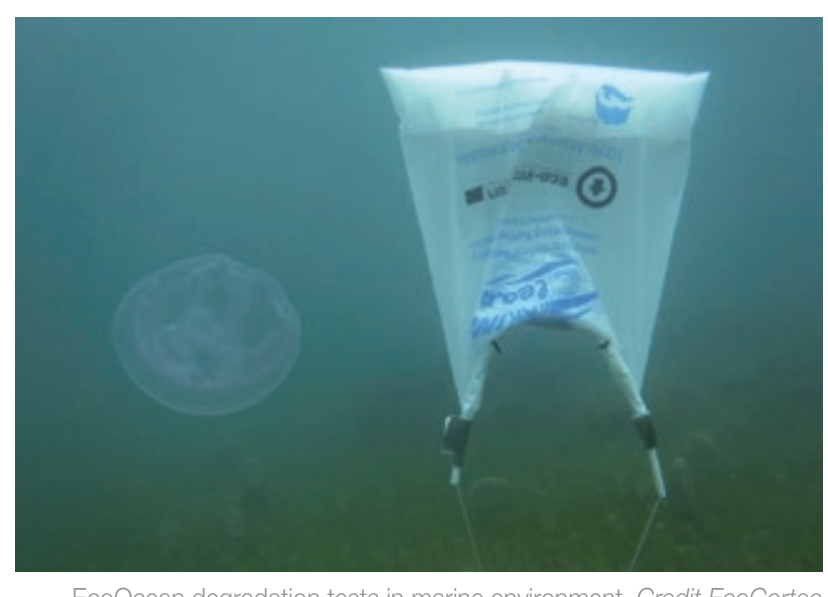

EcoOcean degradation tests in marine environment. Credit EcoCortec marine biodegradable. EcoOcean is designed to biodegrade in marine environments, through anaerobic digestion, in natural soil and water environments, backyard composting systems, and municipal composting facilities.

EcoOcean film products are durable and versatile with the added value of being biodegradable in a wide range of environments. EcoOcean is also marine protective. Although not intended to be disposed of in the sea, in the event this product should reach the waterways, it will biodegrade in months instead of remaining in the ocean for years like ordinary plastic films. EcoOcean is heat- and moisture-resistant, making it ideal for use in compostable bags and many flexible-film packaging applications.

Within the MarineClean project, tests including experiments with photochemical and microbial degradation in microcosms were conducted, as well as degradation in more biologically complex systems with different marine animals, such as aquaria or in situ in the coastal sea. The microbial dynamics were followed using microscopic and molecular techniques to determine the succession rates and species composition of microbial communities as well as possible differences compared to non-degradable plastics. Results showed that the degradation occurred on a time scale from weeks to months. In addition, some of the animals (fish, crabs) were feeding on this decomposing material. These tests have resulted in EcoOcean being awarded several quality certificates:

- USDA BioPreferred*-certified packaging material.

- BPI-certified to meet ASTM ${ }^{* *}$ D6400 for compostable plastics.

- Marine biodegradable per ASTM D7081 standard specification.

- $100 \%$ anaerobically digestible per ASTM D5511 standard test method.

Managed by the US Department of Agriculture (USDA), the goal of the BioPreferred programme is to increase the purchase and use of biobased products.

** ASTM International is an international standards organization that develops and publishes voluntary consensus technical standards for a wide range of materials, products, systems, and services. 
The applications potential is endless, including retail packaging and agricultural films. Regarding the marine environment, the introduction of this material as a container for organic waste on cruise ships would be very advantageous, since this type of waste is ground up and dumped at sea. However, these materials still have a significant cost disadvantage in relation to conventional plastics, which is roughly five times cheaper. It is likely that widespread commercial adoption will require some combination of legislative restrictions of conventional plastics and/or economic incentives for the use of biodegradable plastics. For this reason, EcoCortec, together with the MarineClean partners, has been active and lobbying at EU and national level. The partnership has elaborated a proposal of stricter legislation for garbage return from ships and one of subsidies when using edible and biodegradable packaging both on ships and in coastal areas, both at European and national level.

\section{Challenges addressed}

This initiative proposes an alternative to conventional plastic films and bags that specifically biodegrades in the marine environment, standing out from other materials that only biodegrade on land. This would help prevent pollution even when the bags and film reach the sea.

The main challenge that remains in commercializing the material is the price compared to conventional materials. Indeed, conventional polyethylene costs roughly 1.30 euro/kilo, while EcoOcean is more than 5 euro/kilo.

Another challenge is the lack of a European standard for marine biodegradability; this is why certification

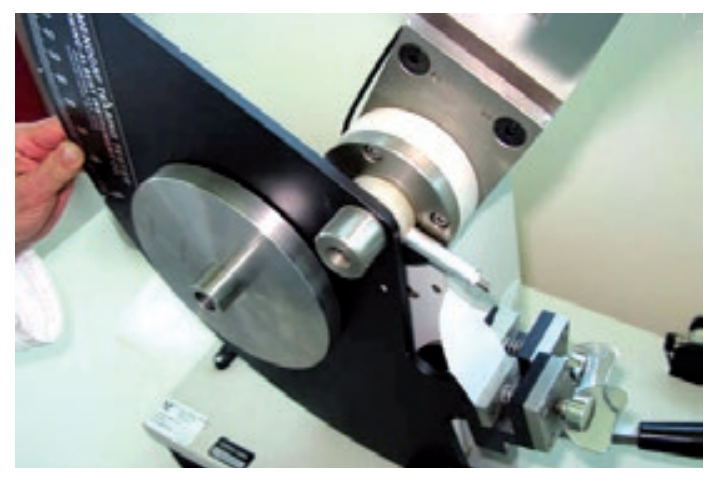

EcoOcean degradation tests. Credit EcoCortec

CONTACT AND FURTHER INFORMATION www.ecocortec.hr

MarineClean project results: www.marineclean.eu Ivana Radić Boršić, EcoCortec, iborsic@cortecvci.com comes from the USA. This fact makes it difficult to take advantage of the existence of these materials and to spread their use in Europe. However, the American standard applies for temperatures of $26^{\circ} \mathrm{C}$, so this certification would only be effective in Southern European waters.

\section{Initiator and collaborations}

EcoCortec is a company based in Croatia aimed at developing eco-efficient production of biodegradable materials that combine new technology and high productivity with positive effects on the environment.

The EcoOcean product has been developed through the participation in the EU-funded MarineClean project. Thus, EcoCortec has collaborated with research institutes and companies. Besides the technical aspects of the marine-biodegradable material, this collaboration is very important in terms of lobbying and making this product competitive in the future.

\section{Financial aspects}

EcoCortec was able to run different tests on EcoOcean with funds coming from the MarineClean project, the cost of which was approximately 30,000 euros. However, the original $R \& D$ investment was handled previously by the mother company, Cortec Corporation in the USA.

As explained previously, the economic disadvantage of EcoOcean compared to conventional polyethylene is the main challenge to introducing it in the market. This is why legislation and economic incentives would be needed to move forward.

\section{Further market opportunities}

This type of initiative could inspire several ways to further develop marine-biodegradable materials and their applications.

However, since the EcoOcean material is already developed, it seems reasonable to place greater efforts towards its commercialization. In this sense, partnerships between distributors and end users, such as cruise companies, could be sought. For cruise companies it would indeed be a great opportunity to improve their environmental performance and corporate social responsibility. A pilot project on the use of EcoOcean bags as a container for organic waste could be set up to raise awareness of the benefits of this shift in use and promote it among other maritime companies. Other desirable applications include its use in coastal and marine nature parks and restaurant and catering businesses. 


\section{Circular Plastics Incubator: BeStart, cleantech start-ups}

Entrepreneurs, creative students and innovators in the field of circular plastic have come to Friesland, the Netherlands, establishing a community of creative talent to launch start-ups and to design new high-quality products.

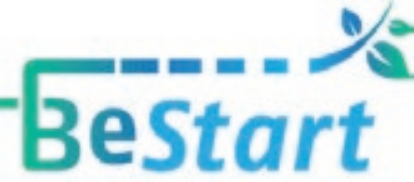

BOOSTING CLEANTECH

Success factors

- All necessary actors involved: local government, waste managers, business, research institutes and academia.

- Physical space of four founders available to interact with the regional network.

- Engaging companies that help start-ups to reach out to the market.

- Communication and marketing.

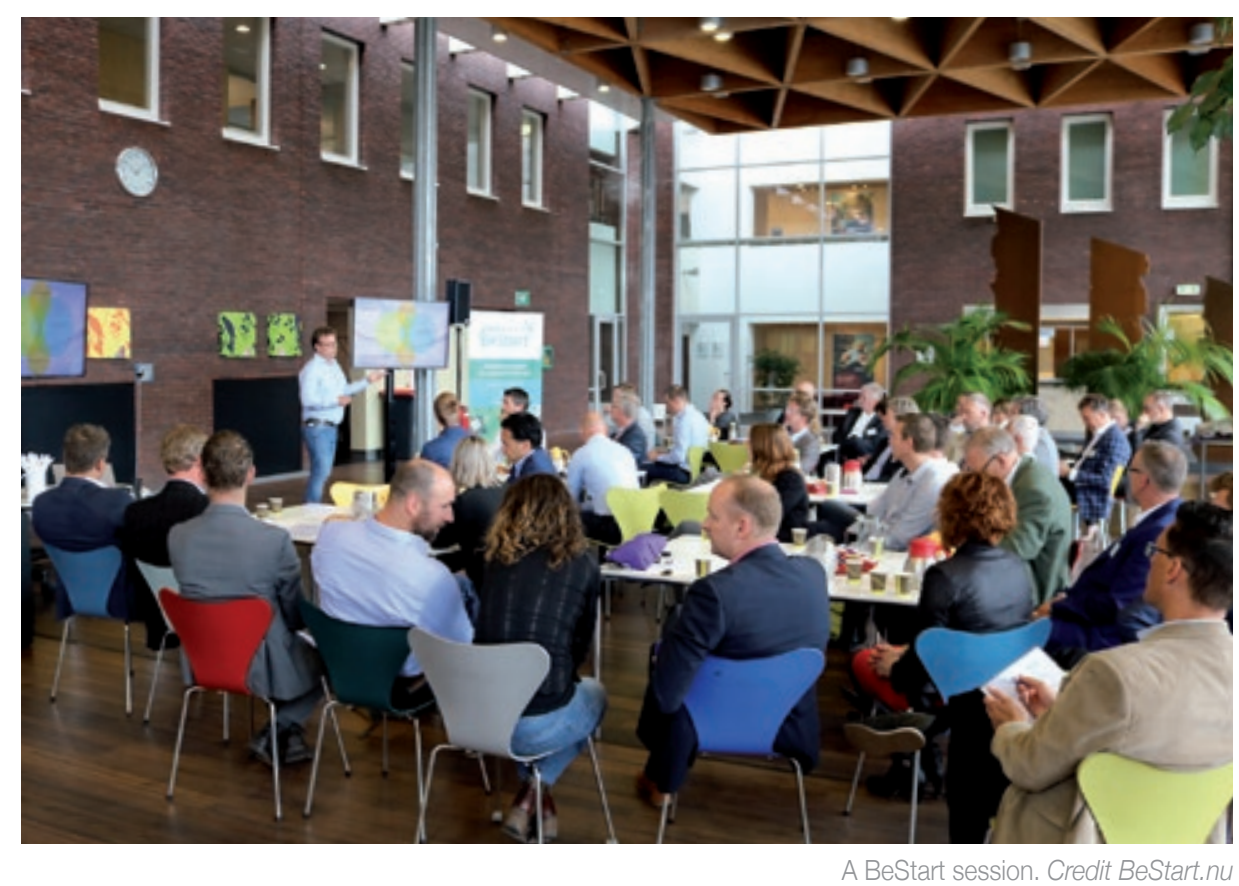

What it's about

BeStart brings together entrepreneurs, creative students and innovators in the field of circular and biobased economy. It is a regional initiative up to national and European standards. The accelerator is located in Friesland, the Netherlands. Within 2 years, BeStart established a community of creative talent to launch start-ups and to design new high-quality products. Since 2016, a number of start-ups have been selected annually for an "accelerator" process, providing them with support to allow their company to grow faster.

The core of BeStart is the accelerator programme. The programme consists of three phases: BeStart Think, BeStart Check and BeStart Grow.

During BeStart Think, companies get a well-thought-out, coherent image of their business. They know precisely what their client's problem is and how their solution addresses it. BeStart Check is about validation. Companies will validate their product in close cooperation with customers. Finally, BeStart Grow is about selling procedures more efficiently and improving fund acquisition.

\section{Challenges addressed}

Among other things, start-ups within the BeStart programme address plastic household waste from a circular economy perspective, aiming to close the loop so it does not leach into the environment, including coastal and marine waters. The main challenges are:

- linking innovative start-ups with launching customers and partners;

- selecting high-potential companies to participate in the accelerator. 


\section{Initiator and collaborations}

In 2013, 90 entrepreneurs from Friesland, the Netherlands, met to seek entrepreneurship opportunities. Ultimately, this resulted in, among other things, Bestart.nu. Their goal was to further develop the attractive north of the Netherlands as an innovative, enterprising region with (young) entrepreneurs who can make a difference. Their focus is now on the biobased and circular economy. BeStart is their flagship initiative related to cleantech start-ups. The incubator has a broad support network, from both the R\&D and innovation and financial sides.

The parties that package their activities through the BeStart.nu accelerator are:

- EcoMunity Park: it is a unique ecological working landscape focusing on soil and biodiversity. Everything is about innovation, entrepreneurship and sharing knowledge and facilities.

- Water Campus: it is the hub for water technology. Everything comes together: start-up, education, innovation, university research, export assistance and a thorough research infrastructure.

- Omrin is the leading waste treatment company that closes the cycle. They provide their national network.

- Paques develops systems for water purification which produce biogas. Office and production facilities are available for BeStart.

\section{Financial aspects}

Financially, broad support is given by public and private bodies and companies such as: ECOstyle, Wetsus, University of Groningen, NHL College, Hogeschool VHL, ROC Friese Gate, Friesland
College, Nordwin College, Province of Fryslân, Municipality of Leeuwarden, Rabobank and FB Oranjewoud.

Further market opportunities and replicability aspects The programme can easily be replicated in other regions of Europe. It requires a strong local/regional network, preferably focused on a specific subject (e.g. the plastics industry). Due to this focus there will already be a sort of basis with start-ups and ideas that might be interested in joining an accelerator. It requires a collective effort, including, among others, businesses, government and research institutes. Potential funding sources: government; private foundations; companies; international subsidies.

BeStart can be implemented quite easily (less than 6 months until the first accelerator). It can be set up with local coaches and entrepreneurs. A precondition is having a strong local network; otherwise it will take more time to develop such a network. Besides investment from local organizations in time and locations (e.g. lab facilities), a budget of about 150,000 euros (cash) per year is required to support 12-15 companies per year. The budget will be mainly used by the coaches and project managers of the programme.

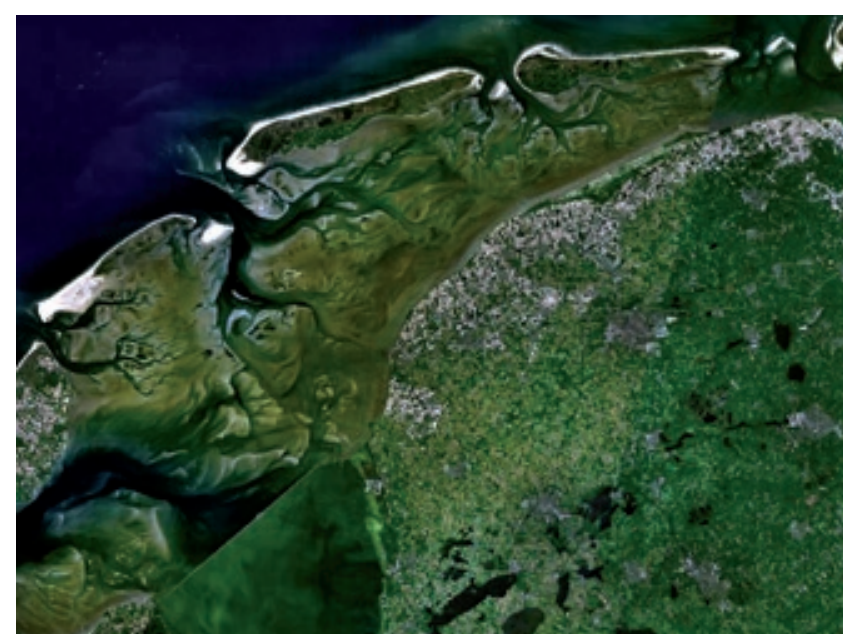

Friesland. NASA World Wind screensho

\section{SIMILAR INITIATIVES}

BeStart combines both an incubator and an accelerator. An accelerator in the field of innovation for plastic products worth mentioning is Think Beyond Plastic ${ }^{\mathrm{TM}}$, which aims to advance the transition towards biobased, bio-benign alternatives to conventional fossil fuel-based plastics. 


\title{
Ocean Plastic Bottle: A new responsible container
}

\author{
Ecover has designed a plastic bottle made from bioplastics, recycled plastics and plastics fished \\ from the oceans. The innovative bottle is $10 \%$ plastic that has been recovered from or was destined \\ for the sea and the rest comes from other recycled sources.
}

\section{ë́over Get nature on your side.}

Success factors

- First plastic bottle produced on a large scale with retrieved plastic from the sea and bioplastics.

- Teamed up with a company that fishes the plastic that is recycled in the new bottle out of the sea.

\section{- Awareness-raising component due to the fact of using marine litter as recycled material.}

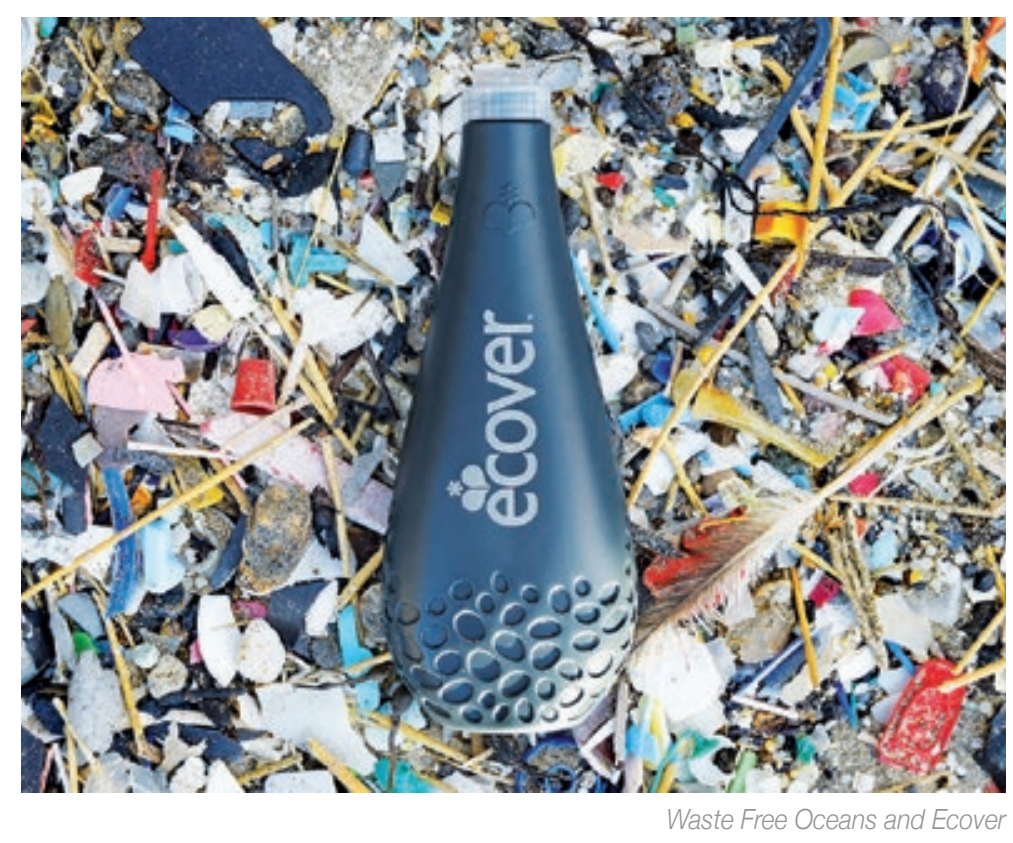

What it's about

Ecover is a Belgian company dedicated to cleaning products and founded by eco-pioneers. Its first product was a phosphate-free washing powder, in response to the water pollution caused by conventional detergents.

The company went a step further for their bottles by launching the Ocean Plastic bottle. On the one hand, there is the use of bioplastics (Plantplastic ${ }^{\circledast}$, that is, plant-based polyethelene), recycled and recyclable plastic and the use of less plastic, which already reduces the potential input of plastic pollution. On the other hand, although the effect of retrieving plastic in the sea might be minimal, there is an effect on people's awareness of the problem and thus a contribution to preventing it.

This type of shift in bottle manufacturing would have an enormously positive impact, especially if other companies, not just bottle producers, would adopt this type of initiative.

\section{Challenges addressed}

This initiative tackles one of the most recurrent pieces of marine litter in the Mediterranean: the plastic bottle. Furthermore, since this is the container used by fast-moving consumer goods (FMCG) products such as detergents and the initiative addresses the design and production phase, the potential for reducing marine litter is very high.

The challenge posed by the massive and increasing production of plastic bottles is addressed in this initiative in a technological and educational way. 


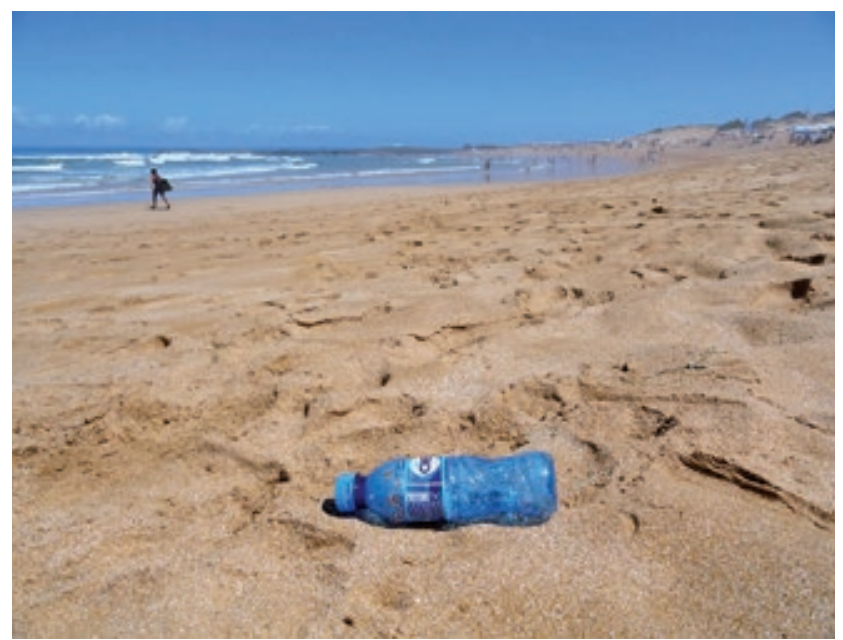

Credit Pedro Fernández

\section{Initiator and collaborations}

Ecover is one of the largest producers of ecological washing and cleaning products in Europe. Founded over 35 years ago in Malle, Belgium, they were among the first to put phosphate-free washing powder on the market. Now these products are available in about 40 countries, and Ecover's contribution to the environment has been recognized by Time Magazine and the United Nations Environment Programme. Ecover initiated the Ocean Plastic bottle by liaising with the company Plastic Whale, the first professional plastic fishing company in the world.

The retail sector is also very important in making sure customers are able to buy this new container. Important massive retailers such as TESCO offer these Ecover products.

Further market opportunities and replicability aspects This type of action could be started by any company using plastic bottles as containers. Companies that have a more evident eco-awareness would be better candidates to take this up, for example, companies/ cooperatives dedicated to bio-agriculture or personal care products.

A first step would be for the company to contact a plastic bottle manufacturer which has the capability of producing from recycled plastics. Simultaneously, the company would make contact with a civil society organization or a company active in marine litter clean-up, either from the sea or from the beach. The three parties should agree on a business scheme for production and supply. Finally, the initiator should design and implement a communication strategy, emphasizing the recycling of plastic found in the sea or on the beach.
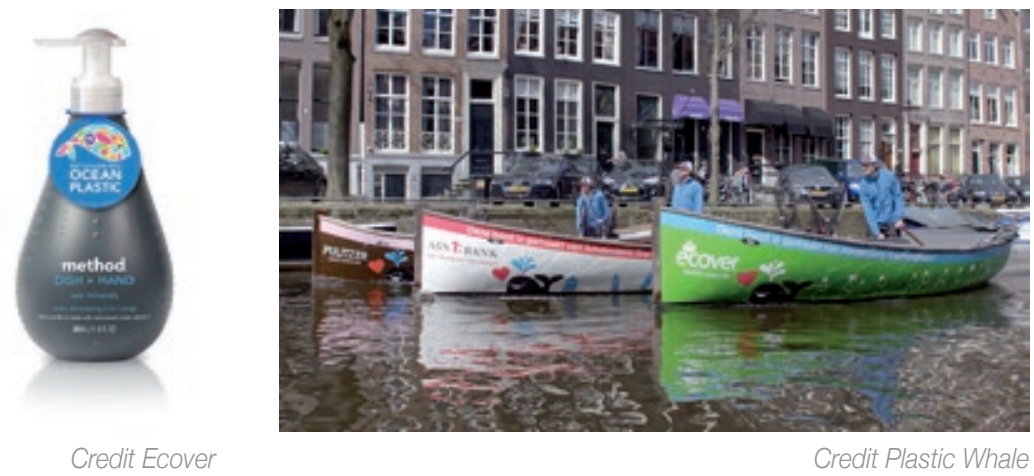

Credit Plastic Whale

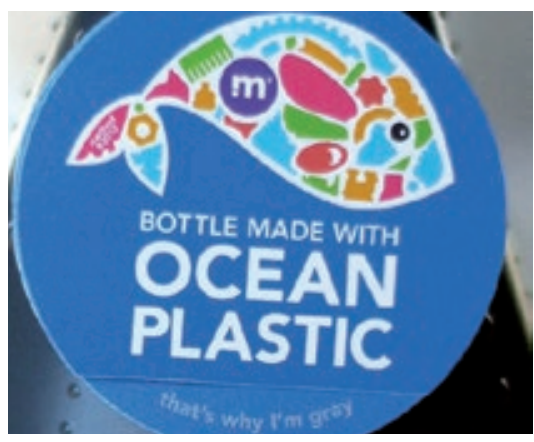

Credit Ecover

CONTACT AND FURTHER INFORMATION

www.ecover.com

\section{SIMILAR INITIATIVES}

Procter \& Gamble Company announced that Head \& Shoulders (H\&S), the world's \#1 shampoo brand, would produce the world's first recyclable shampoo bottle made from up to $25 \%$-recycled beach plastic.

In partnership with recycling experts TerraCycle and SUEZ, this innovation will come to France in summer 2017 as a limited-edition H\&S bottle available to consumers in Carrefour, one of the world's leading retailers. This will be the world's largest production run of recyclable bottles made with post-consumer recycled (PCR) beach plastic, and a first major step in establishing a unique supply chain that involves the support of thousands of volunteers and hundreds of NGOs collecting plastic waste found on beaches. 


\title{
Clickeat: An alternative to single-use plastic cutlery
}

\author{
SIMPLO takes on the challenge of rethinking disposables by designing new products \\ and solutions that improve the experience of use and performance and which, once disposed of, \\ are harmless to the environment and, moreover, cost effective.
}

\section{C:I_IC'KCAT}

Success factors

- The patent not only covers the final product (material) but also the process of creation.

- Guarantee of traceability of the production process.

- Support and visibility through design awards and competitions such as Think Beyond Plastic and Chile Design

Biennial 2010.

\section{- Reaching out}

to the market.

\section{- Communication} and awareness-raising activities working with local communities on sustainable options.

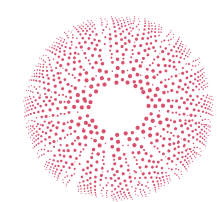

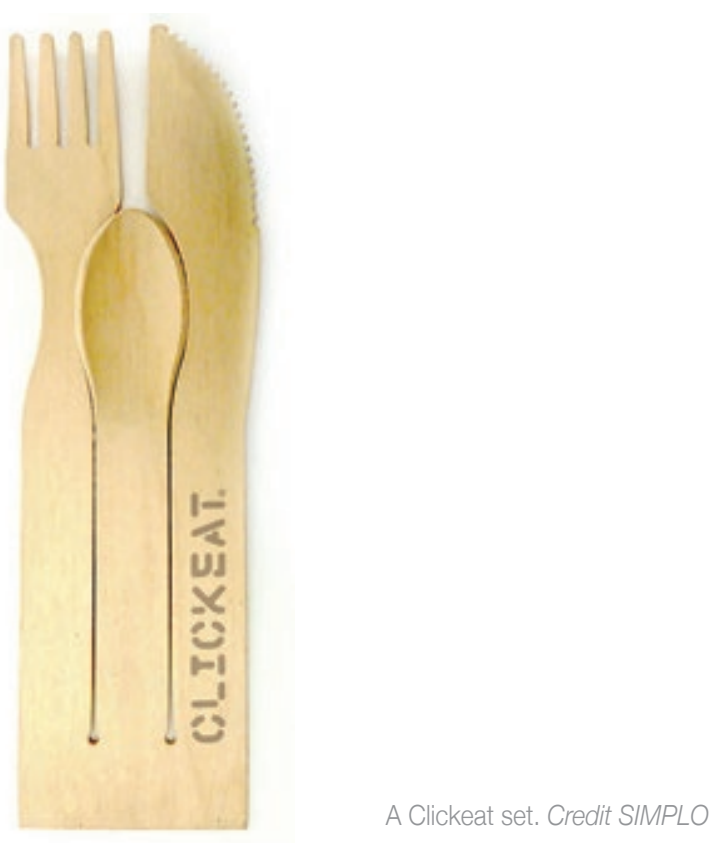

What it's about

SIMPLO is a young initiative bringing together design and sustainability that currently has one patented product line:

- The Clickeat DUO: for fast food and outdoor use.

- The Clickeat TRIO: a logistic and cost-effective solution for the food service industry.

It uses SFC-certified wood particles to produce elegant and lightweight disposable utensils. They are 100\% biodegradable, reduce loss of raw material, improve transport efficiency and can include publicity or messages targeting the end user. As the cutlery comes attached, SIMPLO also avoids the use of a plastic wrap to keep the cutlery utensils together.

\section{Challenges addressed}

In the Mediterranean, marine litter items found on beaches stem mostly from recreational and tourism activities. Single-use food wrappers and cutlery are among the top items. Clickeat provides a biodegradable alternative to traditional plastic cutlery and at the same time places the spotlight on other important features:

- Logistics: all-in-one concept, stackable, light and compact.

- Design guarantees hygiene. As it needs to be detached for use, it cannot be reused without the user knowing. 
- Environmental responsibility: 100\%-biodegradable and compostable.

- The responsibility for the environmental impact does not fall on the user.

- The design does not require instructions.

- Cost-efficient compared to 3 or 2 individual pieces.

- Excellent advertisement media: allows for publicity and messages to be printed on the product.

\section{Initiator and collaborations}

A group of designers started rethinking disposables back in 2001, after metal cutlery was prohibited on airplanes and replaced with plastic ones (wrapped in plastic). Looking at cutlery packs on airplanes, in 2010 they created the start-up SIMPLO to bring together design and sustainability, especially for single-use products. Since then, they have registered the patent for Clickeat and have a number of others under way.

SIMPLO collaborates with the 5 Gyers Institute and with Plastics Pollution Coalition.

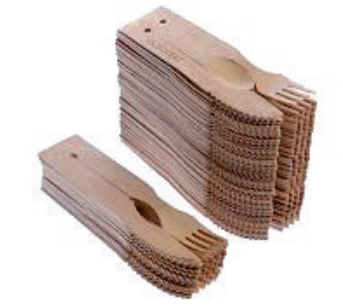

A Clickeat set. Credit SIMPLO

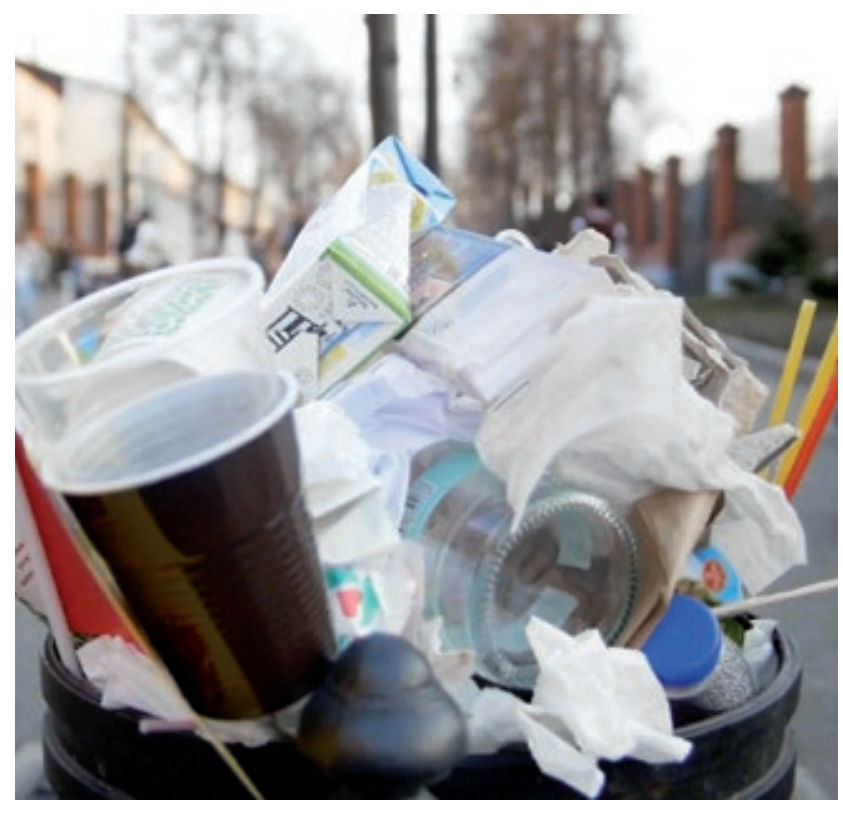

Single-use food and drink containers and packaging.

\section{Further market opportunities} and replicability aspects

Market opportunities exist in the MENA region especially in the leisure industry and fast food services, which rely very heavily on single-use plastic items.

One replication option would be to team up with SIMPLO for distribution or the possibility of creating a local distribution chain. Joint ventures could be formalized to increase the geographical scope of Clickeat's market.

Another option could be working with a licensed patent. In this case, however, the traceability of the production process would be fundamental and therefore the most feasible figure to ensure full control and identical production would be a franchise system. One of the key issues would be ensuring that the raw material be SFC-certified to guarantee that the substitution of plastic with wood would not be causing deforestation.
One on the strengths of these types of entrepreneurial activities is the low dependence on national political contexts. It would, however, be desirable to create economic incentives for those products innovating on a sustainable basis in order to favour their position in the market. Equally, exploring the possibilities of a label or recognition for those "clients" opting for sustainable disposables would generate a much more favourable environment for this type of initiative.

Interest may be raised among hotels and the fast food industry while it is being raised among potential customers. Local entrepreneurs could liaise with SIMPLO in order to demonstrate the product possibilities.

In a first stage, local entrepreneurs could intervene as mediators to start creating local demand, and SIMPLO would supply the products. Later, transfer of know-how could be organized in combination with a franchise model in which the crucial issues would be ensuring adequately high quality, traceable raw material and a sustainable production chain. Traceability would be a key element in this process. Financial support to start up could be sought through loans, private foundations, international subsidies and design awards. 


\section{Operation Clean Sweep ${ }^{\circledR}$ : Engaging industry to prevent plastic leaks}

The campaign's goal is to help manufacturers and operators to implement good practices to work towards achieving zero pellet, flake, and powder loss.

\section{Cperation Clean Sweep.}

Success factors

- Internationally recognized programme.

- Free-of-charge.

- Manual including detailed description of procedures for a potential plastic leak and options to prevent it.

\section{- Customizable} checklists supporting the implementation of OCS at facility and employee level.

\section{What it's about}

Operation Clean Sweep ${ }^{\circledast}$ (OCS) is a voluntary scheme that applies best practices to confine plastics within company facilities. To do so, it uses several instruments and tools: Signing a pledge, both at company and employee level. In return, the company receives a certificate suitable for display affirming its commitment to being an OCS Partner, and it is included in the list of OCS programme partners on the Operation Clean Sweep website.

By signing the pledge, companies commit to:

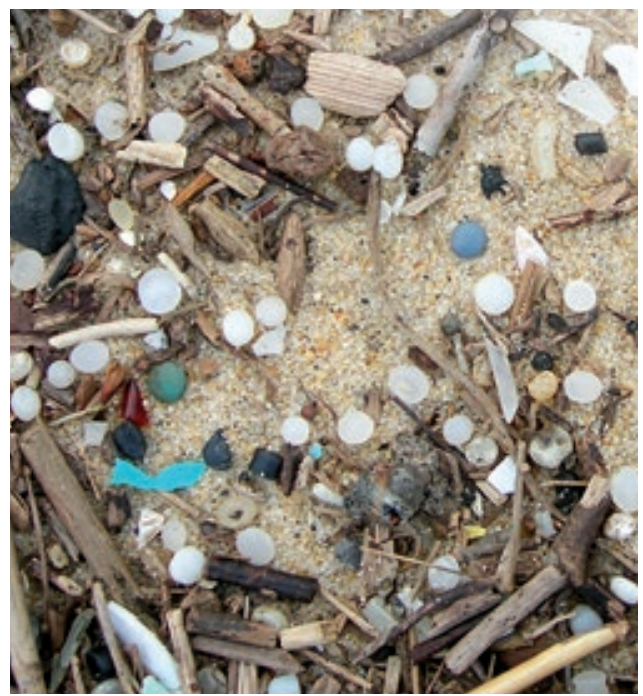

Industrial plastic pellets found on an Aquitaine beach. Credit Plastics Europe

- Make changes wherever possible and practical to improve worksite set-up to prevent and address spills; create and publish internal procedures to achieve zero pellet, flake, and powder loss; and provide employee training and accountability for spill prevention, containment, clean-up and disposal.

- Review performance regularly.

- Comply with all applicable state and local regulations governing pellet, flake, and powder containment.

The OCS manual is provided as a guiding tool and comprises the elements mentioned above. The crucial steps are:

- Assess the company's situation and needs.

- Make necessary upgrades to facilities and equipment as appropriate.

- Raise employee awareness and create accountability.

- Follow up and enforce procedures.

In practical terms, the manual includes a section, "Prevention, Containment and Clean-up Procedures", where specific actions are identified to achieve the OCS objective. There are also customizable checklists that are a remarkable tool for companies.

In Europe, Plastics Europe intervenes together with companies through an OCS working group. For example, a common OCS reporting method is currently under development, which will facilitate monitoring and upgrade tasks. Progress and compliance is verified by audits, which can be internal or 
external. The European OCS website displays the companies enrolled in the programme. A publication is scheduled in October 2017 that will unveil European plastics industry performance in preventing pellet, flake, and powder loss.

\section{Challenges addressed}

Spilled pellets, flakes, and powder can make their way into local waterways and ultimately estuaries and the ocean. Due to their small size, they are indeed very problematic due to dispersion and ubiquity.

Plastic production and manufacturing is widespread all over the globe. Thus, one of the main challenges is to gather all these companies together within this voluntary scheme.

\section{Initiator and collaborations}

In 2011, the Plastics Industry Association released OCS as a royalty-free license for international plastic organizations, enabling other organizations to promote OCS among their own members and encouraging companies to implement the OCS guidelines at facilities all over the world. In 2015, the term "flakes and powder" were added to the programme to enable resin recyclers to also take the pledge. In 2016, OCS 2.0 was launched. Now, OCS counts facilities rather than companies to give a more accurate representation of the industry.

In the case of Plastics Europe, one of the leading European trade associations, the Zero Pellet Loss programme was launched in 2013, targeting producers. In order to work at a larger scale, it adopted OCS and the website for Europe was released. Thus, not only producers, but also logistics and transport compa-

\section{CONTACT AND FURTHER INFORMATION}

OCS website in Europe: www. opcleansweep.eu

Michel Loubry, michel.loubry@plasticseurope.org nies, are now covered by OCS, and currently cooperation with other stakeholders such as port operators is under way.

\section{Financial aspects}

Plastics Europe dedicates a significant amount of time and resources to running OCS, in addition to communication tools. Collaboration is close with industries, who intervene on a voluntary basis.

\section{Further market opportunities and replicability aspects}

OCS is an international initiative and thus there is no need to replicate it in the MENA region. It would instead be much more interesting to implement it or reinforce it in this area. In fact, there are numerous companies in the plastics industry and it would be very beneficial that they join OCS.

To achieve this objective, an umbrella plastics organization in the MENA region and Plastics Europe could start exploring possibilities to enrol producers and related industries. Plastics Europe is indeed considering how they could involve these countries in the OCS programme, though there are currently information gaps that should be tackled. The OCS manual is already available in English and French. A feasible possibility would be to produce the Arabic version. Another important requisite is to raise awareness on the negative effects of plastic leaks and the benefits of being an OCS partner.

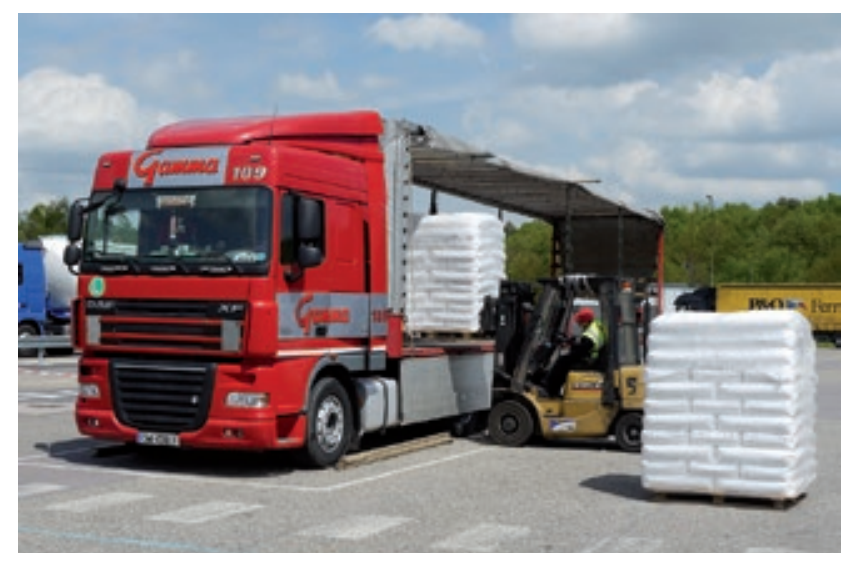

Plastic transport operations. Credit Plastics Europe

\section{SIMILAR INITIATIVES}

Another interesting voluntary scheme in the industry is the Plastic Disclosure Project (PDP) which asks organizations to measure, manage and report on their plastic use, waste generation and recycling rates. The underlying principle is that if plastic use is measured, management of the material will become more efficient, innovative, cost-saving, and sustainable. This fits very well with the move toward the circular economy, as it is hard to know what to "circulate" if you don't have metrics on what you have.

PDP conducts analyses and produces reports based on publicly available information plus information that is provided by the PDP participants that is not confidential in nature. PDP is an initiative by Ocean Recovery Alliance. 


\section{DEC, designing with cardboard}

Cardboard is the raw material used by DEC to produce furniture and much more, with the ability to replace plastic in certain products.

\section{DEC 20 AÑOS DISEÑOS CON CARTÓNO}

\section{Success factors}

- Versatility of the material for numerous applications that can replace less sustainable construction materials.

- Modern and attractive design

\section{- Economic feasibility.}

- Sustainability recognition.

\section{What it's about}

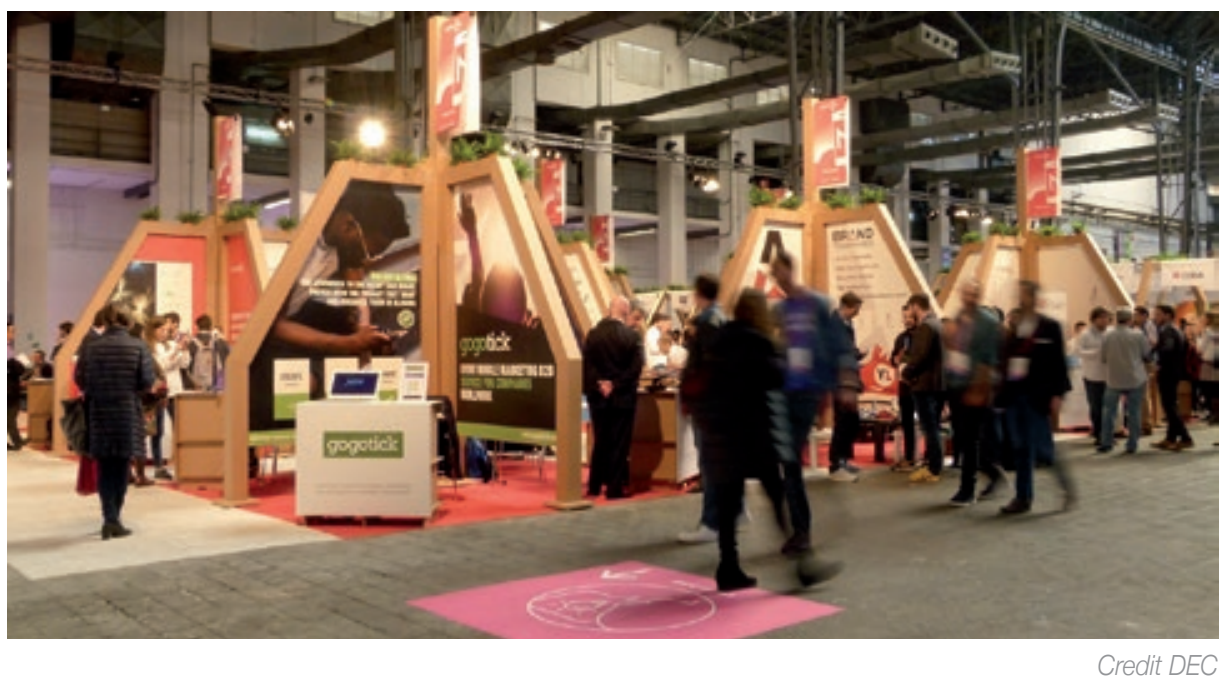

DEC is a Catalan company set up in 1996 and specialized in project development and production of items in cardboard for all types of customers and sectors.

Cardboard is the basic structural element of all these products, which enables formal quality solutions with a sober and modern design that is versatile, durable, sustainable and easily recyclable. The final solution is characterized by its practicality, lightness and ease of assembly.

The versatility of cardboard allows for customized solutions and functional ideas and responds to specific requests from all types of customers and sectors.

Among other items, DEC produces: furniture, exhibition stands, temporary constructions, product exhibitors, information panels, interior designs and furnishing accessories.

DEC works normally with kraft-type cardboard, made with wood pulp and a fraction of recycled pulp. The raw material is currently supplied by a multinational company established in Spain. The result is a cardboard that can function as a form of light, firm and resistant wood, with the consequent ease of manipulation and transport.

Kraft cardboard allows all types of finishes and graphic applications, which gives each project a personal and different look.

DEC's products have been included in the Ecodesign Catalogue of Catalonia, acknowledgement that it is a company fostering circular economy.

\section{Challenges addressed}

The versatility of plastics and their low price has resulted in massive use in manufacturing industries, including furniture and construction. The challenge faced by this initiative is a change of mindset regarding cardboard 
use, a "simple" material, to satisfy people's and industry needs. This company shows that it is technically feasible to produce high-quality solutions made out of cardboard instead of plastics and other materials which are more difficult to be re-used or recycled.

Another challenge is the predominance of some companies in specific market niches that use non-sustainable materials, which jeopardizes the introduction of products based on other materials such as cardboard.

However, the demand for DEC's products has grown progressively. This is mainly a result of word-ofmouth and communication efforts.

\section{Initiator and collaborations}

DEC is a company that began to work in the design and production of cardboard supports, furniture and objects in 1996. The founder, an architect, had the initial idea when designing exhibition support material that could be transported and assembled easily at different locations. DEC was a pioneer in Spain in offering this type of cardboard products.

Later, in order to produce more sophisticated and varied products, a numerical control machine was acquired for a better material cut. This allowed the offer to be expanded to include more complexly shaped products. The founder's architecture background has been very important in terms of the design and study of material performance and applications.

DEC is a small company that collaborates regularly with printing or varnishing companies. This allows them to have low regular expenses and adapt to market needs. A team of 5 people are able to deliver the product.

\section{Financial aspects}

Cardboard products by DEC are economically competitive. This is made possible through direct relations with customers, offering customized products on demand. For example, an exhibition panel can range from 55 to 200 euros, depending on dimensions and quality. A standard table may cost 80 euros. One of the main advantages is that the products can be assembled and disassembled several times, which is very interesting for exhibitors. For example, an investment of 6,000 euros for a trade fair stand can be re-used several times, unlike conventional ones, which makes this option more affordable. In fact, this is where DEC products make the most difference in moving towards a circular economy, by avoiding enormous quantities of waste.

Regarding investment, the most important factor has been the acquisition of the numerical control machine, worth approximately 120,000 euros.

\section{Further market opportunities and replicability aspects}

There are many opportunities to extend this type of business, in terms of geographical scope and market niches. However, externalization has substantial costs that are difficult for DEC to assume. Collaboration may be sought in the MENA region in terms of distributors or manufacturers. It would be important to have public administration provide a boost by selecting this type of product for exhibitions. DEC could intervene, offering to transfer know-how to local entrepreneurs and supplying the first products to provide quality assurance and feasibility.

Interest may be raised among people involved in producing temporary constructions, e.g. exhibitions on the opportunities provided by cardboard products. Local entrepreneurs could liaise with DEC in order to showcase the products' possibilities.

In a first stage, local entrepreneurs could intervene as mediators to start creating local demand, and DEC would supply the products.

Later, transfer of know-how could be organized, for example through work exchanges to build local production capacity. The supply of kraft cardboard could be national or international, depending on local conditions.
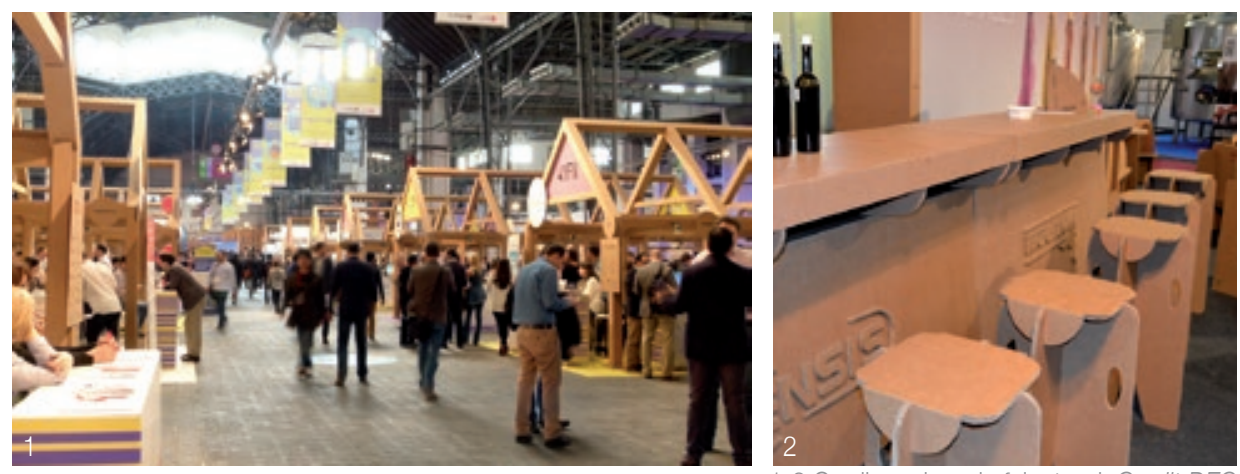

CONTACT

AND FURTHER INFORMATION

www. dec.cat

Jordi Garcia Vilaplana, CEO,

info@dec.cat 


\section{Plan A by Marks \& Spencer: Food packaging component}

In 2007, the global retailer M\&S launched Plan A, a corporate sustainability policy

to reduce waste as a result of food packaging, among other things.

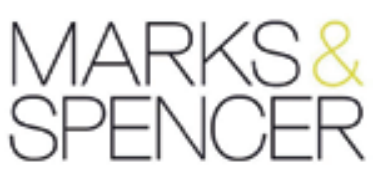

Success factors

\section{- Strong corporate} commitment and traceability resulting in green branding as a market advantage.

- Retail sector as a driving force for improved food packaging waste management, from suppliers to customers.

\section{- Strong partnerships} with public administration, research and customers' organizations.

\section{What it's about}

M\&S launched Plan A in January 2007, laying down an ethical and environmental policy and setting out 100 commitments to achieve in five years. Later, Plan A 2020 was introduced, which consists of 100 new, revised and existing commitments, with the ultimate goal of becoming the world's most sustainable major retailer.

There are several commitments regarding waste. In this regard, the aim set was to use the most environmentally efficient forms of packaging systems throughout the supply chain to help reduce the overall carbon footprint of packaging and products by 2015 .

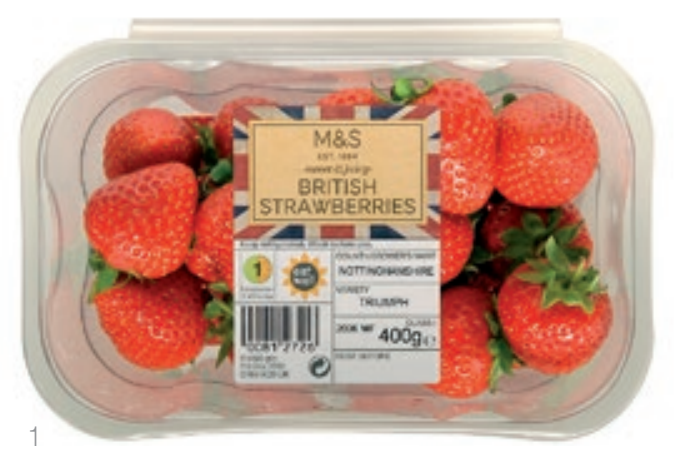

For this case study, the focus has been on food packaging, a type of marine litter of remarkable proportions.

To achieve the target, three key principles have been applied: reducing packaging, maximizing recyclability and using the most sustainable materials available.

The first step was to look at the whole range of food packaging with customer groups and external stakeholders such as the Women's Institute and the Waste and Resources Action Programme (WRAP). From this, M\&S was able to determine which of its current products were excessively packaged and to take action accordingly.

Some examples of M\&S actions to improve packaging since 2008 include:

- All PVC was removed from food packaging by 2000.

- Development of a safe system for the use and labelling of recycled materials in plastics. Not only does this reduce the amount of virgin material sourced from oil in packaging but also helps to drive a local market for municipal recycling.

- Since 2004, M\&S has used 8,000 tonnes of recycled PET (rPET) plastic across produce, food-to-go, chilled drinks and deli products. During 2007$2008,63 \%$ of PET packaging contained a minimum of $50 \%$ post-consumer 
waste. This was further extended to the plastic films on packs.

- Use of 50\%-recycled content across all milk lines, made from HDPE.

- Another part of the sustainable materials strategy is packaging made from paper pulp, which is recyclable or compostable. In 2007, M\&S replaced foamed plastic trays across all apple and hard pears and it has been extended to all stone fruit and soft pears.

These actions have contributed to a $3.9 \%$ reduction in the carbon footprint of packaging used across the UK food industry in 2014 compared to 2012 *

To enable further progress in the future, $M \& S$ continues to work on a range of sustainably packaged projects. These include the use of Plantic bioplastic; the use of mechanically detectable black plastic recipe dish trays that can be easily sorted for recycling; improvements to the barrier properties of recycled carton board; and the replacing of polystyrene packs with types of plastic that are easier to recycle.

\section{Challenges addressed}

Food packaging is among the main categories of marine litter. This type of packaging is needed to ensure that food is protected and hygienic. However, food is often overpackaged and there is room for substantial improvement, as this M\&S case shows. Regarding marine litter, it is particularly important to tackle ready-meal products that are being consumed increasingly, the packaging from which is often turned into litter by beachgoers.

\section{Initiator and collaborations}

$\mathrm{M} \& \mathrm{~S}$ is a global, multi-channel retailer of mainly own-brand food, clothing and home products. There are 1,382 M\&S stores with 82,900 employees.

To achieve the goals set, M\&S has worked in partnership with numerous stakeholders. Particularly important is the cooperation with the charity organization Waste and Resources Action Programme (WRAP), though which it is a signatory

* WRAP's Courtauld Commitment (2015) and active player in the Courtauld Commitment, a world-leading voluntary agreement to work along the entire food chain to reduce its environmental impact**.

Another example of collaboration is the research on better sorting of black ready-meal trays for recycling. The project team consists of: WRAP, M\&S, Sainsbury's, Faerch Plast, the Kent Resource Partnership, Biffa Waste Management, Recoup (RECycling Of Used Plastics Limited), and Nextek Limited.

Finally, M\&S has established partnerships with numerous charity organizations such as the Marine Conservation Society (MCS). Through the carrier bag charge, M\&S donated £1.2 million to MCS over three years to enable it to strengthen beach clean-up actions.

\section{Further market opportunities and replicability aspects} This type of initiative, which becomes a driving force for the entire waste management system, can only be taken by large retailers that have this capability. In the MENA region, such retailers do exist, for example, Marjane in Morocco, Ardis in Algeria, or Metro Market in Egypt.

The first step would be to raise these companies' awareness of the benefits of applying these policies within their firms, in terms of green branding and economic benefits (e.g. preventing superfluous packaging).

Once they are committed to take action on this, as done in the UK, the second step is to conduct an audit on the situation of the food packaging system, in order to know the options that could be taken to improve it in several ways: reducing it, maximizing recyclability, using sustainable materials and improving labelling. The options should then be analysed and implemented progressively, according to the local context in terms of possibilities for recycling, availability of sustainable materials, etc. It is important to note that partnerships with public administrations, waste managers and industry should be sought to jointly draw up recycling schemes.

** See page 44 


\section{Karta-Pack ${ }^{\mathrm{TM}}$, moulding a better world}

PulpWorks' flagship product is Karta-Pack ${ }^{\mathrm{TM}}$, an environmentally friendly alternative to the toxic, dangerous and ubiquitous plastic blister pack. The company offers compostable products, moulded from $100 \%$ post-consumer waste paper and agriculture.

\section{Q PULPWORKS}

Success factors

- Development of recycled material to further reduce collaboration in the process with large companies like Google.

\section{- Packaging reinforces} brand image and it is safe for all applications.

- It is compliant with ISO 14000 and European Green Dot standards, facilitating internationalization.

- Direct work with designers at client companies to ensure that the client is educated on changes that need to be made to make their design mouldable.

\section{- PulpWorks has won}

20 awards locally, nationally and internationally, and has received wide media coverage.

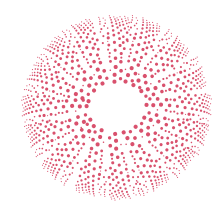

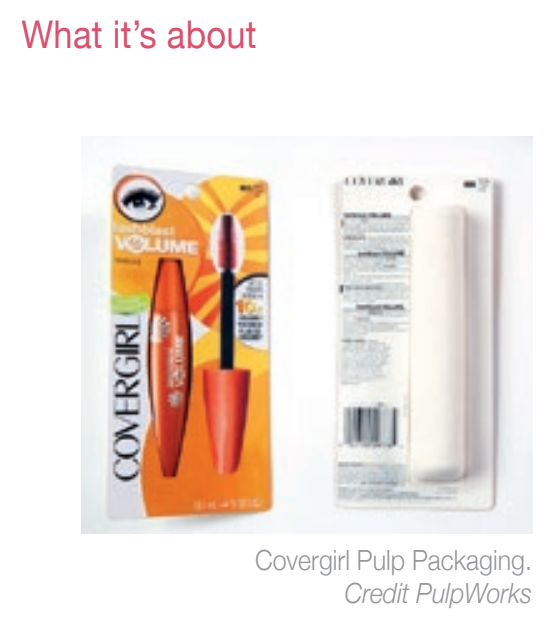

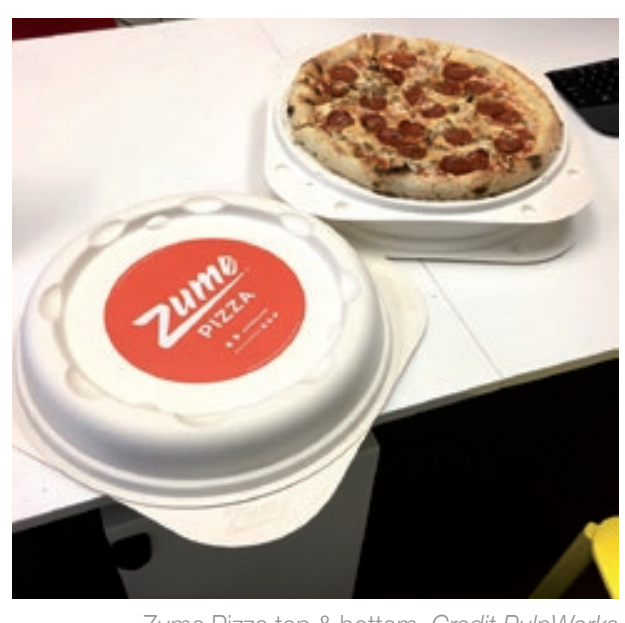

Zume Pizza top \& bottom. Credit PulpWorks

PulpWorks designs and manufactures sustainable packaging for the consumer products industry. The company offers compostable products, moulded from $100 \%$ post-consumer waste paper and agricultural waste such as bagasse (sugar cane), bamboo, wheat straw and renewable plants like switch grass.

The company's flagship product is the patented Karta-Pack ${ }^{\mathrm{TM}}$, an environmentally friendly alternative to the toxic, dangerous and ubiquitous plastic blister pack. The Karta-Pack ${ }^{\mathrm{TM}}$ is comprised of two pieces of compostable and biodegradable material-moulded pulp and cardboard-that are connected to create a single package with the sale item nestled safely in a cavity in the moulded pulp component.

By designing moulds for custom waste-made and fibre-made packaging that is easily compostable and biodegradable, PulpWorks has attracted an international clientele. It is receiving worldwide inquiries from companies asking for help in designing moulds for the packaging of everything from food to electronics, medical devices or cosmetics.

The packaging is created using the same technology that has been used for decades to create egg cartons. However, they have improved it by adding a wide variety of colours, textures, and complexity to make it appealing and elegant for premium products.

PulpWorks uses different business models depending on the needs of its customers:

- Complete turnkey outsourcing: in this scenario, the customer provides the sellable article, while PulpWorks provides all other goods and services necessary to create and deliver a finished product to the customer on time and within specifications.

- Package-only sales: PulpWorks ships the empty Karta-Pack ${ }^{\mathrm{Tm}}$ or other pulp moulded packaging directly to the customer-or indirectly via their sales \& distribution channels-and the customer handles final assembly. 
- Licensing: PulpWorks will license the KartaPack $^{\mathrm{TM}}$ technology to selected manufacturers and distributors.

PulpWorks was the Grand Prize Winner at the 2013 "Think Beyond Plastic" competition sponsored by the international Plastic Pollution Coalition, at the 2014 North Bay Innovation Summit.

\section{Challenges addressed}

The introduction of the Karta-Pack ${ }^{\mathrm{TM}}$ has enabled PulpWorks to spearhead efforts to reduce the amount of plastic-particularly, PVC-deposited in landfills everywhere.

Short-lived products account for more than $70 \%$ of the PVC disposed of in America's solid waste. Similarly, expanded polystyrene foam (EPS, often referred to as Styrofoam $^{\circledR}$ ) is pervasive in the environment. It is extremely damaging throughout its lifecycle and is rarely recycled.

\section{Initiator and collaborations}

PulpWorks Inc. is the capstone in a 35-year career in supply chain management for founder Paul Tasner, who earlier held leadership positions in procurement, manufacturing, and logistics in several ventures. He was named one of the top 10 visionaries in the San Francisco Bay Area in 2016 and selected as TED Resident in 2017.

Co-founder Elena Olivari has a Master of Architecture degree from the Istituto Universitario di Architettura di Venezia (now the Università Iuav di Venezia) as well as a certificate in CSR and Sustainability from the University of California, Berkeley.

The team includes experts in research \& development, industrial design, engineering, and marketing. They have a completely outsourced supply chain comprised of manufacturing, printing, assembly, sales and distribution partners in North America, Europe, Asia and Africa.

\section{Financial aspects}

PulpWorks has a lean structure, only 2 full-time employees; all additional talent is part-time or

\section{CONTACT AND FURTHER INFORMATION}

www.pulpworksinc.com

Paul Tasner, co-founder and CEO,

ptasner@pulpworksinc.com

Elena Olivari, co-founder and CSO. per diem, and all manufacturing and logistics are outsourced to valued partners in those fields.

The production and sale price of moulded fibre is slightly higher than plastic's, but if waste and disposal costs are included in any analysis, moulded fibre is less costly than toxic examples like PVC and EPS. This higher price is compensated by the reinforced brand image provided by the packaging. The company is self-funded, has no outstanding debt and has doubled revenues every year since its founding.

Further market opportunities and replicability aspects The success of the company demonstrates that there are market opportunities for environmental packaging. Opportunities in the MENA region could arise either through licensing agreements for KartaPack $^{\mathrm{TM}}$ technology with selected manufacturers and distributors, or by setting up a similarly-minded company to start from scratch.

The second option would require the following to be taken into consideration:

- Moving forward the company will need a fulltime industrial designer with experience in package design and fibre moulding technology.

- A funding partner would be beneficial only if they were from an allied field and eager to include the venture in their business. Angel investors or venture capitalists are not a good fit for this type of business model.

- Funding to build a manufacturing facility is difficult to accomplish; it is therefore simpler to outsource manufacturing.

- Manufacturing partners must come from the domain of moulded fibre technology changes.

Considering the possibility of setting up a similar company and structure, the following steps should be considered:

- It is crucial to start with a strong idea and address a large network of industry contacts.

- To promote the idea it must be taken to every event and conference. It is equally important to enter every business competition. All and all, it is necessary to get media attention.

- It is important to connect with different companies to research other materials, safe chemicals, and opportunities and work closely with new manufacturers.

- Innovations should start being worked on with target customers. 


\section{Paper-stem cotton buds}

Plastic cotton buds rank among the most predominant types of marine litter.

The UK market has taken steps, boosted by civil society organizations, to offer alternatives to plastic, which is being replaced mainly by paper.

\section{Success factors}

\section{- Citizen and industry} awareness raised

by charities' campaigns.

- Technical and economic feasibility of replacing plastic with paper.

- Main brands and retailers taking action.

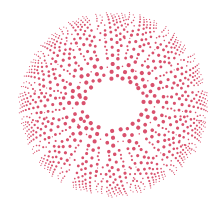

DESIGN AND PRODUCTION

\section{What it's about}

There is a general concern about the presence of cotton bud sticks on beaches around the globe, often confused with lolly sticks. They are commonly used for cosmetic purposes, historically for cleaning the ears and nose, though this is no longer medically advisable. They can make their way to the sea and beaches through the sewage system after being mistakenly flushed by consumers, and, as they cannot be dealt with at wastewater treatment plants, they are released into the marine environment.

The UK is a country that has got a good jump on this issue through different initiatives, both from private companies and non-governmental organizations (NGOs). Early campaigns such as the "Bag it and Bin it" campaign in 2000 focused on changing consumer behaviour and better labelling to reduce the number of buds flushed. Current projects like "The Cotton Bud Project" and "Switch the Stick" have called upon industry and retailers to replace plastic cotton bud stems with biodegradable alternatives. The two projects have slightly different approaches. The first engages with producers and retailers directly, asking companies to phase out the use of plastic, and provides consumers with information on which companies are offering alternatives to plastic. The second asks consumers to sign a petition asking UK retailers to stop making plastic cotton buds by the end of 2017 .

Campaigning has succeeded in achieving this material's replacement. Some companies have already switched to paper; for example, these paper-stemmed cotton bud brands are already available in the UK market:

Simply Gentle Organic Cotton Buds
Muji Cotton Buds
Muji Thin Cotton Buds
Organyc Cotton Buds
Co-operative Fairtrade ${ }^{*}$ Cotton Buds
The Body Shop Cotton Buds
MEt S Collection Fairtrade ${ }^{\star *}$ Cotton Buds
Essential Waitrose Cosmetic Tipped Cotton Buds
Essential Waitrose Cotton Buds
Johnson's Cotton Buds

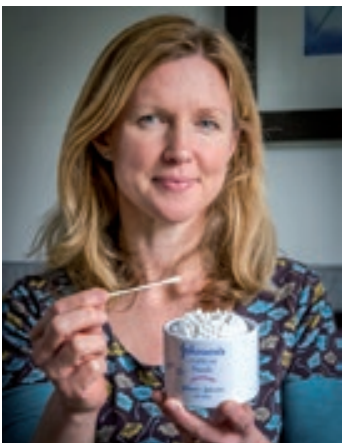

Paper-stem cotton buds by Johnson's. Credit Fidra
Major retailers including Marks \& Spencer's, John Lewis, The Body Shop, and Co-operative already sell paper-stem cotton buds as a result of previous campaigns. Ten further retailers have announced that they will phase out plastic stems by the end of 2017, including Tesco, Sainsbury's and Boots.

However, even if the plastic is replaced, both charities and industry continue to promote a strong "Do Not Flush" message, and all cotton buds should be 
disposed of responsibly with household waste. Ongoing public campaigns remain important to continue to promote this message.

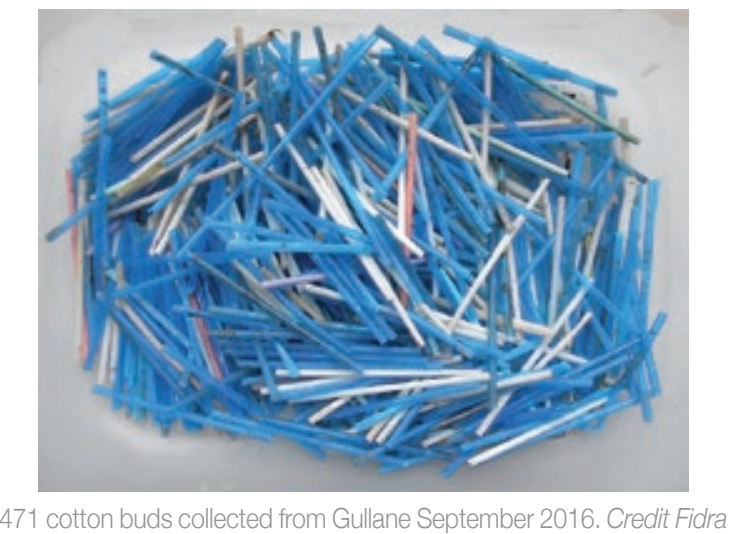

\section{Challenges addressed}

Cotton bud sticks flushed down toilets by consumers continue to be a pollution issue despite "Do Not Flush" labelling, public education campaigns and improved sewage treatment.

Cotton buds are a FMCG in many countries in the world, mostly used for personal care, and, as explained earlier, they are likely to end up as marine litter. This initiative tackles the issue by replacing the stem material. However, there are other options that could be implemented, such as awareness-raising campaigns aimed at changing peoples' behaviour on flushing hygiene products down the toilet, enhanced labelling, reduction in use, or even banning the production and sale of plastic cotton bud stems.

\section{Initiator and collaborations}

This case study is examined from an all-round perspective in which both non-governmental organizations (NGOs) and private businesses are equally important in finding solutions.

As for charities in the UK addressing the problem of cotton buds, there are two behind the two main campaigns cited before: Fidra and City to Sea.

"The Cotton Bud Project" was established by Fidra, an environmental charity based in East Lothian (Scotland) working with Fauna \& Flora International, Keep Scotland Beautiful, the Scottish Wildlife Trust and the Scottish Government. Fidra began engaging with ten major retailers and manufacturers in 2013.
Their public-facing website launched in early 2016, alongside Johnson's announcement to phase out plastic cotton bud stems from the Europe, Middle East and Africa region.

The "Switch the Stick" campaign was initiated by City to Sea, set up as a community-interest company based in Bristol (England) in early 2016. It is funded by a mixture of sponsorship, grant funding and the selling of stainless steel bottles.

The involvement of private companies, including the main producers and retailers in the UK, has been indispensable in its success.

\section{Financial aspects}

One of the keys to the success of this case study is that the replacement of plastic by paper is economically feasible, both for producers and consumers. One of the best-known personal care brands are sold in one of the UK's main retailers for $£ 1.00$ (200 buds pack), which is not very different to conventional plastic cotton buds (prices vary depending on brand).

\section{Further market opportunities and replicability aspects} There are chances that this initiative could be taken up in the MENA region, in different ways.

On the one hand, from the production perspective, a paper-stem cotton bud production facility could be established in the region. This investment could be highly attractive since Mediterranean countries are very concerned about plastic cotton buds, and this would offer an alternative.

On the other hand, there could be collaboration with retailers to commit to stocking paper-stem cotton buds on their shelves, as options are available in other countries.

However, the combination of the two options is the most advisable, which would promote the economy at a local scale while having a positive socio-environmental impact on the whole region.

\section{CONTACT AND FURTHER INFORMATION}

The Cotton Bud Project: www.cottonbudproject.org.uk Madeleine Berg, Fidra, Madeleine.Berg@fidra.org.uk Switch the Stick campaign: www. switchthestick.org Natalie Fee, City to Sea, nat@citytosea.org.uk

\section{SIMILAR INITIATIVES}

In New Zealand, the company Go Bamboo has designed a 100\%-biodegradable cotton bud. These cotton buds have a bamboo stick and come in a recycled paper box. The box is of the sliding-drawer kind, so it is intended for reuse. It is also educational: there is a story that unfolds as the drawer slides open. All Go Bamboo products are designed to be disposed of in and around your own home. The waste factor was designed out of the product at the concept stage. 


\section{Cora Ball:}

\section{A consumer solution to microfibre pollution}

Rozalia Project has developed Cora Ball, a device to be used in the washing machine. It collects microfibres as well as hair and prevents them from flowing out with the drain water.

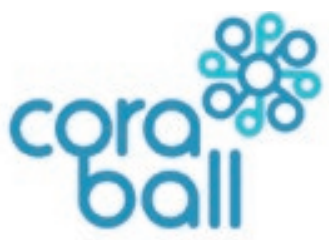

Success factors

- Low-technology and low-cost solution, without the need to replace the washing machine.

- Extremely easy to use by the consumer, works in any washing machine, does not require frequent attention and will last for thousands of washes.

- Design and testing by a multidisciplinary team of ocean scientists, engineers and advocates from Rozalia Project.

- A successful crowdfunding campaign was run and media attention and prizes received, including innovation awards such as the 2016 Think Beyond Plastic Innovation Competition, throughout the world.

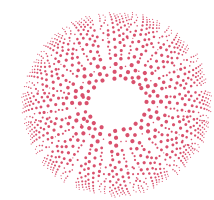

\section{What it's about}

One of the main pollution problems facing our oceans is microfibre: trillions of pieces of tiny fibres breaking off our clothing and flowing into the ocean every time we use our washing machines. Rozalia Project for a Clean Ocean, a non-profit whose mission is to clean and protect the ocean, has developed the first microfibre-catching laundry

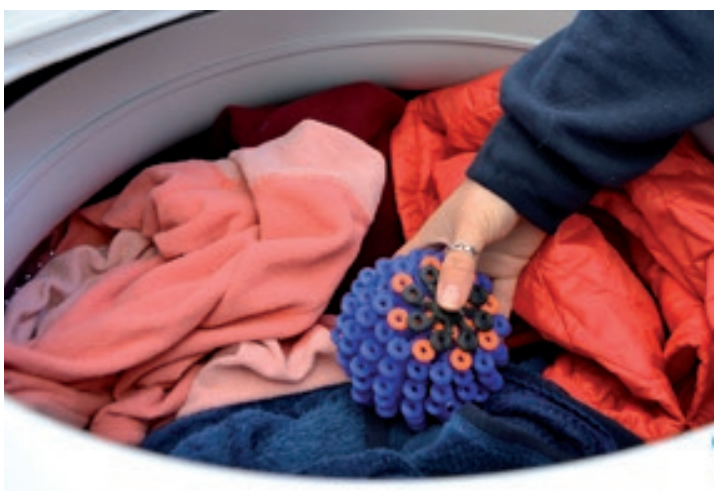

Credit Cora Ball ball to help protect our oceans, lakes and rivers from microfibre pollution. The Cora Ball is a consumer-based solution to this problem. The user just drops or throws it into the washing machine (any washing machine-front- or top-loading, with and without centre spindles) and does the wash as usual. The Cora Ball design is based on coral, which allows water to flow through it while picking up those little pieces of microfibre and catching them in its stalks. When taking it out of the washer, the user just needs to pull out the lint and put it in the trash bin. Rozalia Project is now working to find opportunities to upcycle or recycle the lint and fuzz from the Cora Ball, the primary obstacle being the mixed-material nature of laundry lint.

The Cora Ball (patent-pending) is made from 100\%-recycled plastic, both post-consumer and from manufacturing. It is $100 \%$ recyclable and made in the USA (Vermont). Producers calculate that if $10 \%$ of US households used a Cora Ball, they could keep the plastic equivalent of over 30 million water bottles from washing into our public waterways every year.

\section{Challenges addressed}

Clothing breaks up in the laundry, sending this microfibre (made of plastic and chemical-covered non-plastics) out with the drain water. One single fleece jacket could shed up to 250,000 pieces per garment, per wash.

Microfibres are too small to see but they are big enough for persistent organic pollutants (DDT, PCBs) to stick to them. This happens to plastics in the marine environment. They also have additives capable of leaching chemicals into our public waters, including endocrine disruptors. They are, moreover, ingested by sea creatures: from whales to plankton. Ingested pollutants can unstick from the plastic and end up in the stomachs and tissue of those creatures. The pollution returns to us through the food chain.

The magnitude of this problem is enormous and there are multiple industries with the opportunity for innovation to fight microfibre pollution. The pre-consumer solution is to develop textiles whose fibres do not break and 
to reduce the toxic chemicals used in the textile industry. Additional solutions can come in the form of filters for washing machines and improved wastewater treatment processing. For now, a lowcost and easy-to-use solution such as the Cora Ball will help lower the impact immediately.

\section{Initiator and collaborations}

Rozalia Project is a non-profit organization that uses 4 strategies to address the problem of marine debris: clean-up, education, technology/innovation and solution-based research. It is based in the Northeastern US and operates from American Promise, a 60' sailing research vessel. It was during this work that Rozalia Project's team learned about the problem of microfibre pollution and developed the Cora Ball. The Cora Ball was made possible with support from Rozalia Project's partners: Schmidt Marine Technology Partners, 11th Hour Racing and Surf Sweets Organic Candy.

\section{Financial aspects}

Funding for production was raised via a Kickstarter campaign. The campaign exceeded the original $\$ 10,000$ goal, raising $\$ 353,461$ with 8,635 backers pre-ordering 15,500 Cora Balls in one month.

At this very moment production details are not yet ready. However, the intended retail price of one Cora Ball is $€ 25$.

The Cora Ball is a straightforward product with several opportunities to get into people's washing machines: direct purchase, as a value-added item, through give-away programmes and by being available at events. In terms of direct purchasing by consumers, home, clothing and sports stores are the top three. A brand or shop has the opportunity to demonstrate awareness and action by using the Cora Ball as a value-added item-giving a Cora Ball away with a minimum purchase of fleece jackets, for example. Organizations have the opportunity to have an impact by selling or giving Cora Balls away with memberships or to mark milestones. Along with businesses, organizations and municipalities can use the Cora Ball as a give-away item at events, serving to both raise awareness about the problem and give people the chance to be part of the solution.

\section{Further market opportunities and replicability aspects}

Rozalia Project and the Cora Ball team are very open to partnering with individuals and organizations who are looking to make a positive impact on the MENA region and surrounding waterways. Investment for replication and return on that investment will depend on the type of partnership, which could range from sales and distribution partnerships to licensing programmes and local manufacturing.

In the MENA region, the product could be either distributed or manufactured, depending on the use of the patent. Nevertheless, a prior effort would be necessary to raise awareness of the problem microplastics pose to marine environments and the importance of using our choices as consumers to address the challenge.

Potential replicators could be local entrepreneurs, local environmental associations, thelaundry industry (washer, dryer and detergent makers), clothing and textile companies and municipalities. In any of these cases, setting up an education, communication and marketing programme in parallel would be crucial.

A distribution programme should include the "direct purchase by consumers" option as well as the potential to work with brands, businesses, organizations and even government to use the Cora Ball as a value-added or give-away item.

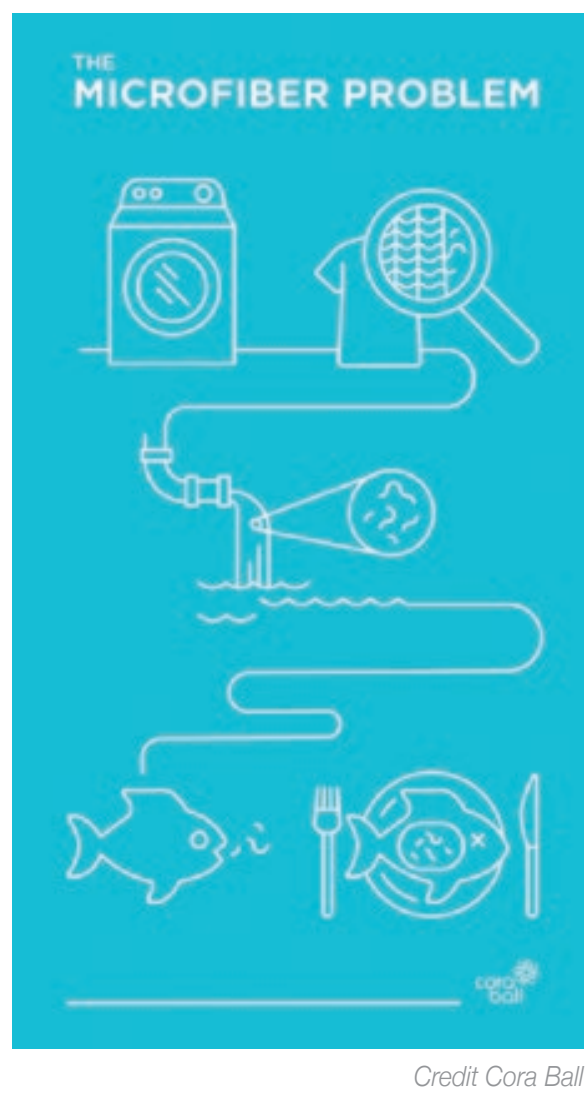

CONTACT AND FURTHER INFORMATION

http://coraball.com

Rachael Z. Miller, Founder/CEO

rachael@rozaliaproject.org 


\section{Festival Republic: Greening mass events}

An increasing number of artists, companies, venues and festivals are joining initiatives to decrease their environmental impact, including plastic waste, and use these mass events to raise awareness and stimulate changes in mindset.

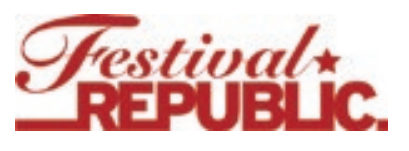

Success factors

- Several renowned environmentally aware artists to promote the effort and give visibility.

\section{- Joining forces}

with research, key elements from the music industry and strategy development and communication and marketing partners.

\section{- Liaising with low} environmental impact product suppliers, waste managers and recycling companies.

- Using the events for in situ campaigning, empowering fans and audiences to demand environmental standards at other events.

\section{What it's about}

Festival Republic, a leading UK music events producer, began addressing sustainability and environmental awareness, focusing initially on their flagship Leeds, Reading and Latitude festivals back in 2007. It

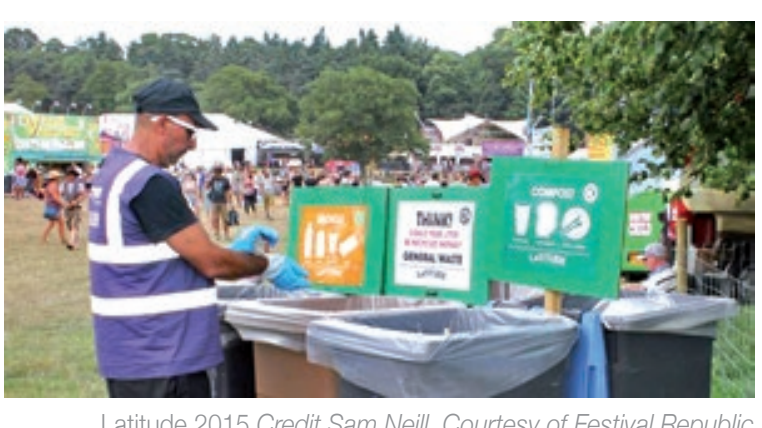

Latitude 2015 Credit Sam Neill, Courtesy of Festival Republic has made notable efforts to reduce the impact of its business and festivals on the environment. Working through every aspect of the festival, it developed systems across key areas such as energy, transport, purchasing and waste. A sustainability manager is employed to work with the Festival Republic team, contractors and suppliers to focus on sustainability issues and develop innovative solutions. Furthermore, systems onsite are implemented in which the audience can participate, providing the opportunity to encourage positive changes in behaviour.

One of the events in question is the Latitude Festival, in the UK, which enacts a significant number of measures to green the festival and reduce plastic waste. Some of them are:

- Reusable pint cup. With every drink bought at the bars, the customer has to pay a $£ 2$ deposit on each cup, which they get back when returning the cup to the bar. The cups are washed and reused over and over!

- Three-bin system at the festival, which means every bin station will have three waste disposal options:

- Compost: food from the traders at the Latitude Festival comes with biodegradable plates, cutlery and napkins, which can be placed in the compost bins along with the food scraps. Single-use plastic food wrap and cutlery is fully avoided.

- Recycling: plastic bottles, aluminium cans, newspapers, magazines and cardboard.

- General waste: there should be minimal left over that goes into the general waste bin.

In 2012, Latitude was awarded a Creative Green certification rating of three stars as well an A Greener Festival Award.

\section{Challenges addressed}

Mass events such as concerts and festivals are traditionally generators of large amounts of plastic single-use items (bags, beverage bottles and cups, 
food wrap, cutlery, etc.), which moreover are often disposed of inadequately. The act of "touring" itself generates additionally unnecessary waste. An average entertainment tour can go through 60 cases of bottled water a month and about 20 plastic bags a day while on the road.

Initiatives such as this one are proof that a shift in paradigm to more sustainable mass events is feasible, giving artists the opportunity to use their fame to become catalysts of change.

The initiative addresses a wide range of sustainability issues such as $\mathrm{CO}_{2}$ emissions, water consumption, local economies, green products and plastic waste generation. It provides clear guidelines on plastic waste reduction options and substitute products, as well as tips to make this approach feasible and manageable, including how to negotiate with venues, festivals and local providers and waste managers.

\section{Initiator and collaborations}

Festival Republic is a leading festival and event promoter with a portfolio of seven music festivals across Europe, including the Reading and Leeds festivals, Latitude Festival, Electric Picnic, and Lollapalooza Berlin. More than half-a-million people attend the festivals they own and co-produce each year.

Festival Republic works very closely with Julie's Bicycle, a non-profit organization working on sustainability within the creative industries.

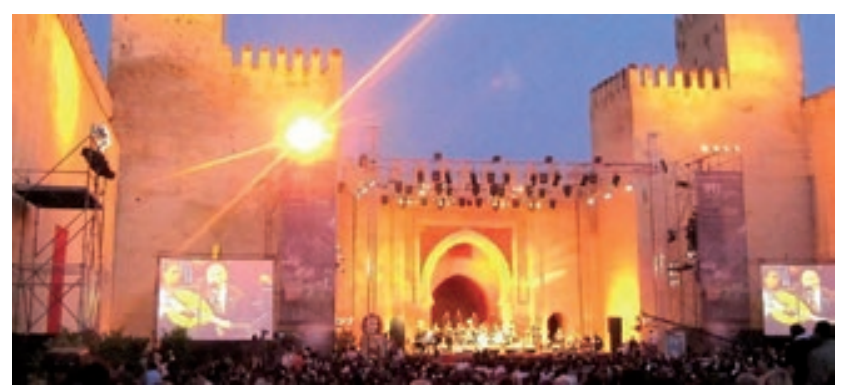

Fes Festival of World Sacred Music Credit guiademarruecos.com

\section{Financial aspects}

At times, this approach has meant decoupling environmental action from financial gain, focusing on integrating the cost of and commitment to green practices. Festival Republic sees environmental sustainability as both an ethical imperative and an investment in the future.

Festival Republic employs a full-time sustainability coordinator, responsible for overseeing environmental action at the Reading, Leeds and Latitude festivals, and each event has a dedicated environmental budget. Operational decisions with an environmental impact are weighed according to their financial and environmental costs and benefits, to strike the balance necessary for a sustainable business.

Further market opportunities and replicability aspects This initiative could be replicated for festivals in the MENA region, since there are large events such as the renowned Fes Festival of World Sacred Music, in Morocco. Some tips for greener festivals include:

- Reaching out to environmentally aware musicians and engaging them in the idea.

- Using them to engage a wider community.

- Joint efforts to put pressure on the music industry to join the platform.

- Agreeing on the environmental principles to defend and the guidelines to follow.

- Campaigning for the movement.

- Joint efforts to make venues, etc. respect and implement the principles and guidelines.

\section{CONTACT AND FURTHER INFORMATION}

www.festivalrepublic.com/green

\section{SIMILAR INITIATIVES}

\section{Litter Free Thaipusam (Malaysia): Thaipusam is a Hindu ceremony held each} year and is celebrated as a public holiday. The most famous celebration is located at the temple at the Batu Caves in Kuala Lumpur, where more than one million people gather for Thaipusam each year. The site has insufficient waste collection bins, leading to extensive littering. The Malaysian Plastic Manufacturers Association (MPMA), in support of the National Waste Separation Policy that came into effect in September 2015, organizes this anti-litter and recycling campaign. Hundreds of uniformed volunteers are stationed at various checkpoints to guide people in placing recyclable materials, including polystyrene foam foodservice packaging, into specially marked recycling bins separate from waste bins.

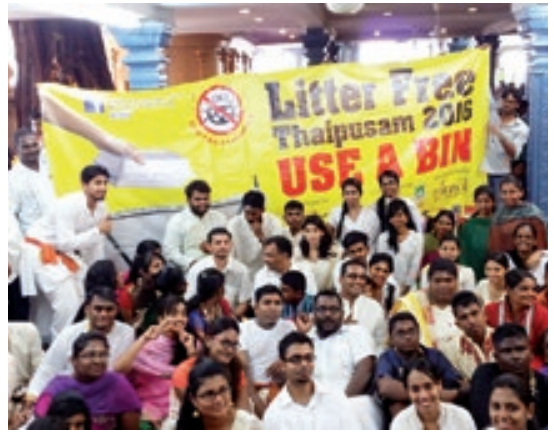

Credit The Malaysian Times 


\section{Return to offender campaign}

This campaign sends marine litter items found on UK beaches back to the manufacturers and distributors to improve their commercial performance with the ultimate goal of preventing marine litter generation.

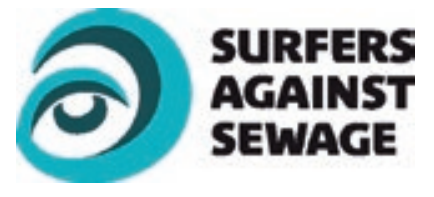

Success factors

- Creative and attractive campaign.

- Awareness-raising campaign that gives an active role to citizens.

\section{- Ease of shipping} the items to producers, including freepost.

- Industry responding to citizens' claims.

\section{- Awarded Best Green}

Marine Campaign

by Coast Magazine.

\section{What it's about}

It all started in 2006, when Surfers Against Sewage (SAS) campaigners and professional surfers from Hawaii, Australia, South Africa, America and the UK launched the "Return to offender" campaign, taking a break from the WQS Highland Open Surf competition, to clean the reef. Collecting the identifiable litter, SAS cam-

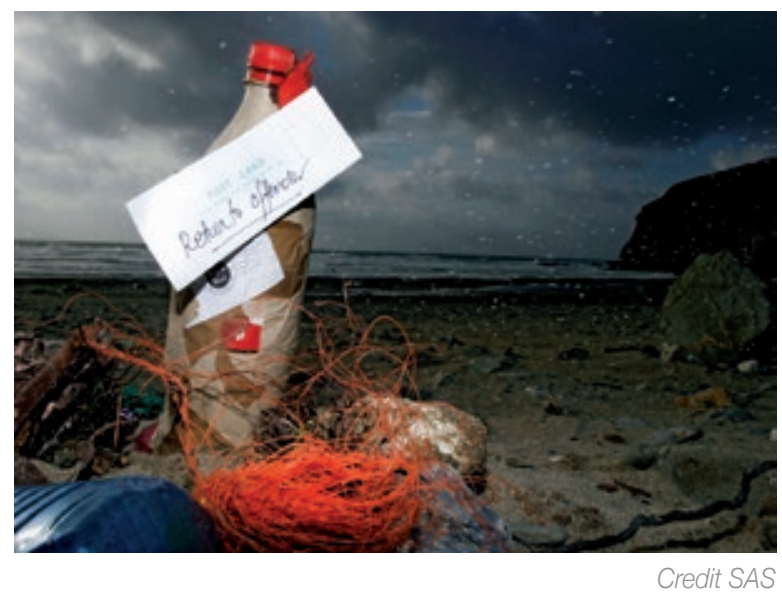
paigners and pro surfers called the "offending" companies, requesting them to help their customers stop littering.

The campaign targets UK manufacturers and distributors challenging them to take action towards:

- Extended producer responsibility: developing active and improved product stewardship strategies to better protect the marine and wider environment from their products and associated packaging.

- Behavioural change campaigns: supporting school education programmes and wider behavioural change campaigns to transform how the public buys, uses and consumes products.

- $\quad$ Reduce, reuse \& recycle: reducing the amount of unnecessary packaging used, supporting and facilitating re-use and recycling, particularly at beach and coastal locations.

- Grassroots conservation: supporting grassroots marine conservation initiatives and beach clean-up activities.

- Environmental impact labels: developing environmental impact icons and messages to encourage recycling \& better disposal.

SAS continues to encourage people to keep an eye out for identifiable marine litter when visiting beaches. Users can download a template letter from the campaign website, fill in some specific data and send it along with the litter item found to the manufacturing/distributor company, urging them to take action to prevent marine litter generation.

SAS provides a file with addresses to help activists to post the litter products and letter. Moreover, considering that postage may be expensive, SAS indicates freepost addresses for members of the "Dirty Dozen", the worst offenders, and a few others. In that file, the counts per product/parent company are noted as well as the number of responses companies have given, including 
"bad responses". The two companies whose products are discarded most often on UK beaches and sent back to them by post are PepsiCo and Coca-Cola.

Finally, participants are encouraged to send pictures and information to SAS.

Some companies have reacted positively to the campaign. In 2014, Haribo contacted SAS after receiving numerous items of Haribo packaging. SAS advised them on how to improve Haribo anti-litter messaging across their product catalogue and sales resources. Haribo have implemented some responsible updates to the anti-littering advice on their packaging and educational materials.

As an anecdote, in 2008 several shipping containers were lost overboard in the Atlantic, near the southwest tip of the UK. Winds, waves and tide relentlessly deposited the contents of these containers on the UK's shores. SAS campaigners collected hundreds of Baxter medical packs (containing saline solution) and returned them to the Baxter head office in Holland.

The campaign was awarded the Best Green Marine Campaign by Coast Magazine in 2009.

\section{Challenges addressed}

Food and drink containers are at the top of the marine litter list and the companies that put them on the market are easily recognisable. SAS takes advantage of this fact to call specific industries, manufacturers and distributors to take action against (marine) litter. The challenge faced is that they are often not sufficiently aware that their products end up on beaches and in oceans around the world, or there is no social demand for them to change the way containers are managed after use. The fact is, industry cannot afford to have a bad image because their products end up polluting the environment.

With this in mind, a media and activist method was put in place: post the waste back to the producer. Thus, industry is called upon to take voluntary action to satisfy consumers' expectations.

Another challenge that the campaign faced was how to send the items to the producers. To overcome this issue, postal address information was made available as well as free postal services for those more recurrent offenders.

\section{Initiator and collaborations}

Surfers Against Sewage is a national marine conservation and campaigning charity that inspires, unites and empowers communities to take action to protect oceans, beaches, waves and wildlife.

SAS projects target coastal environmental issues including marine litter, sewage pollution, climate change, toxic chemicals, shipping, industry and coastal development.

It aims to create measurable improvements in the state of our oceans, waves and beaches through changes in public behaviour, government policy and industry practices.

\section{Further market opportunities and replicability aspects} Although the campaign was specifically conceived for the UK, it would be feasible to run the same scheme elsewhere. In the case of the MENA region, domestic as well as multinational companies operate and have registered offices in these countries to which the litter could be sent back.

A civil society organization in the MENA region could raise funds to implement the campaign as a project, or get sponsored. First, it should implement a communication plan to explain why this type of action should be taken, calling citizens to take part. It is also very important to supply company addresses to which items can be sent as well as provide freepost options. As SAS has done, a website could provide a template letter to be sent to the manufacturer, as well as the number of items that are being posted and companies that are reacting to this.

\section{CONTACT AND FURTHER INFORMATION} www.sas.org.uk

Andy Cummins, Campaign Director, info@sas.org.uk

\section{SIMILAR INITIATIVES}

At a global scale, Beat the Microbead campaign has taken a similar approach, calling citizens to identify hygiene and body-care products that contain microbeads. This had two purposes: on the one hand, to create an app that offers customers information on the presence or absence of these substances in certain products by introducing the bar code. On the other hand, companies that use microbeads are being urged to phase out microbeads in their products. Some of them have taken action in this regard and have started substituting them in their products. 


\section{Courtauld Commitment 3: Resource efficiency in the grocery sector}

Working in partnership with grocery retailers, brands and suppliers as well as governments, WRAP developed and delivered a collaborative solution to reduce waste.

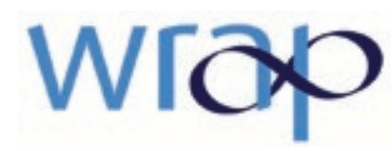

Success factors

- Awareness of the issues and opportunities for food waste and packaging prevention generated among businesses. The engagement of employees and other stakeholders has been critical to its success.

\section{- Working together}

in partnership and in working groups. Best practice outputs and guidance are shared among the signatories.

\section{- Institutional support through funding from the governments in England, Scotland, Wales and Northern Ireland, thus covering the entire UK.}

\section{What it's about}

The Courtauld Commitment is an agreement signed by all major grocery retailers and many household brands and manufacturers to reduce waste across the UK, brought about by WRAP.

Despite food waste being very important, it is a different topic to marine litter. Thus, the focus here

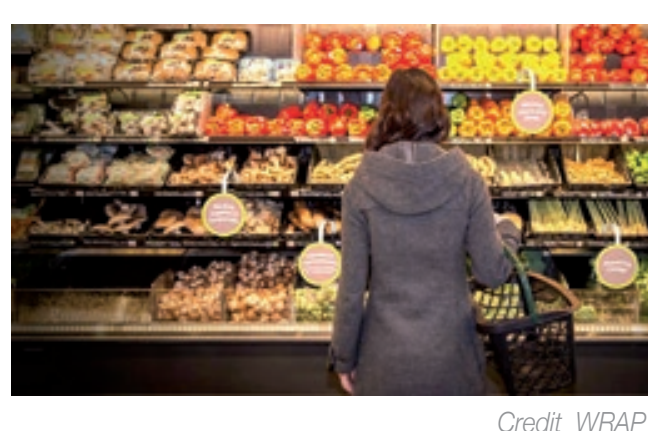

Credit WRAP for the purpose of this publication has been placed on packaging waste. Significant achievements were made in optimizing grocery packaging under Courtauld 1 and the first two years of Courtauld 2. Adding up the achievements reached under both agreements, around 1 million tonnes less packaging were used. At this point, there were limited opportunities for more substantial reductions in packaging without risking increases in food waste.

Thus, the focus in the $3 \mathrm{rd}$ phase was on improving design to optimize recycled content, improving recyclability and helping to reduce food waste.

In this regard, two targets were set, measured against a 2012 baseline:

- Manufacturing \& retail target: Reduce traditional grocery ingredient, product and packaging waste in the grocery supply chain by $3 \%$ by 2015 , against the 2012 baseline. Taking into account external influences, this target represents a reduction of $8 \%$ in relation to anticipated production and sales volumes.

- Packaging target: Improve packaging design through the supply chain to maximize recycled content as appropriate, improve recyclability and deliver product protection to reduce food waste, while ensuring there is no increase in the carbon impact of packaging by 2015, against the 2012 baseline. Taking into account external influences, this target represents a carbon reduction of $3 \%$ in relation to anticipated sales volumes.

After the CC3 implementation period, the results report was published, detailing the levels of achievement.

Regarding the manufacturing and retail target, the target has been achieved, with manufacturing and retail waste (including waste to sewer) falling by 74,000 tonnes, from $2,504,000$ to $2,430,000$ tonnes, a reduction of $3 \%$. In addition to this absolute reduction, significant volumes of waste have moved up the waste hierarchy, from landfill disposal or incineration to recovery (including energy from waste) and recycling. The recovery and recycling rate grew from $95 \%$ in 2012 to $99 \%$ in 2015 (equivalent to 89,000 tonnes of additional recovery in 2015). 
the impact of packaging in terms of carbon emissions by 2015 . At end of the agreement, data showed a reduction of $7 \%$, significantly better than the target outcome, while the amount of packaging material placed on the market incre ased by $1 \%$ over the same period, to just under three million tonnes. The main contributing factors for this fall were increased recycling rates for different packaging materials and changes in material composition, where wood, polymer, aluminium and steel packaging have seen reductions both in total weight placed on the market and $\mathrm{CO}_{2}$ equivalent impact.

CC3 signatories provided data on the amount, material and recycled content of packaging within the scope of the Commitment. This information, combined with the $\mathrm{CO}_{2}$ equivalent impact of each material*, was used to estimate the carbon emissions of packaging materials.

Courtauld Commitment 2025 is the 4th phase of this initiative. In the years to come, the focus will be on reducing food and drink waste, on the greenhouse gas intensity of food and drink and on the impact associated with water use in the supply chain. This was launched in 2016.

\section{Challenges addressed}

Every year around 11.4 million tonnes of packaging are used in the UK. About 5 million tonnes are householdrelated and, if they aren't reused or recycled, can end up being disposed of via landfill or incineration. This is the main issue addressed by the Courtauld Commitment: a consumption society constantly on the rise.

Another important challenge, which turned into a driving force, was getting major grocery companies to agree to join in reducing waste, as well as making sure achievements were traceable.

\section{Initiator and collaborations}

First established in 2000, WRAP is a non-profit organization and registered charity that envisions a world where resources are used sustainably. WRAP works with governments, businesses and communities to deliver practical solutions to improve resource efficiency.

More than 50 signatories, including retailers such as Tesco and brands and manufacturers such as Unilever, support this agreement, and they collaborate by

\footnotetext{
* For details of the method used to calculate the carbon factors, see "Methodology for assessing the climate change impacts of packaging optimization under the Courtauld Commitment phase 3", WRAP (2014).
}

sharing best cases, taking part in working groups and delivering data to WRAP.

\section{Financial aspects}

Total investments have been driven by the scale of activities and the amount of research needed per year. On average, $£ 3-4$ million per year (indicative) was invested by the UK Government (Department for Environment, Food and Rural Affairs), devolved to national administrations in Scotland, Wales and Northern Ireland.

Further market opportunities and replicability aspects Working in partnership in the different countries in the MENA region is feasible, although an important challenge. Some of the important actions to be taken include:

- Fundraising from governments

- Capacity-building among local associations to monitor efforts on waste reduction and knowhow transfer

- Awareness-raising campaign targeting the main national grocery companies

- Analysis of waste reduction possibilities

- Setting up of reduction targets

- Ensuring sign up to those targets by businesses signatories and commitment to annual confidential reporting

- Implementation of waste policy

- Analysis of results, report and dissemination

Finally, tools to help the grocery sector that have been developed under the CC could be applied or adapted.

\section{Case study ALDI:}

Over a million reasons to switch to reusable plastic trays

$\begin{array}{ll}\text { In 2013, all whole chicken lines } & \text { - Reduction in volume of card } \\ \text { were transferred from single-use } & \text { accumulated in store } \\ \text { card cases to reusable plastic } & \text { - Standardisation of secondary } \\ \text { trays. There have been several } & \text { packaging across all whole } \\ \text { benefits of this move: } & \text { chicken lines. } \\ \text { - A saving of } 1.5 \text { million single } & \text { Aldi have also rolled out } \\ \text { use card cases in } 2013 & \text { returnable packaging in other } \\ \text { - An increase in the lifetime of } & \text { key categories such as Produce } \\ \text { the case: reusable plastic trays } & \text { and Beverages, and continue to } \\ \text { are used for approximately } 240 & \text { work on other potential category } \\ \text { trips } & \text { opportunities. }\end{array}$




\section{Goccia Verde: Sale in bulk to avoid single-use plastic containers}

Goccia Verde addresses the need to raise social awareness and bring about a transformation in current consumption patterns through the commercialization of detergents and soaps in bulk.

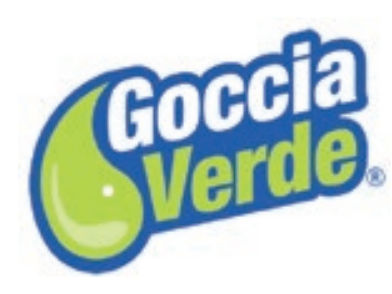

Success factors

- Own product offered, manufactured nationally, taking full control

of processes and costs.

- Rollout through a low-investment franchising model, addressing replication and sharing production and promotion costs.

- Acceptance of any thick plastic container for reuse and any amount of product for sale.

- Diversified clients: single consumers through the franchisees and hotels and restaurants directly with the company.

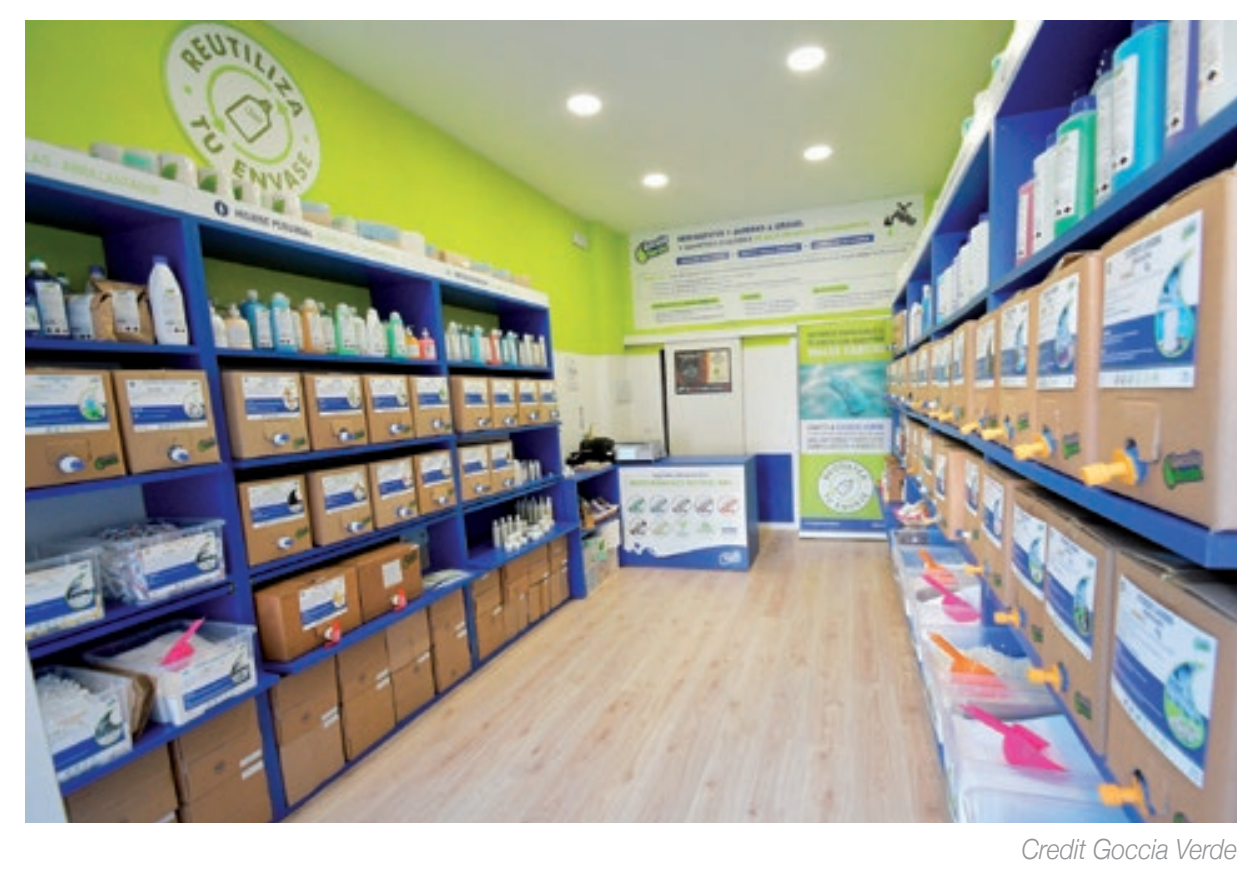

What it's about

Goccia Verde is a franchising business which offers a whole range of low environmental impact cleaning products for home, clothes and dishes, as well as for personal hygiene and care. They offer and encourage their bulk purchase option to decrease plastic waste, actively promoting reuse over recycling.

Key elements of their approach are:

- Respect the environment: own production of detergents, soaps and bodycare products of optimum quality and low ecological impact.

- Re-use: reusing plastic containers contributes to the fight against marine litter and climate change.

- Bulk purchase: this results in savings on packaging costs and allows the client to buy only the amount needed.

- Saving: direct sale without intermediaries; own production and distribution.

Challenges addressed

Goccia Verde addresses three main challenges: the contaminants in cleaning products, the excess in packaging for these products and the need to empower consumers to bring about a swift change in production and consumption patterns.

Packaging is a major source of marine litter, and Goccia Verde reported a container reuse rate of $75 \%$ in 2016 . This represents a drastic reduction in the number of containers likely to end up as marine litter. Additionally, this is saving 6,500 tonnes of $\mathrm{CO}_{2}$ emissions and 11,500 tons of water. They aim to increase the rate to $100 \%$. 
Initiator and collaborations

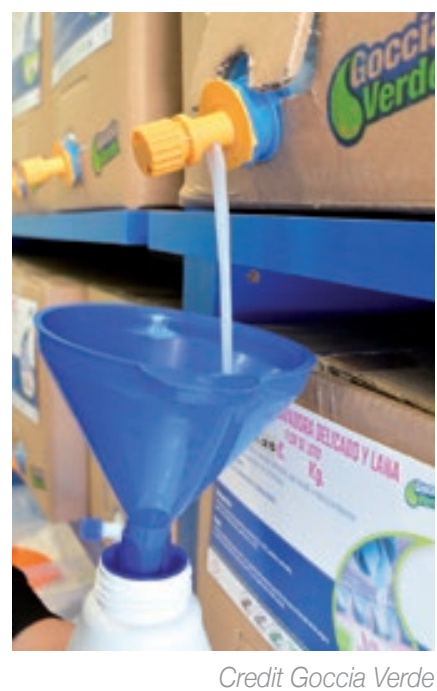

Goccia Verde is an expanding Spanish company led by Italian Matilde Leone, who since 2012 has been devoted to this personal project based on her own environmental awareness. The main objective of this small company is to make the final consumer an active participant in issues related to sustainability and environment.

Goccia Verde has the legal form of "Private Limited Company". The business has matured and expanded without any kind of external support and despite confronting difficulties in gaining visibility. It develops its own product, outsourcing production to factories but always keeping control of the production process.

Goccia Verde collaborates with other likeminded initiatives such as the Orangutan Foundation, joining forces in publicising the impact of palm oil (a component in many cleaning products) production on the tropical forest habitat, home to this endangered species.

\section{Financial aspects}

Goccia Verde follows a franchise model, which includes the company and a network of 26 franchises (at the time this report was written).

The core company is an SME of less than 10 employees. It is responsible for the design, testing and (externalized) production of formulas, promotion, communication and advising.

It is also responsible for exploring and reaching product certification. However, certification has proven to be a challenge for small companies, as, even if all requirements and standards are met, the price of certification is so high that it would have an important impact on the price for final consumers. The company aims to make low environmental impact products affordable for the everyday consumer and takes special care to control costs that are external to the definition and production process. Regarding the franchises, and in the context of the Spanish economy, the financial figures are as follows:

- Minimum capital/investment: 19,500 euros + VAT

- Canon input: there is none

- Royalty of exploitation: none

- Canon marketing: there is no

- Contract: six years

- Minimum size of the premises: $35 \mathrm{~m}^{2}$

- Minimum inhabitants: 20,000 inhabitants

- Staff required: one or two people

- Total franchises and stores currently open: more than 25

- Competition: low

- Amortization: 3 years

Further market opportunities and replicability aspects A bulk sale business like Goccia Verde could be replicated in two ways.

On the one hand, a similar franchise business in the MENA region could be initiated addressing the bulk sale of diverse products. This scheme would require setting up a company with a precise and effective bulk sale model aimed at consumer awareness and behaviour and that, more importantly, provides and promotes a packaging reuse option.

On the other hand, the Goccia Verde franchise system could be established in the MENA region. Goccia Verde is a business under national and international brand reinforcement and expansion. When expanding, one main challenge would be to avoid transport expenditure, due to the economic and environmental cost. Therefore, one key element would be to find local factories that can guarantee the production process.

CONTACT AND FURTHER INFORMATION

www.gocciaverde.es

Marc Borrell, Communication and Marketing Manager, sedespana@gocciaverde.net

\section{SIMILAR INITIATIVES}

Jean Bouteille, in France, brings together two modes of ecological consumption to save the consumer money: the bulk system and the returnable bottle system. 


\title{
Plastic bag charge in supermarkets
}

\author{
Numerous supermarkets in the world have introduced charges to the free distribution \\ of the plastic bag, whether on a voluntary basis or driven by government action. \\ This has brought about a drastic reduction in their use.
}

\section{Success factors}

- Donation of income from carrier bag charge to charity, including causes related to the marine environment.

\section{- Transparency in publishing} the evolution of plastic bag use before and after the charge.

\section{- Offering responsible options to customers so they can use other types of re-usable bags.}

\section{What it's about}

Although few peerreviewed studies or government surveys have provided estimates for global plastic bag use, there are estimates noting that between 500 billion and 1 trillion plastic bags are used each year worldwide*.

Supermarkets are one of the main providers of plastic bags to

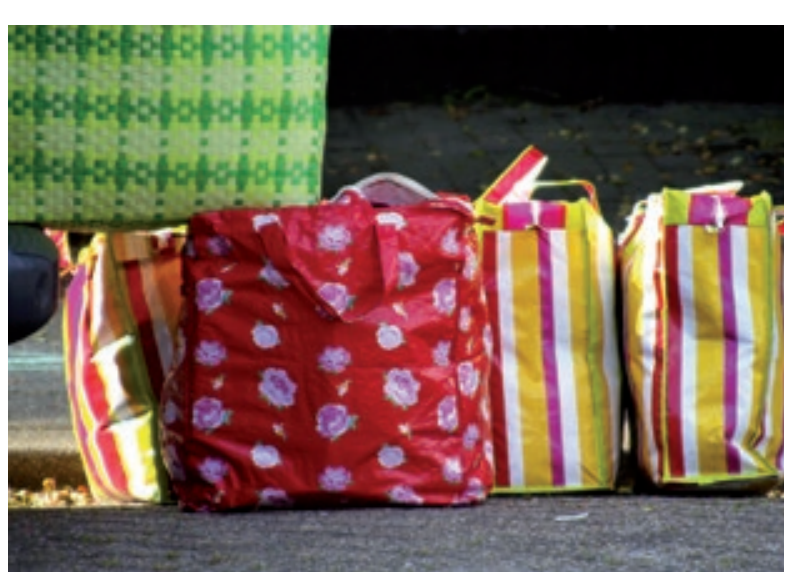

Multiple-use carrier bags customers, and many of them have addressed this issue by charging their patrons. It is important to note that the cases discussed here are a voluntary action taken by private companies and not driven by law, which also occurs, as explained in this case study.

For example, in early 2007, Pingo Doce supermarkets (Jerónimo Martins Group) in Portugal replaced the free distribution of plastic bags for bags that cost $€ 0.02$ each and promoted their reuse. Through this action in its 372 stores, in five years, Pingo Doce decreased the distribution of plastic bags in weight by $47 \%$, which equated to 7,667 fewer tonnes of bags in landfills ${ }^{* *}$ Later, in 2015, the Portuguese Government obliged supermarkets to charge 10 cents per plastic shopping bag. As a result, the use of plastic bags in stores and supermarkets across the country has seen a drop of more than 90 per cent since the introduction of the government tax on their use ${ }^{* * * *}$.

In the UK, in 2007, M\&S set two goals to mitigate the impact of carrier bags. Firstly, to reduce carrier bag usage by $33 \%$ and, secondly, to reduce the environmental impact of its bags by making them out of recycled polythene. That same year, M\&S introduced the "Do you need a bag?" campaign and launched a new bag-for-life range selling at 10 pence a bag. A range of organic cotton bags was introduced targeting M\&S clothing and home customers.

In February 2008, M\&S introduced the 5 pence charge for carrier bags in food halls across the UK. Profits from the sale of the 5-pence bags, over $£ 10$ million, were donated to the environmental charity Groundwork, who used it to create parks, gardens and play areas across the country. Since

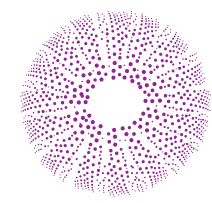

USE AND CONSUMPTION 
2011 the proceeds have been given to the WWF and the Marine Conservation Society (MCS). The result has been a $75 \%$ reduction in bag usage across M\&S food halls ${ }^{\text {****** }}$.

To further support the introduction of the bag charge, M\&S and Unicef UK have teamed up to create an ethically sourced tote bag designed by designer Barbara Hulanicki. The bag has a unique design and is intended to raise funds for Unicef UK; it retails at $£ 4$, with $100 \%$ of the profits ( $£ 1$ per bag) being donated to the campaign to protect children from danger. In another first, M\&S has worked with one of its suppliers, London Linen, to utilize recycled fabric reclaimed from hotel and restaurant table linens to make the bags-ensuring it's not only desirable, but also sustainable.

Currently, across the UK carrier bags are charged 5 pence by law, and retailers need to report to the Government on how the money collected is being used.

\section{Challenges addressed}

The challenge addressed by supermarkets through the introduction of a carrier bag charge is to bring about a change in customers' behaviour without losing their loyalty to the brand. To ensure this happens, it is essential to explain clearly why a reduction in plastic bag use is necessary, including its contribution to the fight against marine litter. As seen in the case of M\&S, it is important to donate the gains from this charge to charity causes, so it is not perceived as a company gain but rather as a benefit for the entire society.

In fact, these retailers have become frontrunners, since currently the levy is compulsory in many countries, which gives them a leg up in terms of their green image in comparison to their competitors.

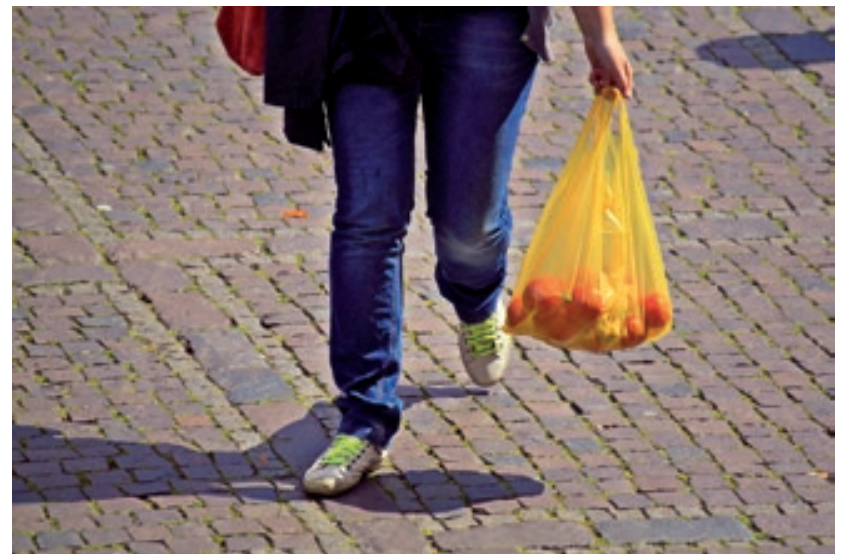

A single-use plastic bag

**** M\&S 2015. Carrier Bag Charge.

http://corporate.marksandspencer.com/blog/stories/carrierbagcharge

\section{Initiator and collaborations}

Both in the Portuguese and British case the initiators are one of the most important retailers in the respective country. In the case of M\&S, collaboration takes place mainly by donating revenues from the charge to charity. This company also collaborated with a fabric supplier to recycle fibres for their later use in the cotton bags sold to replace the plastic ones.

\section{Financial aspects}

This type of action has no cost for initiators, except for communication actions with customers. On the contrary, this measure brings about profits for supermarkets, which in turn have two options: to keep the money or donate it to charity.

This is the main difference between the two cases explained here. While Pingo Doce in Portugal does not report on how the profits are used, leading one to assume that they are kept within the company, M\&S does donate this money to charity and takes advantage of this in communication terms. In 8 years, the retailer has donated the over $£ 10$ million raised by the charge. Furthermore, it also donates 100\% of the profit coming from its tote bag initiative with Unicef UK. From a governmental perspective, the UK hopes that the $5 \mathrm{p}$ charge will raise $£ 730$ million for charitable causes. This will imply two other important benefits: $\mathfrak{E} 60$ million in savings in litter clean-up costs and $£ 13$ million in carbon savings.

Further market opportunities and replicability aspects The initiative could be adopted by main retailers in the MENA region. Firstly, the programme design should include: determining the price of the plastic bag, communication action with customers explaining the problem posed by plastic bags, stamping an environmental message on plastic bags, providing reusable bags of a different material (e.g. raffia bags) and deciding how to use the revenue generated by the charge. Once implementation starts, the evolution of plastic bag sales should be monitored and have a baseline as a reference. Finally, it is important to explain how the funds are being used, whether for charity or corporate social responsibility actions. 


\section{Bye Bye Plastic Bags, the power of youth}

Youth power to drive change can convince an island like Bali to go plastic bag-free. It consists of a volunteer team of 25-30 students, both local and international, from schools all around Bali.

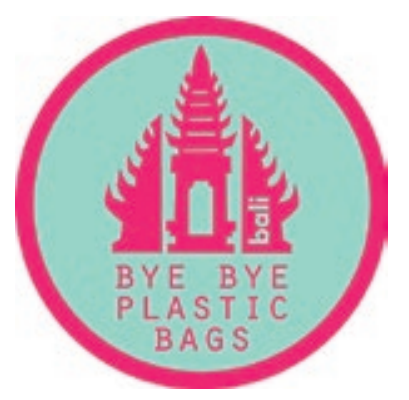

\section{What it's about}

Bye Bye Plastic Bags (BBPB) is an NGO driven by children that works to get the people of Bali to stop using plastic bags. It kicked off back in 2013 and it has become a well-known and recognized movement of inspiration and youth empowerment island-wide as well as at national and international level. The movement has inspired the Bali Airport to become plastic bag-free and is in the process of getting a government commitment to make the island plastic bag-free by 2018 .

The initiative is based on four main pillars:

\section{Success factors}

- Very strong

communication skills

with outreach capacity.

Public speaking

and storytelling abilities.

Use of social media.

- Grassroots movement led by highly motivated

and well-informed youth.

- Liaising with recyclers and innovative companies.

- Lobbying capacity to achieve policy reforms.

- Forbes has included the two founding sisters in its list of the top 10 most inspiring women in Indonesia.

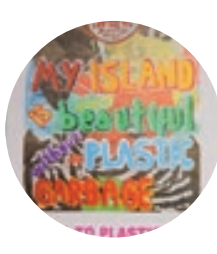

Education

Education is where the change can happen. They have edited a 25-page booklet in Bahasa Indonesia. Illustrated by one of the local team members (aged 12), the booklet is all about waste management, marine debris, the 3 simple "Rs", and youth empowerment. Their aim it to spread it through the entire school system in Bali and beyond.

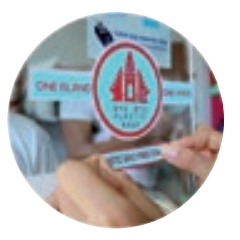

\section{One Island, One Voice}

This campaign provides eco-friendly marketing value. It highlights those shops, restaurants, hotels, etc., that are plastic bag-free by putting a sticker indicating that they are "One Island, One Voice - Plastic Bag-Free Zone". The businesses are further promoted on BBPB social media.

\section{Pilot Village}

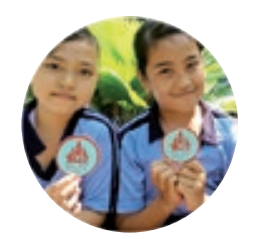

They run a pilot project at Pererenan, a village with about 800 families. They distribute at least 200 alternative bags every Saturday at local shops. It is an intense lobbying campaign and a learning process, where the understanding of cultural habits helps to stimulate change.

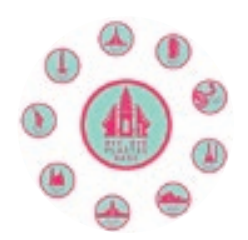

Global

Young people from every corner of the globe approach the movement asking about how they can replicate it. BBPB is now organized in Australia, Jakarta, Guadalajara, New York, Nepal, Myanmar, Tenerife, Ibiza, and the Philippines. 


\section{Challenges addressed}

Campaigners address one key item of marine litter: the single-use plastic bag. Other types of litter are further addressed by their beach cleaning actions, but for the past four years the NGO has been working towards making the island plastic bag-free. In order to achieve this, they managed to work with local government, taking up the challenge of understanding the complexities within government systems. They have managed to engage with the airport, hotels, restaurants and others, addressing the litter coming from recreational activities and municipal waste. It is not only about awareness; the movement is achieving real change through policy reforms.

\section{Initiator and collaborations}

The founders are two teenage sisters who started this venture back in 2013 and now have a volunteer team of 25-30 students from all schools around Bali as well as international spinoffs. BBPB is a nonprofit NGO driven by children. As its members are legally underage, their parents have guardianship of the legal entity. BBPB has two founders, four board members, a secretary, and a financial officer; the rest of the team is made up of volunteers.

From its inception and throughout the development process they have counted on the support of John Hardy, co-founder of Green School Bali, the mission of which is to create a community of learners who will make the world sustainable. They also count on the partnership and support of Avani, a young and dynamic Indonesian company that produces 100\% plant-based alternative packaging, including bags; Eco Bali, one of Bali's waste management centres; and iniBags.

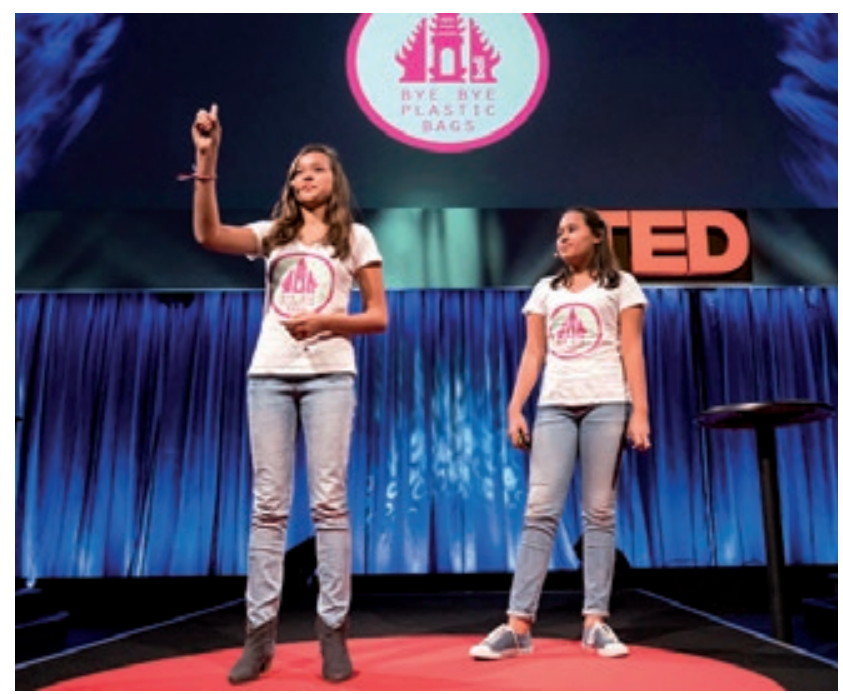

TED talk by the founder sisters. Credit Bye bye plastic bag

\section{Financial aspects}

Funding is a challenge for a child-driven nonprofit NGO. BBPB depends on private donations, merchandise sales (alternative bags) and grants.

The initiative started out small. It was family who funded the first stickers and banners. As the movement became bigger, along with success came the need for private donations. Today BBPB is financed mainly by the sale merchandise. There are plans to set up a social enterprise to work with local women in the mountains of Bali to produce the alternative bags for sale.

\section{Further opportunities and replicability aspects}

At the moment, there are only 38 countries in the world that have said no to plastic bags. The message of Bye Bye Plastic Bags is therefore needed and easy to replicate. The crucial component is to get a group of young, likeminded friends together to start the movement. To encourage replication, BBPB has been launched globally, providing guidelines, tools, tips, handbooks and monthly meetings and offering free support to start-ups in any country or city internationally. The BBPB Global Team is currently active in 9 countries worldwide. Steps to be taken include:

- Building a strong and motivated team.

- Once the decision to join the global movement has been made, registering at: www.byebyeplasticbags.org/global

- Analysing local, national and regional surroundings in order to understand which parts of the solution are already in place (from policy, waste management, business and behavioural points of view, among others) and to identify opportunities for improvement.

- Identifying and engaging collaborators from businesses, communication and waste management.

- Setting realistic targets, planning initial steps with easily reachable goals to maintain motivation and empowerment.

- Participating in local community events, school presentations, booths at festivals and markets.

- Using social media for outreach.

CONTACT AND FURTHER INFORMATION

www.byebyeplasticbags.org

www.welcomealternativebags.com

byebyeplasticbag@gmail.com 


\section{Breaking the world record with the longest plastic-bag chain}

With a length of $9 \mathrm{~km}$, the longest plastic bag chain in the world was made from 30,000 plastic bags in Berlin, 2014.

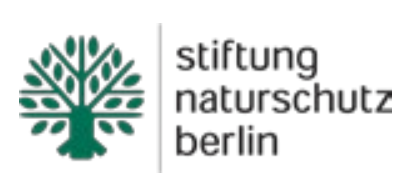

Success factors

- This action was prepared as part of an environmental festival to draw in a wider public and encourage them to join various activities, maximizing attendance.

\section{- Key actors were} involved: local government, waste managers, NGOs and schools.

\section{- Physical space} in which to interact.

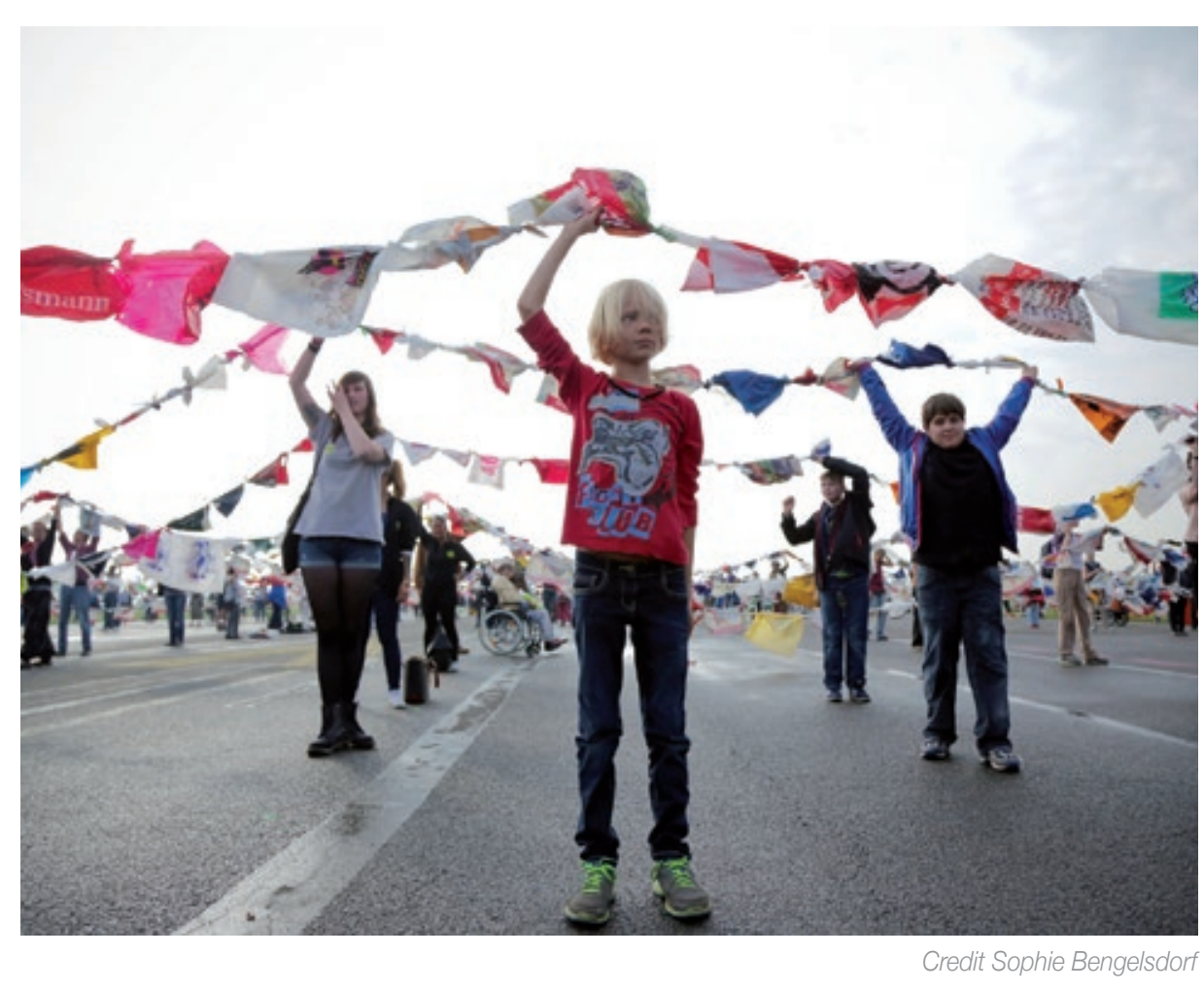

What it's about

With 30,000 collected disposable bags, the longest plastic-bag chain in the world was formed as a sign against resource waste. It was a campaign to raise public awareness that wanted to make a statement about the use of plastic bags-and to set a world record.

Within the framework of the initiative Berlin tüt was, 30,000 plastic bags were collected over the course of several months. Thousands of Berliners handed over their disposable bags, which were no longer needed, to dozens of collection points all over the city in exchange for reusable multipacks.

The 30,000 plastic bags were knotted in the form of a chain and shaped into an exclamation mark by more than 3,000 world record holders. This not only set a clear signal about the influx of plastic bags, but also significantly exceeded the previous world record of 10,615 plastic bags. The 30,000 plastic bags are symbolic of the bags that go over the shop counter every hour.

Together with various project partners, the Foundation Naturschutz Berlin organized this campaign in Tempelhofer Park, in Berlin.

\section{Challenges addressed}

According to Foundation Naturschutz Berlin, initiatives to educate and actively reduce the consumption of disposable plastic bags are lacking in Germany. All initiatives to raise public awareness are welcome and needed. In many other countries, regions and cities, however, there are already initiatives and laws 
in place for the prevention of plastic bags. Member States of the EU apply a wide range of measures, ranging from voluntary agreements with trade (England) and the introduction of taxes (Ireland, Denmark and Belgium) to the prohibition of nonbiodegradable plastic bags (Italy). Instruments for plastic bag reduction are also interlinked; for example, if taxes or duties do not lead to a reduction in the consumption of plastic bags, the next step would be prohibiting them. A further combination would be voluntary agreements with industry, which would lead to the introduction of a tax or levy if they were not met with. In countries and cities outside Europe, much more restrictive action is being taken against plastic bags. For example, plastic bags are forbidden in China, Mexico, Australia, Bangladesh, Rwanda, San Francisco and Los Angeles (complete or partial): the aim of the initiatives is to reduce packaging waste, to promote reusable bags, to prevent the littering of plastic bags, to use the raw material efficiently and to reduce dependency on fossil fuels for raw materials.

\section{Initiator and collaborations}

The Foundation Naturschutz Berlin, a civil society organization, initiated this action in cooperation with three partners: Environmental Action Germany (Deutsche Umwelthilfe eV), Berlin City Cleaning

\section{CONTACT AND FURTHER INFORMATION \\ Website of the world record campaign: $\underline{\text { berlintuetwas.de }}$ \\ Foundation Naturschutz Berlin website: www.stiftung-naturschutz.de info@berlintuetwas.de}

(BSR) and Trenntstadt Berlin.

Furthermore, there were about 70 participating plastic bag collection points around the city: plastic recycling points, supermarkets and stores.

\section{Financial aspects}

For this campaign, a mix of private and public funding was made available. The Foundation Naturschutz Berlin also has its Trenntstadt Berlin Fund, with which it initiates and supports innovative and creative waste projects.

\section{Further opportunities and replicability aspects}

Potential opportunities for setting up a public awareness-raising campaign similar to this one require a collective effort and commitment from key parties, including city councils and key NGOs, in order to create partnerships and ways of engaging with civil society. Potential funding sources are government, private foundations and private company sponsors.
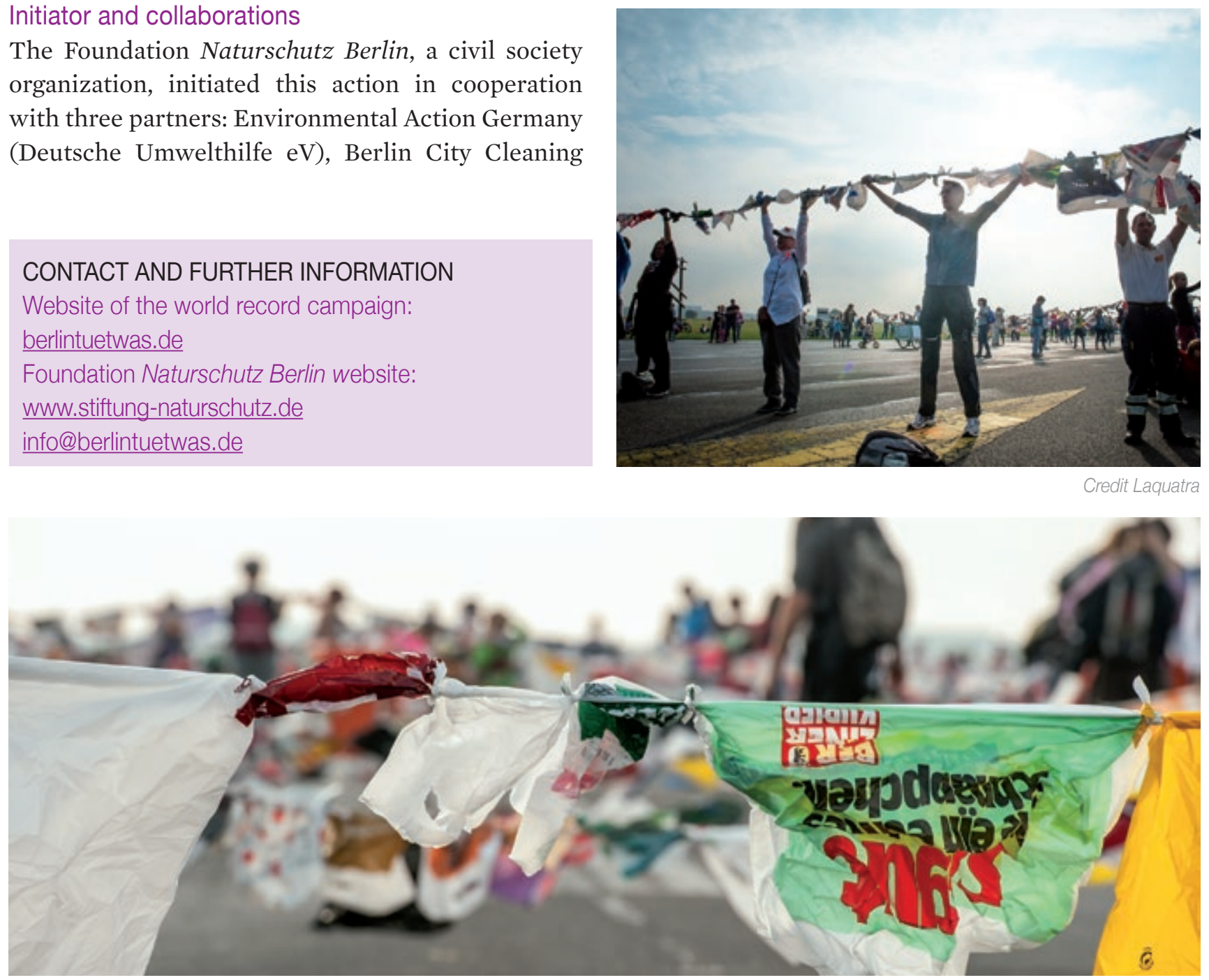


\section{Bag it and Bin it - Don't Flush it}

This awareness-raising campaign in the UK is aimed at reducing the incidence of sewage-related debris on beaches and riverbanks.

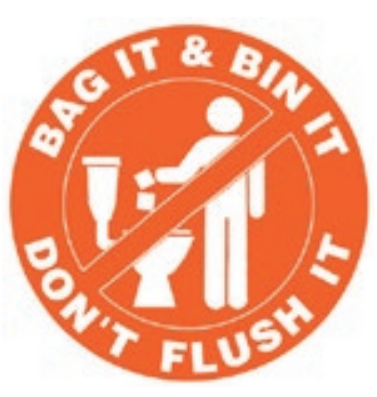

Success factors

- Inclusive partnership.

- Involvement of retailers and producers to improve labelling.

\section{- Media coverage.}

- Evidence of beach litter reduction.

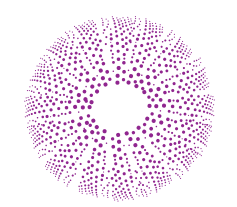

USE AND CONSUMPTION

\section{What it's about}

The aim of the campaign was to reduce the incidence of sanitary items and other sewage-related debris (SRD) on UK beaches and riverbanks through a programme of promotion, education and partnership. It sought to raise awareness of the problems of SRD and to encourage people to dispose of personal waste carefully, whether in their own household waste bins or in special disposal bins in public toilets.

The awareness campaign was particularly focused on women between the ages of 15-45, asking them not to flush products down the toilet, but to bag them and bin them

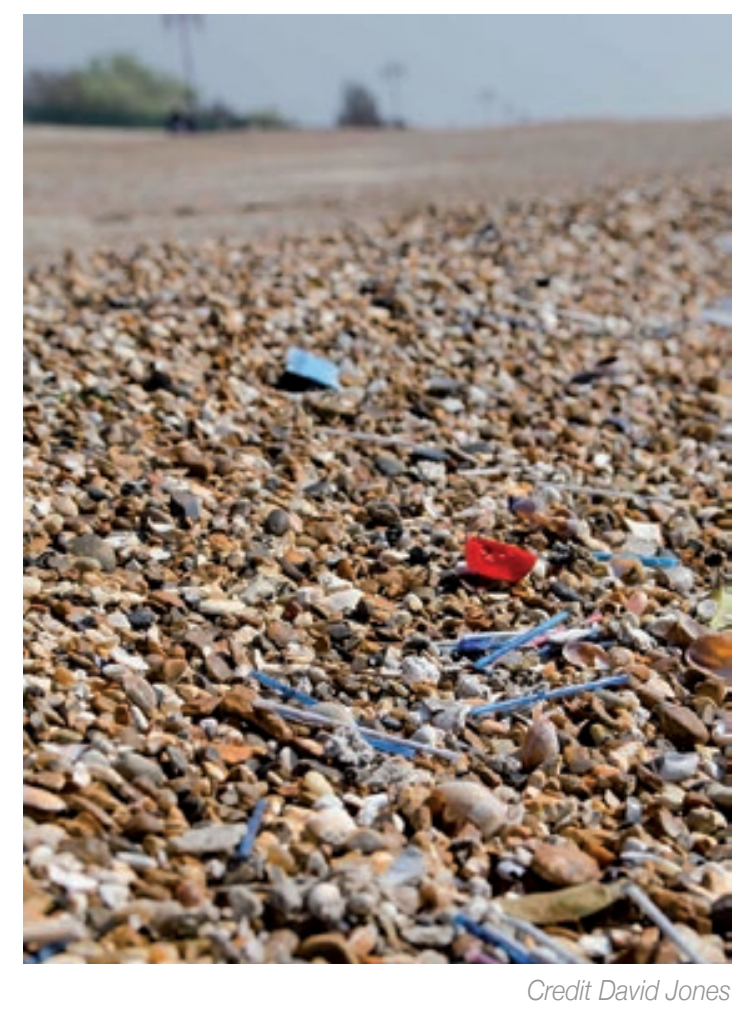
instead. In 2002, a school campaign was launched across 6,000 UK schools. A variety of campaign materials were produced, including the "Bag it and Bin it" logo, leaflets, posters, and stickers. As part of the campaign, manufacturers and retailers were encouraged to apply the logo and/or message to their products. In 2007 and 2008, the MCS and Surfers Against Sewage used the Bag it and Bin it campaign to focus on cotton bud sticks, to encourage manufacturers and retailers to improve labelling of these products and to replace the plastic cotton bud stick with a paper one. The campaign also received significant press coverage, with over 700 media features.

The campaign received support from leading retailers (Tesco, Sainsbury's, Safeway, Morrison's, Somerfield, ASDA, Co-op, Superdrug, and Boots) and key manufacturers (e.g. Johnson \& Johnson and Smith \& Nephew), who included the campaign logo and/or the correct disposal messages on products that consumers might flush. The logo was printed on over 100,000 toilet stickers, 700,000 disposal units, 45 million products, and packaging for 80 million disposal bags.

The 2007-2008 focus on cotton bud sticks led to agreements from The Body Shop, Co-op, Marks \& Spencer, Asda and Tesco to endorse the logo on their cotton bud products, and commitments from some of these retailers to produce cotton bud sticks with paper stems. Results from the 2007 MCS Beachwatch event marked a decrease in the number of cotton bud sticks observed on UK 
beaches, from 172 items $/ \mathrm{km}$ in 2006 to 97.5 items $/ \mathrm{km}$ in 2007.

Overall, the quantity of cotton bud sticks and SRD on UK beaches declined when the national campaign was running (and following times of extensive publicity), and started to rise when national funding ceased in 2012. This indicates that well-organized campaigns with consistent messaging over time can have a positive effect (Evaluation of the Effectiveness of Voluntary Measures in Place to Raise Awareness of Non-Agricultural Diffuse Pollution Summary Report, Defra, 2006).

\section{Challenges addressed}

Sewage-related debris is a very important proportion of marine litter, particularly beach litter. Many sanitary items flushed down the toilet, due to size, shape or the type of sewage and rain collection system they enter, end up in the ocean and on the beaches. In other cases, especially in the case of wet wipes, they even block the sewage system or create dysfunctions in the wastewater treatment plants. In the Thames region alone, disposal of unsuitable products, combined with fats, oils, grease and food waste poured down the sink, causes 1,000 homes and 5,000 gardens to be flooded each year. The nationwide cost of unblocking the sewers maintained by the water and sewerage companies already runs to $£ 88$ million a year.

\section{Initiator and collaborations}

The campaign was launched following discussions between South West Water, the Marine Conservation
Society, Surfers Against Sewage and other organizations concerned about SRD in the marine environment.

The campaign was "steered" by a national group, whose members included:

\section{- Water UK}

- Women's Environmental Network

- Surfers Against Sewage

- National Household Hazardous Waste Forum

- Marine Conservation Society

- Absorbent Hygiene Product Manufacturers Association

- EPC Environmental Services

- Department of the Environment, Transport and the Regions

- Environment Agency

Further market opportunities and replicability aspects This type of awareness initiative and partnership with the private sector is desirable and feasible in the MENA region, since sewage-related debris is an important issue, aggravated by sewage infrastructure problems in many areas of the region. Although several initiators could take up the action, a partnership between sewage companies/administration and civil society organizations would be ideal. The activities could be similar to the ones in the UK, such as developing the logo, producing stickers, leaflets and posters, and seeking agreements with retailers and producers so they use the logo.

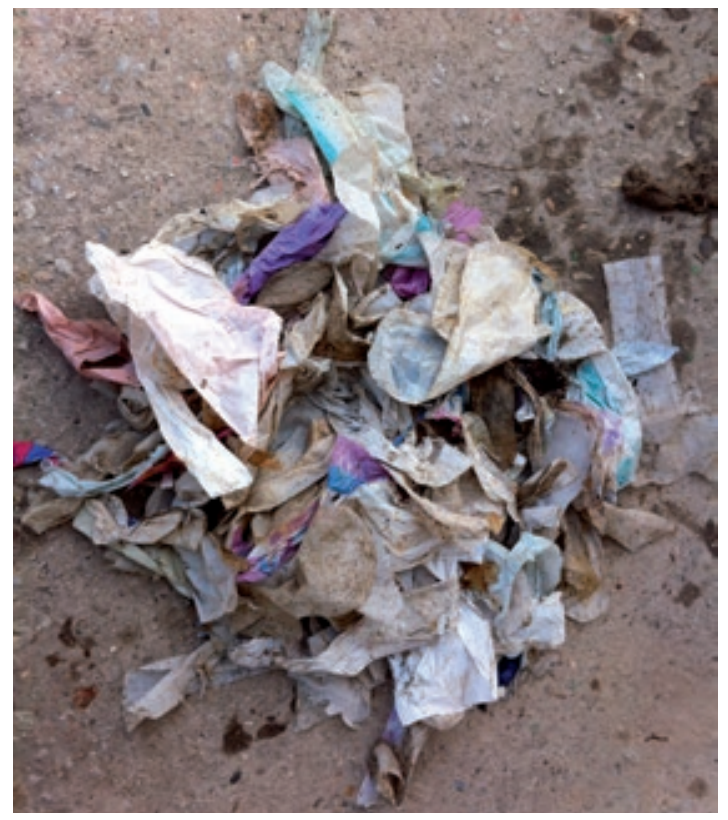

Sewage-related debris. Credit Catalan Waste Agency

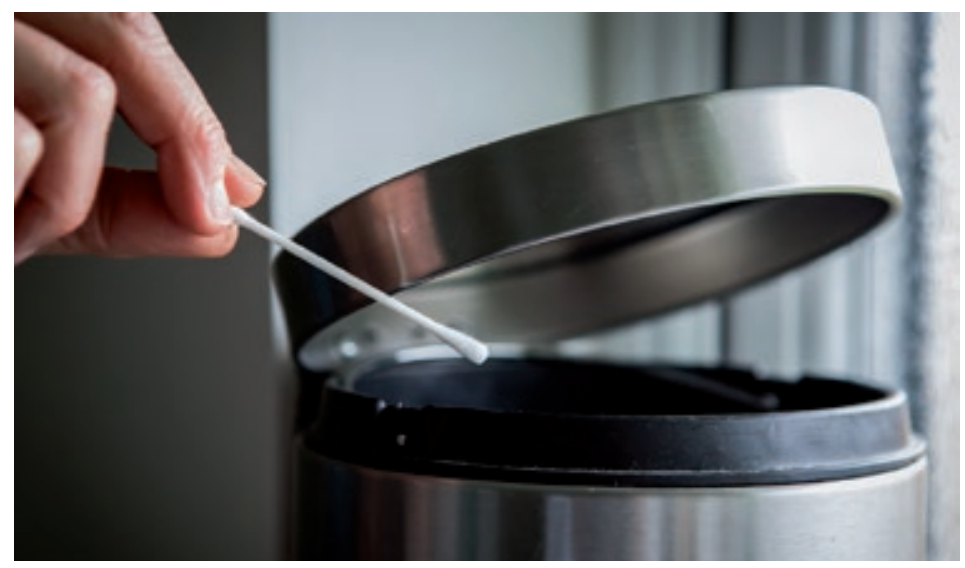

Credit Fidra 


\section{Antivolabossa, \\ a device preventing bin sacks from blowing away}

This small yet efficient device is designed to prevent the wind from blowing bin sacks away and spreading their content throughout the public space.

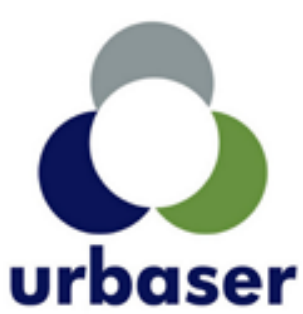

Success factors

- Notable improvement of the waste collection system.

- Device made with recycled material.

- Savings in waste generation (garbage bags).

- Social inclusion component.

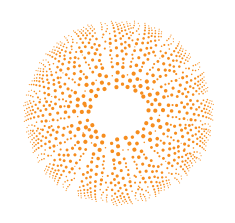

COLLECTION AND WASTE TRANSFER

\section{What it's about}

Along coastal zones and maritime boulevards, where the wind is often stronger, bin sacks blow away easily and often, spreading the content, making the public space dirty and likely becoming marine litter. The city of Barcelona, concerned by this problem, launched a call (through

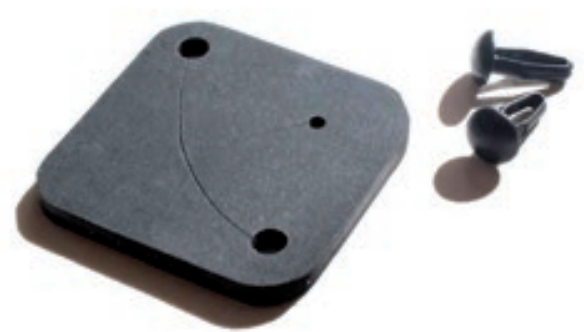

Antivolabossa. Credit Salvador Fàbregas the outsourced company Urbaser) to improve the bin retention system, which consisted of a PVC clip that fixed the sack to the bin but was not very efficient under windy conditions. What's more, it was removed along with the sack in the regular replacement process by street cleaners.

Then, Antivolabossa was designed. It is a small device installed inside the bin, between the bin surface and the sack, so the latter is fixed to the bin and does not blow away when it's windy. Moreover, Antivolabossa avoids wasting thousands of garbage sacks, since improved fixation allows for longer sack life (the content is poured into a wicker basket and the sack stays in the bin).

One of the mains features of this product is that it is manufactured with rubber from the curtains of recycling containers that need to be replaced: 47 units of Antivolabossa can be obtained from each of these curtains. In addition, thanks to this product, a material of high quality but which is difficult to recycle (with the associated cost) has been given further value.

The manufacturing process is simple: cold die-cut. Furthermore, its lifetime is longer than the current plastic clip. This allows savings in terms of waste generation. In the city of Barcelona, for example, with 28,000 bins, it can save 2,190,000 sacks per year, which translates into 4.3 tonnes of waste saved.

Antivolabossa is being installed gradually, each time a curtain is replaced. Right now there are more than 12,000 bins in the city of Barcelona using the new device. It is important that street cleaning workers be aware of the Antivolabossa system and set the plastic sack properly.

Last but not least, the product is manufactured locally by a special work centre, thus promoting social integration of disadvantaged groups.

\section{Challenges addressed}

Proper collection of waste in coastal areas is key to preventing marine litter generation. This is especially important in the Mediterranean region in the summer period, when millions of people gather by the sea.

Currently, even though many municipalities install bins by the coast and people use them, wind can play a role by blowing away the bag bins and thus the waste they collect. Considering the closeness to the sea, this waste will likely become marine litter.

Moreover, it is important to consider the negative effect the fact of seeing 
waste being spread all over the street on windy days has on people's awareness. This may lead certain individuals to not bin their waste.

In this context, Antivolabossa is a simple yet effective way to fight against marine litter, by fixing the bag more securely in the bin and making sure the waste is retained.

\section{Initiator and collaborations}

There are three players involved in developing Antivolabossa.

First is Urbaser, responsible for street cleaning in Barcelona, who detected the important amount of waste being blown away from bins and questioned the former system, in which the PVC clip not only became waste but also broke the bin sack. The company promoted designing a better solution, which the municipality of Barcelona adopted and is applying it to the entire city.

Second, there is Salvador Fàbregas, the person behind the design, who founded his own studio. He holds a degree in Industrial Design and another in Mechanics. He specialized in project development following a productive career in street furniture design and unique, made-to-measure projects in the landscaping and community fields. His approach is based on sustainable design, in perfect harmony with his workshop-based production process.

Finally, Xarxa Ambiental is a non-profit organization that aims to intermediate between businesses and local social organizations, to integrate people at risk of social exclusion in the service sector of public administration. This organization is in charge of maintaining selective collection containers and recycles the rubber curtain used to manufacture the Antivolabossa. This has positive effects in terms of having no carbon footprint, as everything is done at one location.

\section{Financial aspects}

Rubber curtains that can no longer be used must be managed by a special waste manager company, with the associated cost. By giving a second life to this material, that cost is avoided. An Antivolabossa item is slightly more expensive than the conventional plastic clip; however, since Antivolabossa has a much longer lifespan, it is cheaper in the long term.

\section{Further market opportunities and replicability aspects}

There is significant potential to explore the extension of Antivolabossa to other Mediterranean cities. There are mainly two ways of doing so: either producing the devices in Barcelona through Xarxa Ambiental and selling them elsewhere, or producing them elsewhere (this option is feasible since there is no manufacturing patent in place, but permission should be given by the Barcelona municipal authorities).

If the latter option is implemented, one of the main positive effects is that it would generate economic income, and it would be desirable that production be entrusted to a non-profit association working with disadvantaged groups.

There is also a third option, in which Urbaser incorporates the system in other cities that have bins similar to those in Barcelona, with the company providing the cleaning services. This would not have to be limited to Spain, it could include Mediterranean cities in Morocco, Spain, France and Italy.

No matter which option is implemented, it would be necessary that street cleaning companies commit to using this device and training street cleaners, something that could be made easier by municipalities requesting this in their terms of reference (when the service is outsourced).

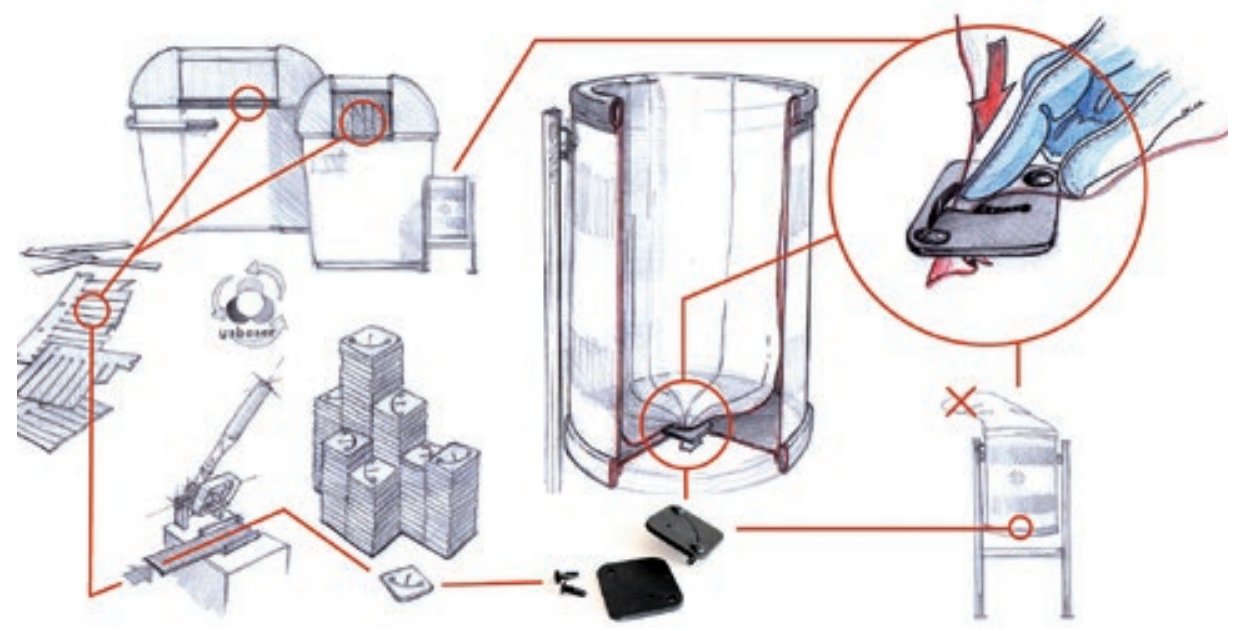

Sketches illustrating the issue and conception of Antivolabossa. Credit Salvador Fàbregas

CONTACT

AND FURTHER

INFORMATION

www.urbaser.es

Contact person:

Víctor Cardador 


\section{Waste management on AIDA cruises and Deerberg Converter ${ }^{\circledR}$ technology}

AIDA's cruises implemented an efficient waste management system, using the latest technology available, such as the Deerberg Converter $®$, and prevention actions.

\section{What it's about}

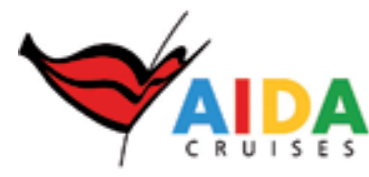

Success factors

- Deerberg Converter ${ }^{\circledR}$ can treat all kinds of unsorted waste, provides volume reduction of up to $80 \%$, delivers a dry and sterile end-product and can be operated 24 hours a day, everywhere, especially in ports \& coastal areas.

- Work with certified waste management companies at port.

- Successful waste prevention policy.

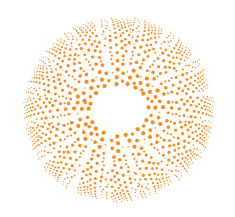

COLLECTION AND WASTE TRANSFER

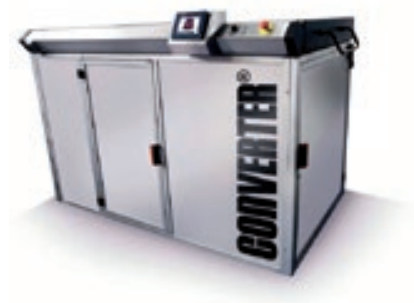

Credit Evac Germany GmbH

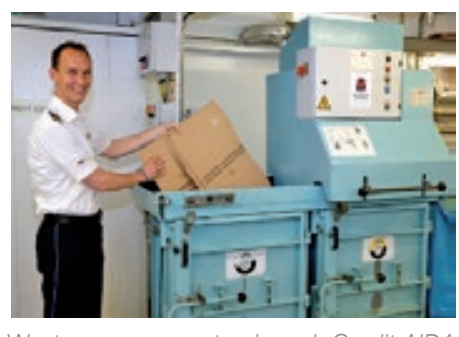

Waste management onboard. Credit AIDA
Cruises can be a major source of marine litter, and thus waste management systems on board are a must as well as proper facilities in ports. In the case of the German company AIDA, the disposal options at the individual ports are thoroughly examined as early as in the route planning of ships. Based on the findings, waste management for each voyage is planned so that the most environmentally friendly disposal option is used.

Waste management on board is essential and compulsory for cruises in order to comply with international regulations. Thus, waste separation is a high priority at AIDA. Metal is pressed and glass is broken down to save storage space. Food waste is also compacted and dehydrated. The result is a biologically degradable substance. Furthermore, in 2012, the company Deerberg introduced a technological innovation: the Converter ${ }^{\circledR}$.

It is not a replacement for on-board waste management systems but an addition to them. It provides volume and weight reduction and a sterile end-product and, more importantly, has no air emissions, so it can be operated 24 hours a day. In a single cycle it converts all waste, including dry waste, food waste, plastics, glass, fabrics and even metal, into a sterile fluff. This fluff, which is highly energetic, can then be compacted into briquettes and, when taken ashore, incinerated to produce energy. Thus, the converter is a good solution to current waste management problems on board a large number of ships, and it has been incorporated in several AIDA cruises. The unit is available in many sizes and can be installed as a stand-alone or integrated system.

At all destinations, AIDA works with the best waste disposal companies. To ensure that waste is disposed of correctly, AIDA environmental officers visit the waste management companies on site and conduct company audits and inspections.

But however well a waste management system works, it is even better to generate as little waste as possible. That is why AIDA places efforts in reducing waste generation per guest and per day. From 2012 to 2014, the company reduced the waste per person per day from 4.6 to 3.9 kilograms.

Many beverages on board AIDA are no longer purchased and offered in bottles but in special beverage containers with large-volume capacities. In figures: each year, 3 million litres of wine are delivered to AIDA ships in reusable 
containers with a capacity of 1,045 litres rather than in the usual containers. Thereby the equivalent of 4.2 million wine bottles of 0.75 litres each is saved. In addition to this, the following packaging waste is avoided: 6 million soft drink bottles of 0.33 litres each, 5.75 million beer bottles of 0.33 litres each, and 800,000 Tetra Paks of fruit juice concentrate of 1 litre each.

Another action is the reduction of plastic waste in the kitchen area by doing away with cocktail stirrers and switching to cling-wrap film that is $10 \mathrm{~cm}$ narrower. In 2014, numerous single-use products, such as tasting spoons in the kitchen, disposable aprons, and disposable bottles, were replaced with reusable products. In regard to the remaining disposable products on board, such as paper napkins or straws, biodegradable options are favoured.

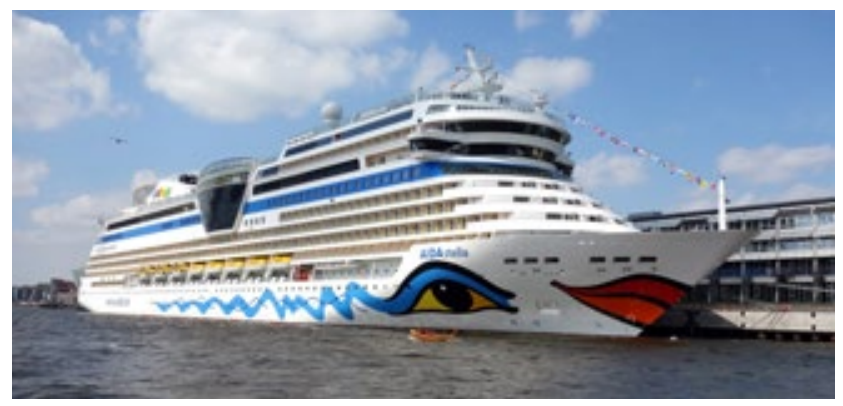

Credit AIDA

\section{Challenges addressed}

Cruises generate an enormous quantity of waste considering the amount of people they accommodate. For example, the ship AIDAstella can host 2,194 passengers, producing more than 8 tonnes of waste per day. Therefore, waste management on board and prevention actions are a must.

Modern waste management systems today are highly integrated systems designed to handle almost automatically accumulating waste. Solid waste, food and wet waste, recyclables, oily waste, hazardous and medical waste and large amounts of grey and black water, as well as the generated bio-residues, have to be managed with the lowest possible environmental impact and at the lowest possible operating costs.

Other drivers for the development of waste prevention policy and on-board technology are local rules and regulations, which in recent years have become more and more stringent.

Having an equally massive impact on the technical specifications and the way waste is handled today is the continuing limitation or prohibition. As most waste management concepts today are based on incineration systems, new future-oriented technologies have to be developed to make sure that owners and operators can manage their wastes with the same efficiency and with a comparably low environmental impact.

\section{Initiator and collaborations}

AIDA is an American/British-owned German cruise line based in Rostock, Germany. It is now one of ten brands owned by Carnival Corp, based at Miami, Florida, accounting for $6.5 \%$ of its share of revenue.

Deerberg-Systems, the German-based systems developer and producer, has been active in maritime environmental protection and waste management for over 30 years. Evac Germany $\mathrm{GmbH}$ and Deerberg-Systems GmbH retroactively merged on 1 January 2017 to form Evac Germany GmbH. To date, more than 900 vessels have been equipped with waste management systems and components from Deerberg-Systems.

\section{Financial aspects}

The installation of an efficient waste-handling system on board, for example on the ship AIDAstella, where this brought about a $28 \%$ improvement in recycling quotas, requires an investment of approximately 10 million euros. However, this represents only $1-2 \%$ of the cost of building a new ship.

Prevention actions, far from having a cost, contribute to reducing the expenditures of cruise operations, both from the viewpoint of saving resources and cheaper waste handling.

\section{Further market opportunities and replicability aspects}

A proper waste management system at ports in the MENA region is very important from a marine litter perspective, both so ships can discharge waste generated on board and ports can handle waste according to the best environmental standards. In this sense, two actions may be considered in the MENA region. On the one hand, adopting technologies like the Deerberg Converter ${ }^{\circledR}$ to reduce the volume of waste and take advantage of the energy component, without harming the surrounding environment. On the other hand, waste handlers could pursue environmental and quality certificates so they have a competitive advantage in the cruise business.

\section{CONTACT AND FURTHER INFORMATION}

www.aida.de

EVAC (formerly Deerberg): https://evac.com

info@deerberg-systems.de 


\section{"Recycling we all win": Reverse vending machine franchise}

First green SME to commercialize reverse vending machines (RVMs) in Spain, giving incentives to reward the action of recycling.

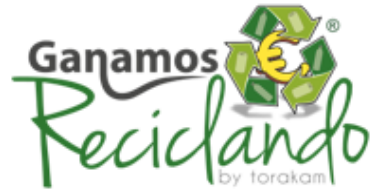

Success factors

- Direct, immediate reward to the user through an economic incentive. It fosters customer loyalty.

- It provides eco-friendly marketing value

to the businesses adopting the initiative.

- It works similarly to a deposit-refund system, but it is fully private, independent from policy processes.

\section{- There is no deposit; it does not increase the price.}

\section{- FitSur Award 2016}

for being the most innovative and most environmentally sustainable franchise.

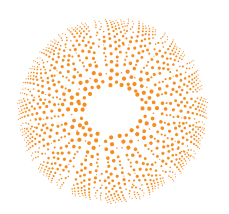

COLLECTION AND WASTE TRANSFER

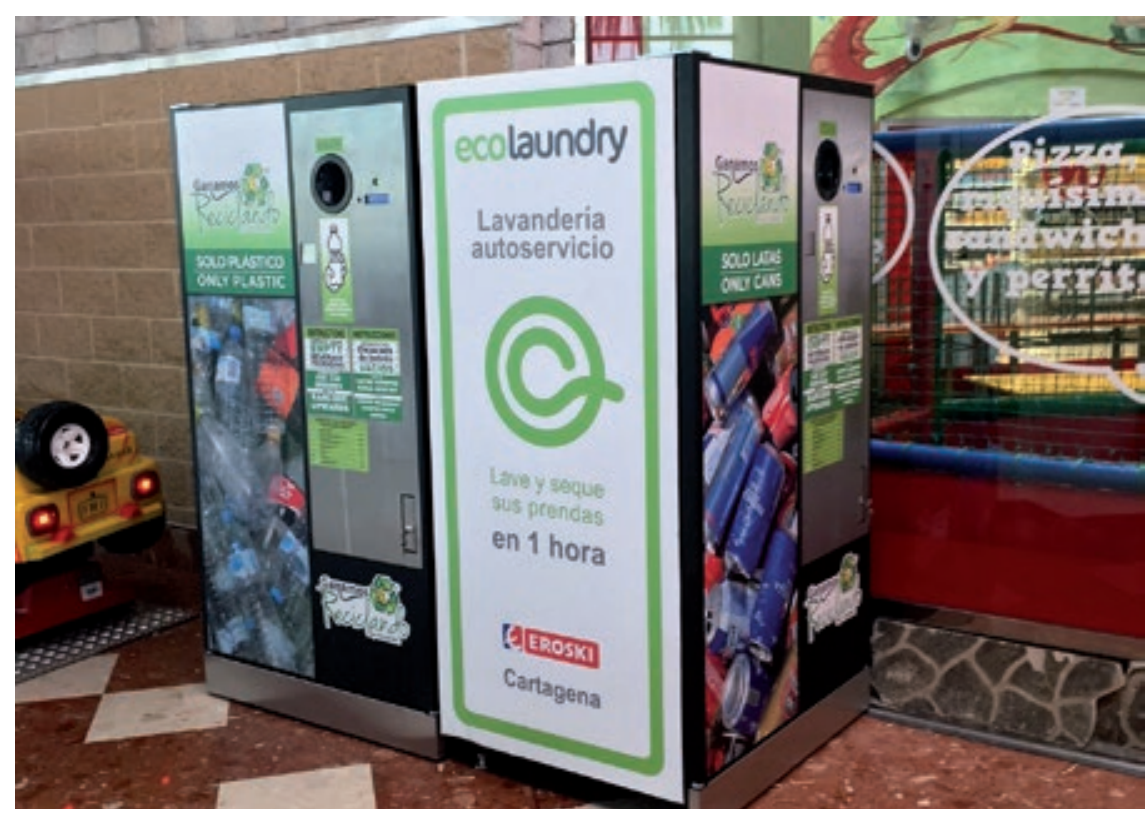

Reverse vending machine. Credit Ganamos Reciclando

\section{What it's about}

Ganamos Reciclando (Recycling we all win) is a Spanish company providing "reverse" vending machines with incentives to reward the action of returning for recycling. It is a franchise business model that facilitates selective recycling in diverse sectors and with activities aimed at raising awareness on responsible recycling.

It uses a relatively simple approach by providing, on a franchisee-agreement basis, reverse vending machines (RVMs) to be placed at food retailers, schools, sport centres and all kind of businesses. The customer returns the empty beverage packaging, the machine identifies the type of container by its barcode and provides on return either coins or a discount ticket for a small amount of money ( 0.01 or 0.02 euros per piece, depending on type) to be used in the shop or businesses adhering to the scheme during a certain period. Depending on the expected volume of use, the business can choose to place a compacting RVM or a simpler one that accumulates the containers; it can also opt whether to return coins or discount tickets. Once the containers are collected, Ganamos Reciclando purchases these items; they are sorted by material and sold to waste management companies within the commercial group.

On the website, the places where collection takes place is displayed, so the users know exactly where to do so.

Ganamos Reciclando started in Murcia, Spain, and has already expanded to a good number of cities in the country as well as to Portugal. It raises citizens' 
awareness of the importance of selective recovery for recycling and contributes to raising the recycling rate of these containers.

\section{Challenges addressed}

The initiative addresses two single-use plastic objects that are among the most widespread marine litter items: beverage cans and bottles. They recently launched the first reverse vending machine (RVM) for glass bottles.

The company directly aims to raise the Spanish recycling rate, as well as improve the quality of recycled material by providing better-quality prerecycling material (it is not polluted with a mix of different materials).

\section{Initiator and collaborations}

Ganamos Reciclando is the commercial name of Torakam Aplicaciones, SL. Its headquarters are in Madrid, the technical office in Murcia and several delegations in the Canary Islands and Galicia, among others. It is a young company founded in 2015.

\section{Financial aspects}

The initiative has proven to be financially feasible both for the initiator and the shops. The latter has a positive economic balance through selling the collected waste to Ganamos Reciclando.

Some characteristics of the franchise model are:

- Starting fee (including investment): 2,000 euros

- Monthly royalty: 20 euros/machine

- Publicity fee: none

- Duration of the contract: 5 years

- Investment: 8,500 euros

- Minimum population: 4,500 inhabitants

\section{CONTACT AND FURTHER INFORMATION \\ www.ganamosreciclando.com \\ Adela Munuera Fenor, \\ expansion@ganamosreciclando.com}

\section{Further market opportunities and replicability aspects} It might be possible to extend this system to countries in the MENA region. To do so, the waste collected could be sent either to waste managers related to Ganamos Reciclando in Spain, or, preferably, agreements with local waste managers would be sought. In that case, Ganamos Reciclando could install the collecting machine and provide training, and the franchised shop would sell the waste to a local waste trader or manager, which in turn would have an agreement with Ganamos Reciclando.

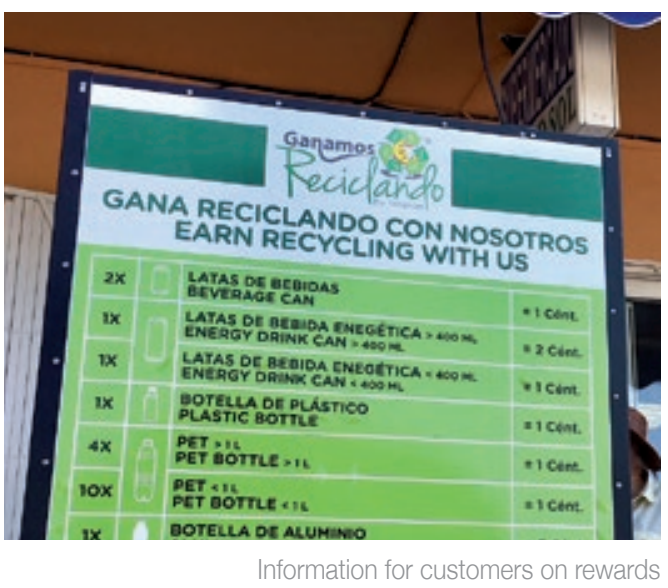
for returning containers. Credit Ganamos Reciclando

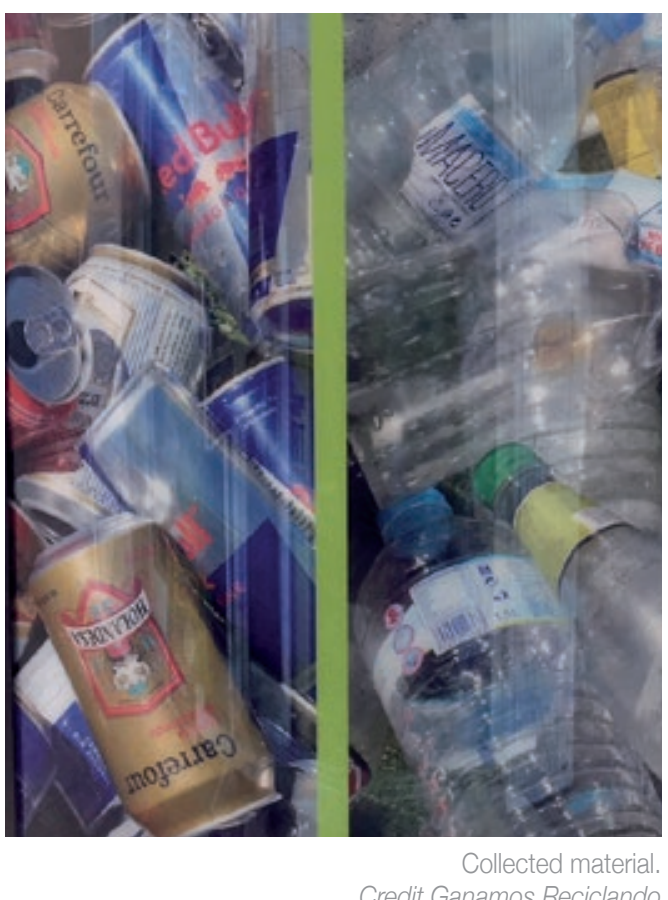

\section{SIMILAR INITIATIVES}

The Green Med Initiative is a European ENPI CBC project managed by the Chamber of Commerce, Industry \& Agriculture of Beirut and Mount Lebanon (CCIA-BML) in partnership with 11 Mediterranean organizations from 6 Euro-Med countries: Egypt, Italy, Lebanon, Tunisia, France and Spain. This initiative has tested RVMs systems in pilot projects at universities in Catalonia (Spain), Egypt, Italy, Lebanon and Tunisia. The machines placed at these universities gave out raffle tickets for leisure activities for each beverage container returned. 


\section{Fishing-line recycling bins}

This initiative not only raises awareness about marine debris but also provides containers along the South African coast which collect discarded fishing lines.

\section{Plastics $\mid \mathrm{SA}$}

\section{Success factors \\ - Local communities and fishing sector support and engagement. \\ - Innovative solutions to address the fishing line problem. \\ - Cleaner beaches and marine environment.}

\section{What it's about}

The results of an International Coastal Cleanup event showed that discarded fishing lines continue to be a major pollutant worldwide on our beaches. To address this issue, a key partnership was established to provide funding and PVC pipes which were converted into bins that were erected on beaches. These pipes are resistant to the elements and corrosion and prevent the lines from blowing away.

More than 150 pipes were donated by DPI Plastics for the rollout of the project. Also, fisherman along the Overberg Gansbaai shoreline and beaches on the Western, Northern

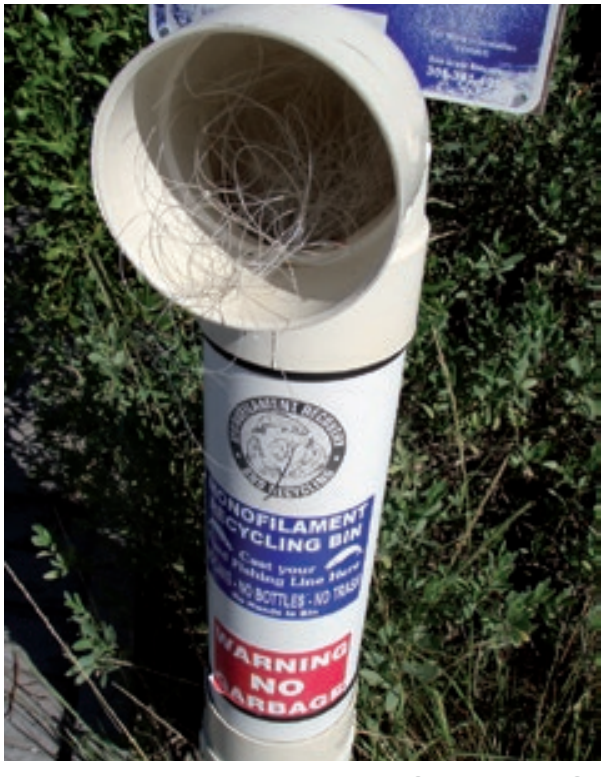

Monofilament recovery bin. Credit Plastics SA and Eastern Cape Coast were provided with their very own bins where they could discard their broken or used lines.

\section{Challenges addressed}

A summit in 2013 entitled "African lessons to inspire local actions" was the first of its kind ever to take place and saw the local plastics industry join hands with the Department of Environmental Affairs, the South African National Biodiversity Institute and the United Nations Environment Programme to bring together marine debris researchers, natural resource managers, policy makers, industry representatives and the non-governmental community from across Africa to focus specifically on the issue of marine litter.

Although it became apparent that the objective of getting the entire continent to agree on one strategy was too lofty and that many of the undertakings could not be met as a result, the summit helped to paint a big and fairly accurate picture of the extent of marine litter found in the oceans around the African continent. Sea birds and marine life are often trapped or killed as a result of fishing line that was not properly discarded and removed from our oceans or beaches each year. The project coordinators and partners called for support from committed volunteers to remove the fishing line and hooks from the bins on a regular basis. The hope was to eventually recycle the discarded fishing line bins into benches. Moreover, an important goal was to educate the public on the responsible disposal of plastics and the sensitivity of our oceans, so that they may provide joy for many years to come.

One problem encountered was the fact that in some areas the pipes were stolen or parts taken; however, this was not a major loss as the pipes were provided at 
no cost. Also, in certain areas, the pipes have become receptacles for anything resembling string or rope, which is positive, as this leads to less material that can cause entanglement. In some cases, the bins have been taken over by local communities, who also use them to discard hooks and sinkers.

\section{Initiator and collaborations}

Plastics S.A., who represents all sectors of the South African plastics industry, partnered with the Southern African Plastic Pipe Manufacturers Association (SAPPMA) and one of its members, DPI Plastics, who provided funding and PVC pipes. Furthermore, the Dyer Island Conservation Trust, in association with Overstrand Municipality, established the Fishing Line Recovery and Recycling Programme in 2010 as a best practice with which to manage the bins.

More recently, after bins were provided to Afripack and the Green Hub of Durban, demand for more bins was generated in the province of Kwazuu Natal, and bins have been provided to the blue flag beaches and areas and reserves managed by Ezumvelo KZN Wildlife. The fishing line recycled was used in craft projects such as necklaces and mobiles, offering a great opportunity to uplift the surrounding community as well as protect wildlife.

\section{Financial aspects}

DPI Plastics provided the pipes and fittings, and cost to the company has been very minimal, as pipes and

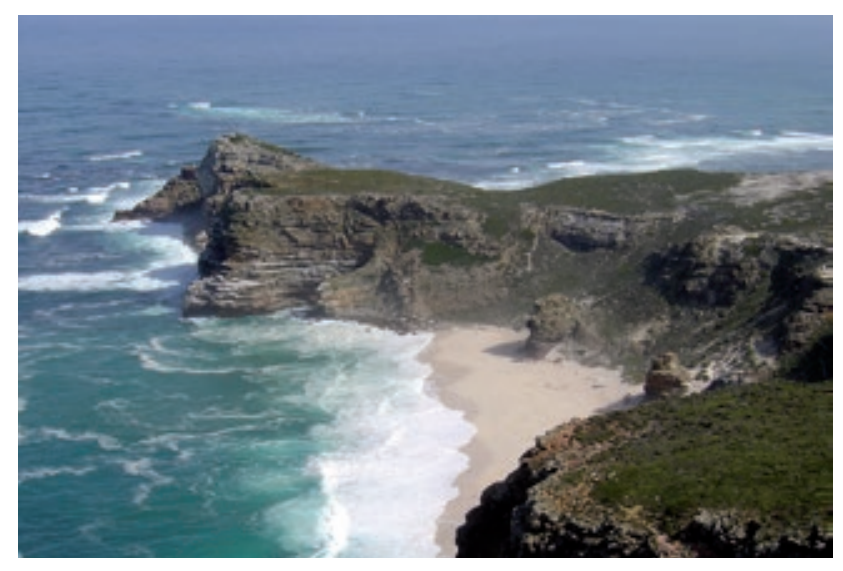

Cape of Good Hope, South Africa. Credit Zaian fittings that had been discontinued due to design changes and discolouration were used.

The funding of the printing of the decals and distribution was provided by Plastics S.A. The most intensive work came from the management of these bins on-site, which cannot be put into financial numbers, but without it the project would not have been possible.

Some figures regarding the process are:

- The printing of the decals: 20,000 ZAR (1,300 euros).

- Distribution travel costs and organization: 40,000 ZAR annually (2,600 euros).

- Glue for pipe fittings: 1000 ZAR (70 euros), and fixation to poles, etc., 10,000 ZAR (650 euros).

\section{Further market opportunities and replicability aspects}

The project is still up and running and the amount of bins distributed and placed has increased along the coastline with the possibility of moving to inland fishing areas. It has been quite successful and there are other similar examples that try to tackle this problem. Therefore, it would be feasible to run the same approach elsewhere. In the case of MENA region, the same sort of stakeholders could engage and apply the use of PVC bins where fishing lines could be collected. These could be placed at beaches, ports and recreational ports and marinas.

A civil society organization in the MENA region could raise funds to implement the campaign as a project, and get sponsors involved. First, it should implement a communication plan to explain why this type of action should be taken, calling citizens to take part. It is also very important to engage key partners from the plastics industry as well as recyclers to whom these items could be sent, providing freepost/transport options.

\section{CONTACT AND FURTHER INFORMATION \\ www. plasticsinfo.co.za \\ John Kieser, Sustainability Manager, \\ John.Kieser@plasticssa.co.za}

\section{SIMILAR INITIATIVES}

Monofilament Fishing Line Recycling is an initiative which is part of the Clean Marina Program in New Jersey, USA. Discarded monofilament fishing line can harm the marine environment by entangling, injuring and killing marine birds and aquatic wildlife. It can also cost boaters thousands of dollars when it gets caught in boat propellers and other gear. The New Jersey Coastal Management Program is partnering with the BoatUS Foundation and the BoatUS Angler Program to collect and recycle monofilament fishing line. The partnership has distributed collection bins and signs to various locations. 


\section{Thread: Responsible fabric from Ground to Good ${ }^{\mathrm{TM}}$}

Thread's mission is to alleviate poverty by creating dignified jobs and high-performance fabrics. Thread transforms plastic bottles from the streets and canals of Haiti and Honduras into responsible fabric.

\section{thr $\equiv$ ad}

\section{Success factors}

- Job creation and income opportunities in Haiti and Honduras.

- Cleaner neighbourhoods and cleaner land and marine environments.

- Innovative solutions from Ground to Good ${ }^{\mathrm{TM}}$.

- Sustainability recognition.

\section{What it's about}

Thread builds responsible, transparent supply chains from Ground to Good $^{\mathrm{TM}}$. They invest heavily in the first mile of the supply chainthe individuals and areas where plastic bottles are picked up from the ground, and then taken to collection centres. This is one of the main features of this initiative, since it offers economic and dignifying opportunities. The first mile of supply chains is an area often ignored and, as a result, this portion of supply chains tends to cause ecological and human harm.

Thread engages with industry standards and brand coalitions all

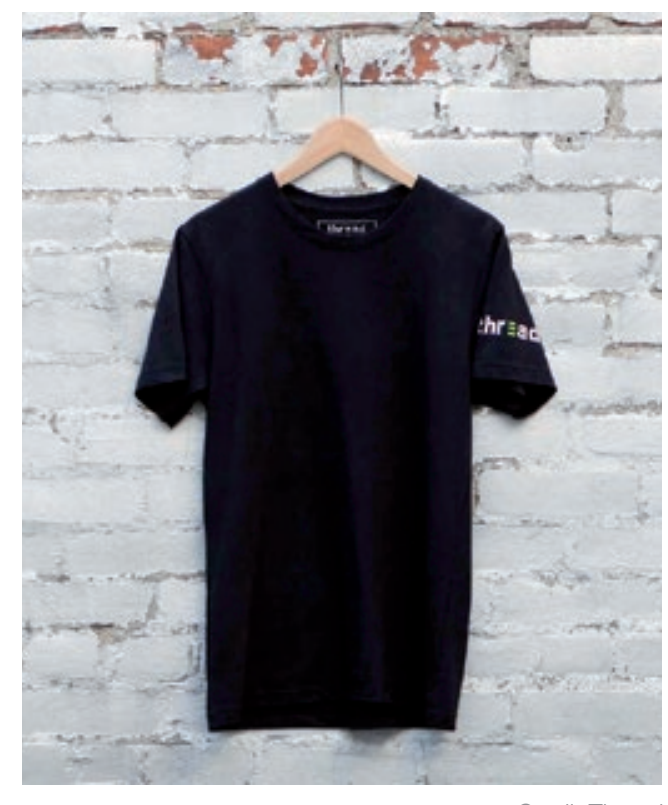

Credit Thread over the world. Thread has also found that an enormous opportunity for social impact exists in the first mile of supply chains. Often, the work at this stage is informal, unregulated, and difficult to monitor. The individuals involved are constantly changing, making it difficult to track exactly who is responsible for the collection of raw materials. While there is a movement among apparel brands to become increasingly transparent and publicly list their suppliers, many brands are only able to list their tier-1 or possibly their tier-2 suppliers. These are the places where goods are cut and sewn, or perhaps where the fabric is finished.

\section{Challenges addressed}

As a part of its approach, Thread places the principles of circular economy at the forefront. The circular model is one in which materials are not thrown away, particularly in the case of plastic bottles that could enter the marine environment, but rather are returned to the production chain, remaining effective and useful. Everything that is currently discarded has the ability to be a useful raw material again. Circular economy looks to capture this value. Another challenge it addresses is in regard to poor socioeconomic conditions, which Thread tackles by converting informal and disgraceful activities into decent and profitable jobs.

A recent report, McKinsey on Sustainability \&t Resource Productivity, Number 4, 2016, highlighted that supply chains are responsible for more than $90 \%$ of the environmental impact of products, leaving less than $10 \%$ of direct environmental impact in the hands of consumers. 


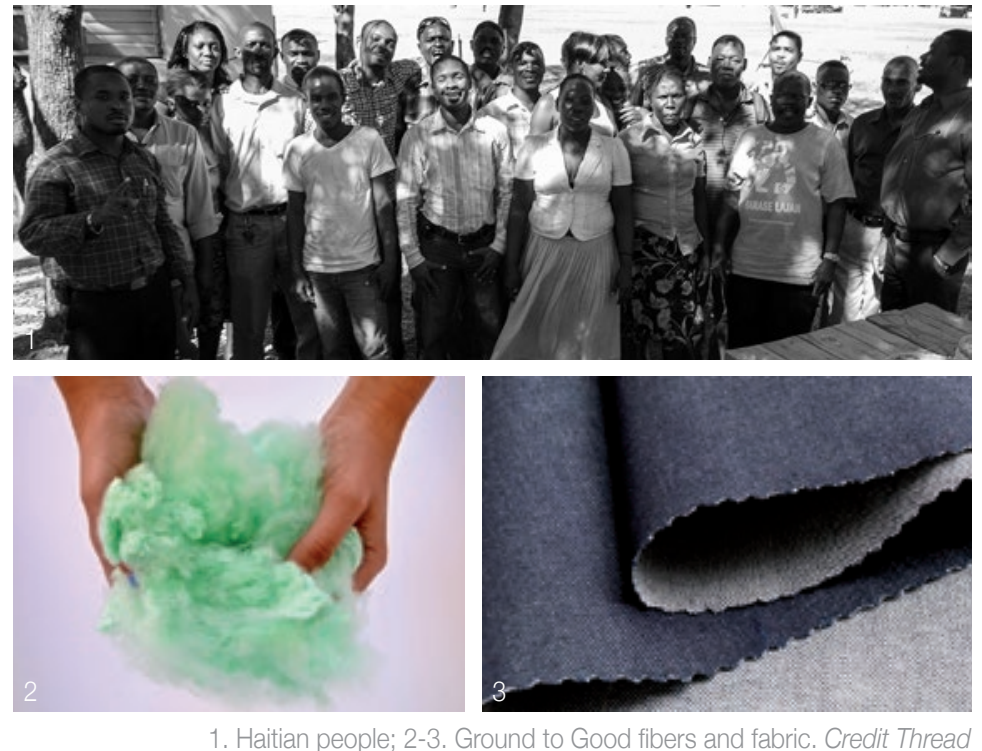

Initiator and collaborations

Thread started in 2014 in Pittsburgh, PA, in the USA. Presently, it is a part of the Clinton Global Initiative, which commits to transforming waste in the poorest parts of the world and utilizing it as a resource to create useful products. It is also committed to improving conditions in the Truitier landfill area in Haiti. Furthermore, as an emerging innovator of the Ellen MacArthur Foundation's CE100, Thread is involved in shaping the discussion around the concept of a circular economy. It is also a member of the Sustainable Apparel Coalition, which seeks to forge a shared vision of industry supply chain sustainability through the creation and use of the Higg Index.

Early on in 2017, one key cooperation endeavour resulted in Timberland's collection of boots and bags being made from durable Ground to Good ${ }^{\mathrm{TM}}$ canvas. These products are now available for sale.

\section{Financial aspects}

There are various investors and funding organizations that are supporting the work of Thread, such as: Draper Triangle (creating iconic and disruptive businesses in emerging markets); Riverfront Ventures (investing in high-growth early-stage companies located in South-western PA); BlueTree Allied Angels (angel group investing in regional, early-stage companies); Idea Foundry (Pittsburgh non-profit, innovation acceleration and commercialization organization focused on creating innovationrelated jobs); Good Company Ventures (offers a bold new approach to business that anchors global impact with real traction) and Innovation Works.

In 2016, Thread started a micro-loan programme, available to their Haitian suppliers. The programme came about because many of their suppliers had to close their centres due to small problems such as broken equipment or cash flow problems. Loans are granted every month based on applications submitted by the suppliers. In 2016, 13 loans were granted with a repayment participation of $100 \%$.

Further market opportunities and replicability aspects The economic advantages of a circular approach are clear. The circular economy approach holds tremendous opportunity for low-income countries and the communities where companies such as Thread base their supply chains. Participation in the circular economy will bring not only much needed economic opportunity to these countries and regions in the form of income generation, job creation, and valuable exports, but also it could allow them to invest directly in innovative waste management systems, leapfrogging some of the outdated waste systems that hold more industrialized countries back from circularity.

\section{CONTACT AND FURTHER INFORMATION \\ www.threadinternational.com \\ connect@threadinternational.com}

\section{SIMILAR INITIATIVES}

ECOALF was created in Spain in 2012. Since then and to this day, it produces a collection for men and women made of recycled marine debris. Collected with the help of Spanish fishermen, it is 100\% traceable, 100\% recycled and manufactured in Spain. The yarn is the only one on the market that comes from the bottom of the ocean and allows ductile clothing to be made by covering the filament with Tencel $\circledast$, linen and recycled cotton. The yarn made from the waste from the bottom of the ocean saves $20 \%$ in water, $40 \%$ in energy and reduces $\mathrm{CO}_{2}$ by $50 \%$.

On a European scale, Healthy Seas is a cross-sector initiative created by three founders-one NGO and two enterprises - that have joined forces to tackle the problem of marine litter. Healthy Seas recovers abandoned fishing nets polluting our seas and coasts, and reclaims the nylon to make high-quality yarn that is turned into brand-new sustainable textiles. 


\section{Plastimobile, reduction through plastic recycling and prevention of littering}

This educational programme is aimed at teaching school children and the wider public about the environmental impact of plastics. The programme promotes plastic awareness, recycling and litter prevention.

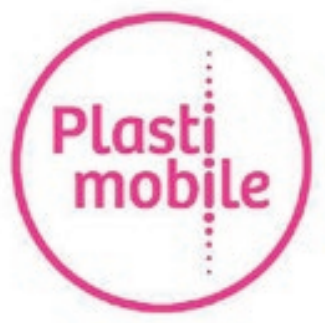

Success factors

- Greater understanding of the different types

of plastics, and which can and cannot be recycled.

- Key actors involved: schools, plastic producers, local government.

- Opportunity for the plastics industry to create jobs.

\section{- Sensitization on the field}

by young technicians who play the role of "ambassadors" and give the message

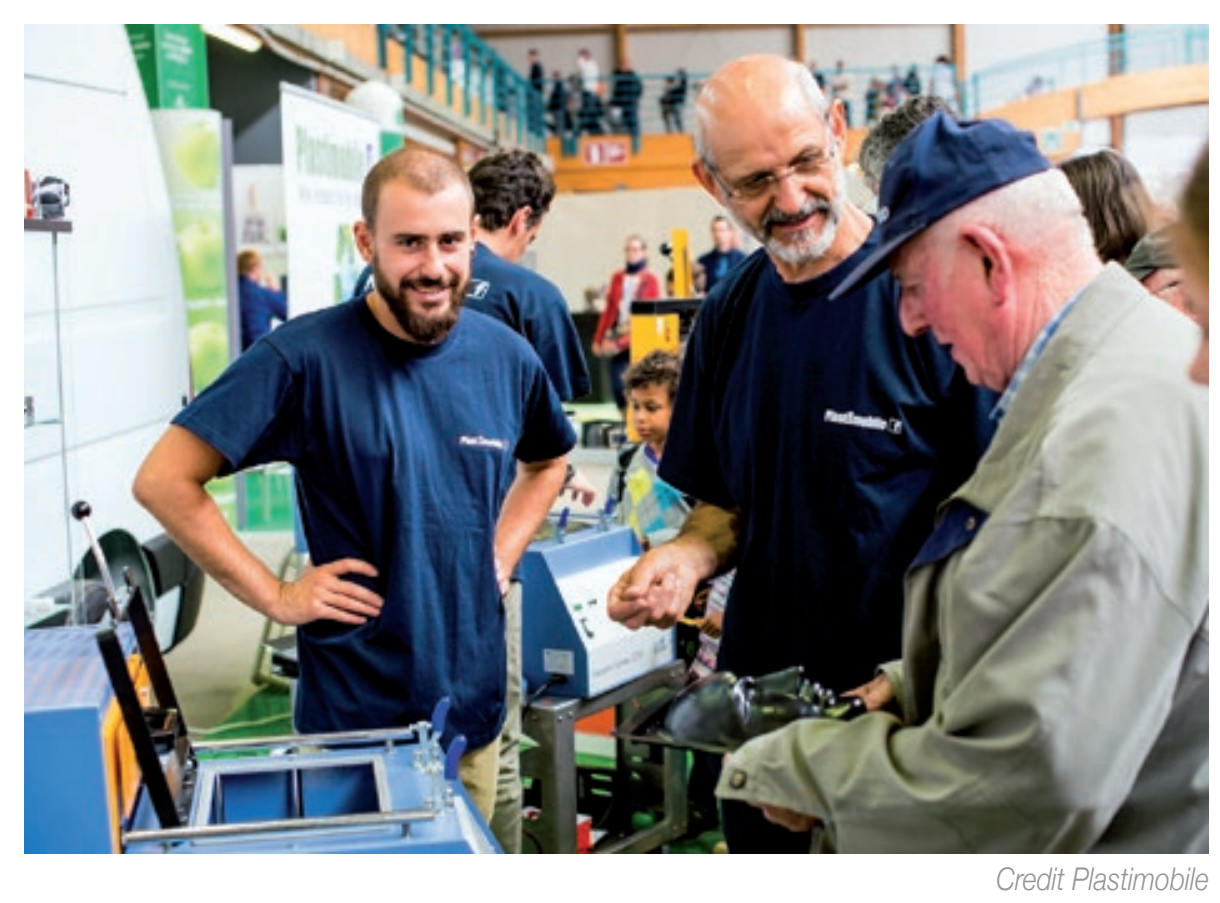

What it's about

Plastimobile is a mobile workshop in Belgium that recycles plastics to create new plastic objects. It is an educational tool for plastic recycling as well as a teaching device for science, technology and chemistry. Plastimobile can go anywhere at the request of teachers or organizers of public events.

Plastimobile has a van and a trailer that can be installed over an area of 40 square metres. As it uses a generator, it is fully autonomous in terms of electricity. Its flexibility of use and its mobility enable it to reach the most distant publics. The machines allow everyone to "get the job done". They are machines specially developed for the Plastimobile: they work like real industrial machines, but in miniature and in "manual" version to make it easier for the public to understand.

\section{Challenges addressed}

Like those in any field, plastic recycling professionals need a common language in order to communicate effectively. Teaching the wider public and children about plastic recycling has never been an easy task. Better communication throughout the plastic recycling industry will result in more efficient, more effective and more profitable plastic recycling. Therefore, everything and anything there is to know about plastics must be brought to schools throughout Belgium. Plastimobile has been very involved in making sure this happens and that the educational tools it makes available are being used. In several workshops, the students learn through play about the technical processes of recycling that give objects a second lease on life.

They get acquainted with funny machines, crushing old car bumpers and trucks. Next to this they can see a sweater made of fibres from recycled plastic 
bottles, right beside the insulation squares made up of recycled car tyres.

Plastic has multiple ingredients and $4 \%$ of it is oil. However, other natural components may be used in its composition, such as beetroot or maize.

For teachers, Plastimobile it is a great opportunity to continue to study the subject in greater depth in class, touch upon the fundamentals of chemistry, and, most importantly, stress the importance of recycling plastics.

These workshops are organized in schools by FEDERPLAST, the Belgian Association of Plastic and Rubber Product Manufacturers. Through this initiative, the Federation hopes to create new employment opportunities. The sector employs some 20,000 people in Wallonia, and companies are always looking for scientists, industrial engineers and operators-assemblers of moulds for particular machines.

\section{Initiator and collaborations}

This initiative was started back in 2011; however, on 4 January 2017, Plastimobile became an association to consolidate the initiative. The Belgian Federation for Chemistry and Life Sciences Industries, essenscia, and its plastics section, Federplast.be, trade unions and four companies are its constituent members. Plastimobile thus brings the entire industrial chain together, working towards a common goal.

\section{Financial aspects}

Several partners support the work developed by the association. They are: Co-Valent, the training fund for the chemicals, plastics and life sciences sector; Federplast.be, which represents plastic and rubber product manufacturing companies (which encompasses Agoria, the federation for the technology industry, and essenscia); Sirris; Go4Circle, the federation of circular economy enterprises; Athénée Royal du Condroz Ciney, Plastics Section; Athénée Royal Pierre Paulus in Châtelet; Technocampus; and Plastiwin.

Further market opportunities and replicability aspects Setting up an awareness-raising campaign similar to this one would require a collective effort and commitment from the key parties, including plastic producers and key NGOs, in order to launch and create partnerships and ways to engage with the schools and civil society. Potential funding sources are government, private foundations and sponsors such as private companies.

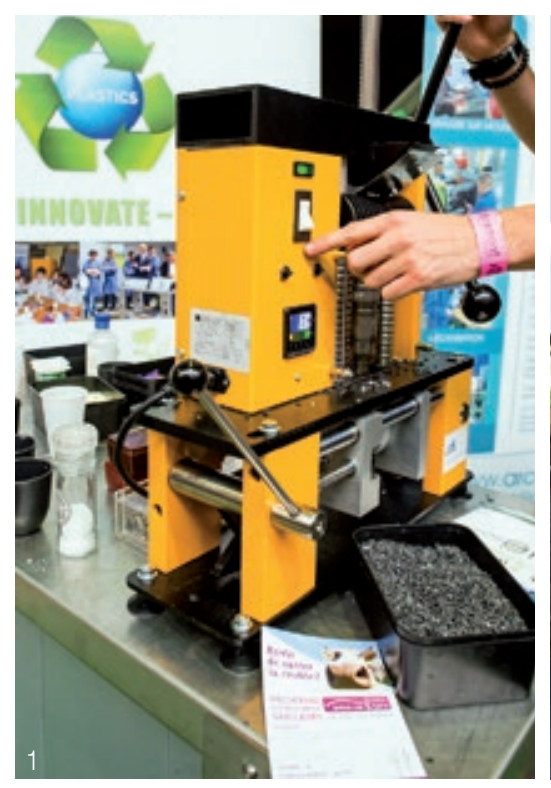

\section{CONTACT AND FURTHER INFORMATION \\ www.plastimobile.com \\ BPhilippe@essenscia.be}

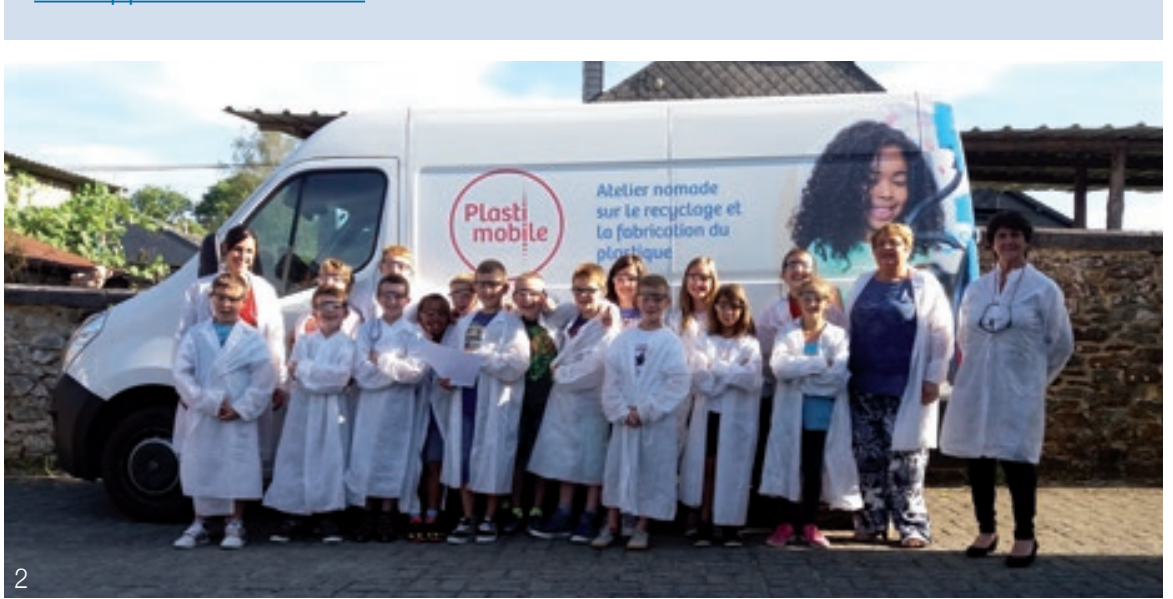

1-2. Credit Plastimobile

\section{SIMILAR INITIATIVES}

The Marine Conservation Society (MCS) in the UK runs an education programme for children (from 5-10 and 10-16 years old) known as the Cool Seas Explorers. There are many activities involved as well as online tools, such as an interactive game and quiz. There is also the opportunity to host a Cool Seas workshop that supports the development of environmental awareness, conservation, sustainability and global citizenship in relation to the marine environment. Their workshops are linked to content from each UK school curriculum. In particular, attention is given to marine litter and plastics in the marine environment. 


\section{Josinilin:}

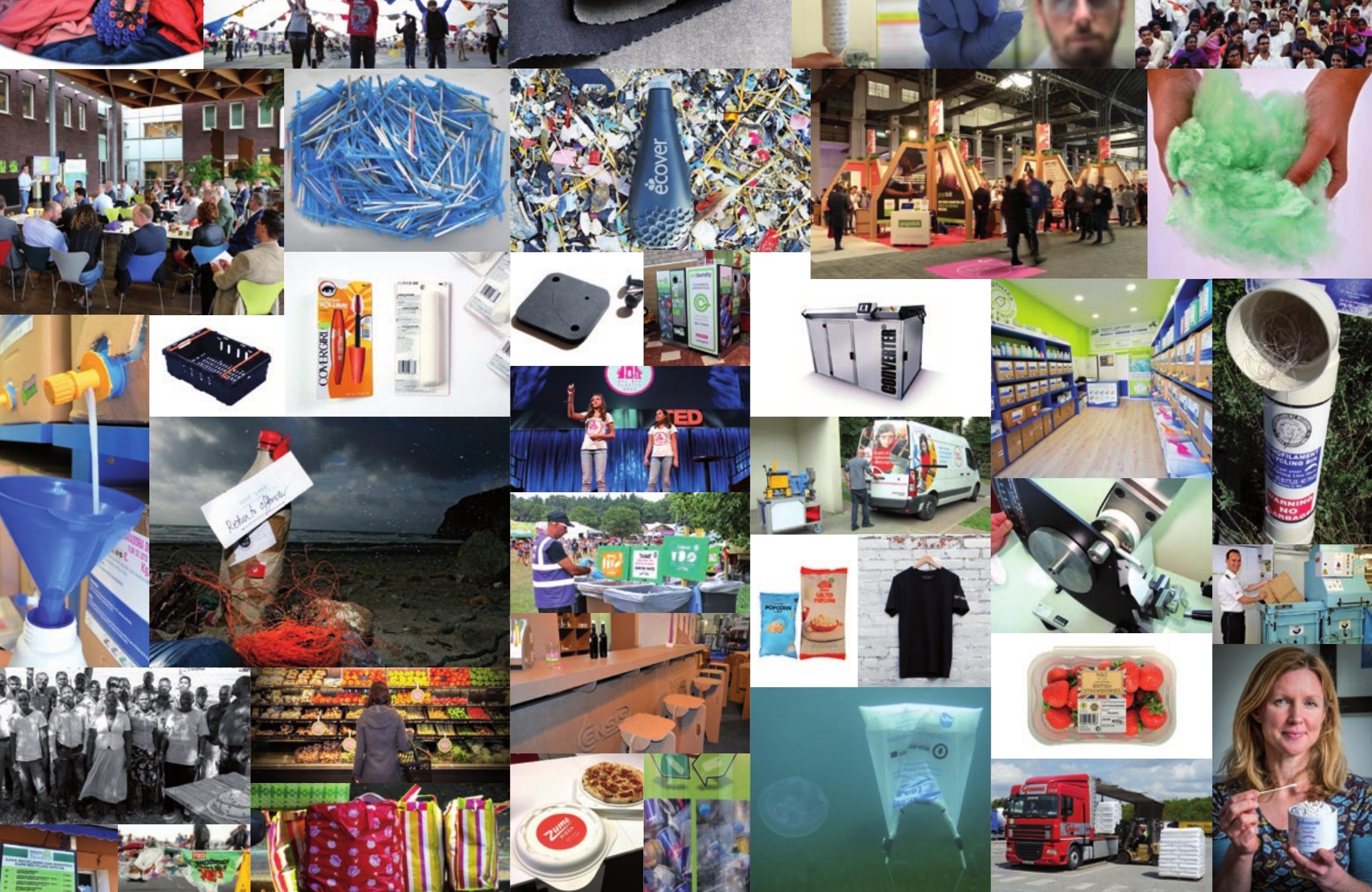

$$
\text { . }
$$




\section{Concluding remarks}

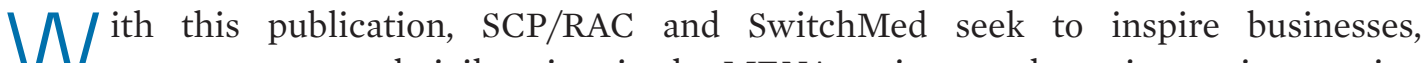
entrepreneurs and civil society in the MENA region to take action against marine litter. Many of the actions involved in the initiatives listed here bring with them a competitive advantage or an increase in revenue, thus making their implementation feasible. In summary, employing different initiatives at different stages of the product-to-waste chain will help in combating marine litter. This includes:

- Products that are designed to be long-lasting and reused, repairable and remanufactured, and recyclable, with the most effective use of resources, minimizing the use of virgin non-degradable materials and toxic substances. Manufacture and transport use renewable energy.

- Superfluous consumption is limited. Inappropriate disposal behaviour is discouraged and citizens are enabled to make responsible, well-informed decisions about the products they buy. Sustainable product systems are available to citizens.

- Adequate systems to promote collection and separation of different types of waste are in place to maximize return rates of high-quality materials that can be reused or recycled (not down-cycled). Waste is regarded not as "waste" but rather as a valuable resource, which minimizes its loss from the system.

- Recycling is favoured over the incineration and landfilling of valuable "waste" commodities, with energy being recovered from the non-recyclable fraction. New technologies for recycling and markets for recycled materials are encouraged and strengthened.

Combining all these actions to the maximum extent possible will certainly make a great contribution to tackling the problem of marine litter.

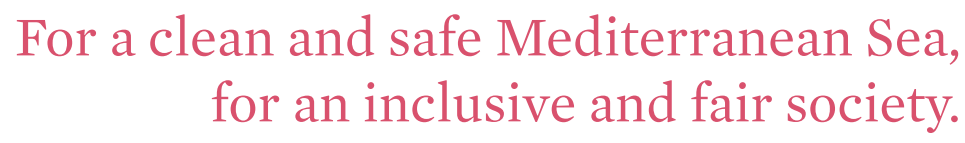




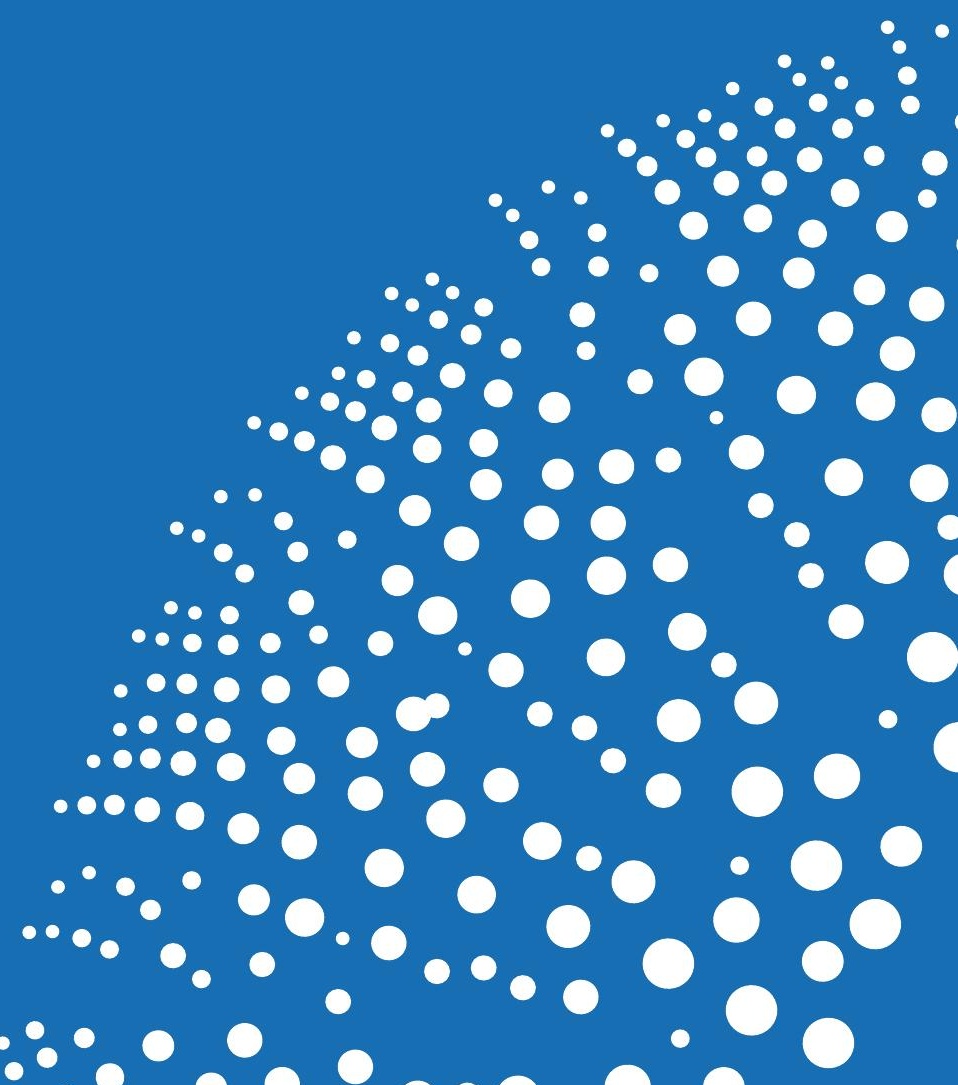

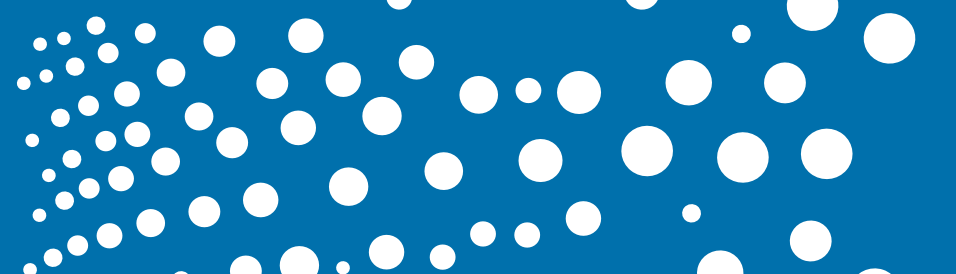

$$
\begin{aligned}
& .000 .00 .0000
\end{aligned}
$$

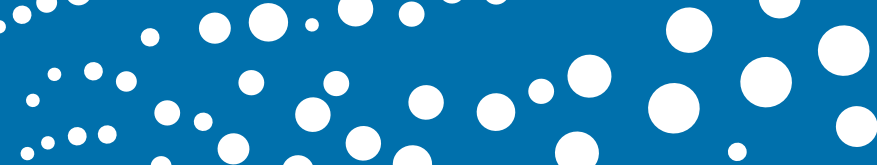

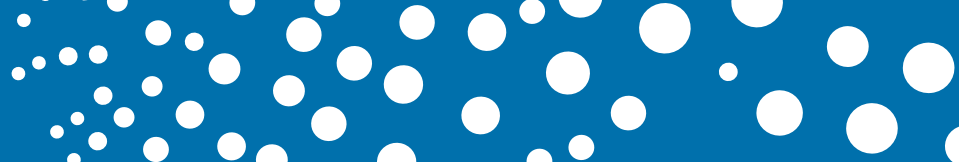

$$
\begin{aligned}
& \because \because 00000 \\
& \because \because 0_{0}^{0} 0_{0}^{0} \\
& \begin{array}{ccccccccc}
0 & 0 & 0 & 0 & 0 & 0 & 0 & 0
\end{array}
\end{aligned}
$$

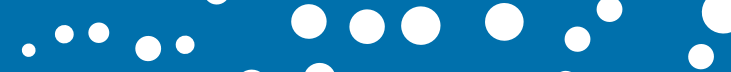

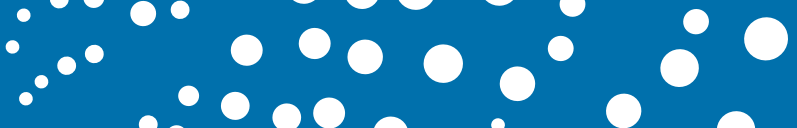

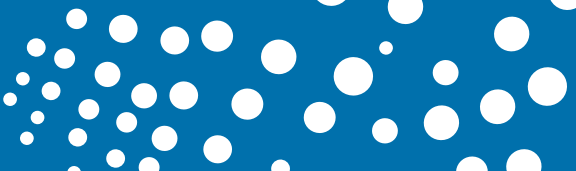

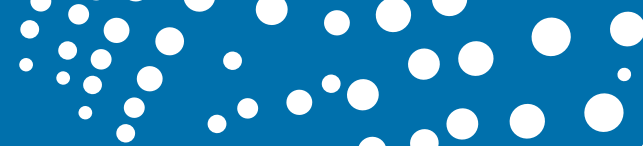

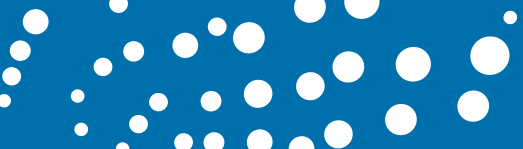

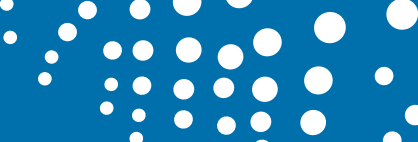

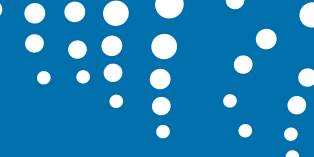


Regional Activity Centre for Sustainable Consumption and Production (SCP/RAC)

UN Environment/Mediterranean Action Plan - Barcelona Convention for the protection of the Mediterranean Sea

Sant Pau Art Nouveau Site - Nostra Senyora de la Mercè Pavillion

Carrer de Sant Antoni Maria Claret, 167.

08025 Barcelona, Catalunya (Spain)

Tel. +34935538790

www.scprac.org 